\title{
Super-Slab® Precast Pavement System
}

\section{FORT MILLER}

THE FORT MILLER CO., INC.

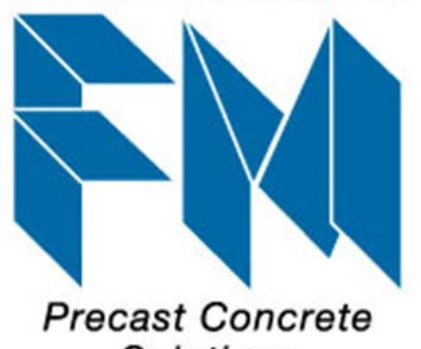

Joint Transportation Research Project

Precast Concrete Pavement Forum

Solutions

\author{
Indianapolis, Indiana
}

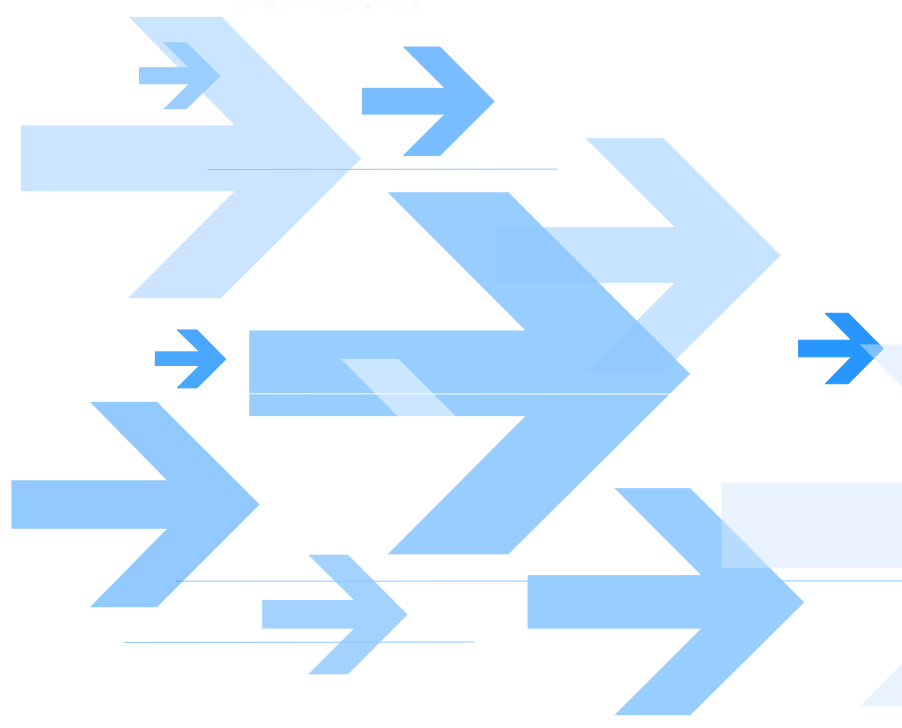

\author{
August 11, 2016 \\ The Fort Miller Co., Inc. \\ Dan E. Moellman, P.E.
}




\section{The Fort Miller Co., Inc.}

- Located in upstate New York

- Transportation products

- Highway barrier

- Precast retaining walls

- Bridges

- Precast pavement slabs

- Specializing in accelerated bridge construction

- Developer of the Super-Slab® Precast Pavement System
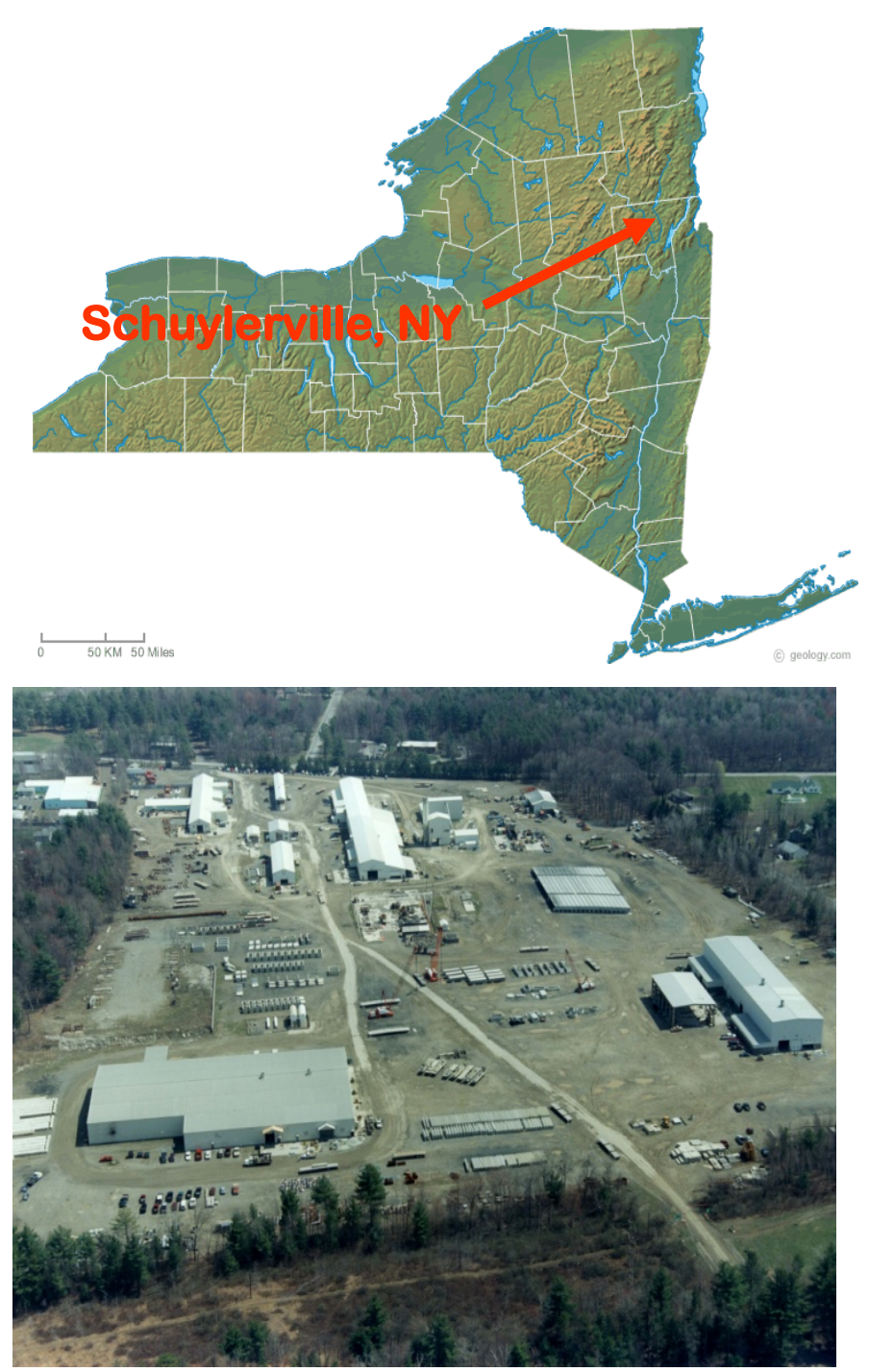

The Fort Miller Co., Inc. 


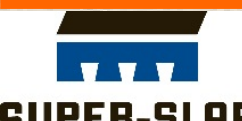

\section{Precast Concrete Pavement Slabs = Overnight Repairs}

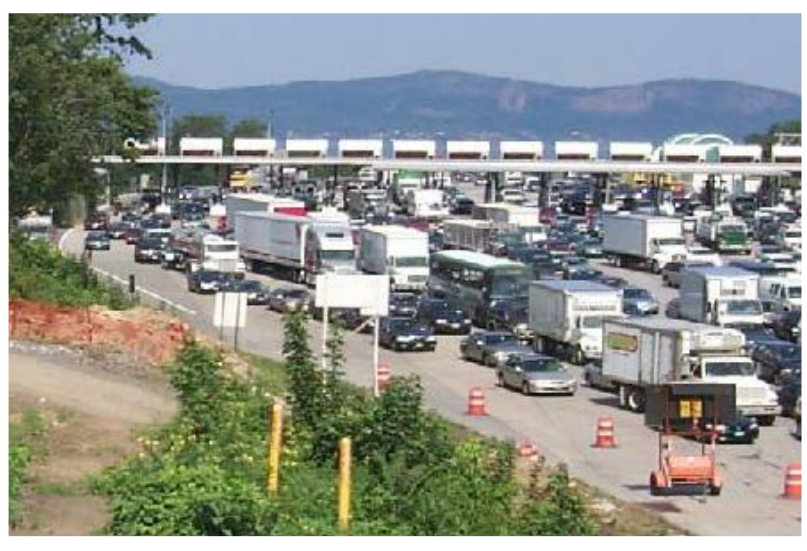

145,000 ADT

I-287, Tarrytown, NY

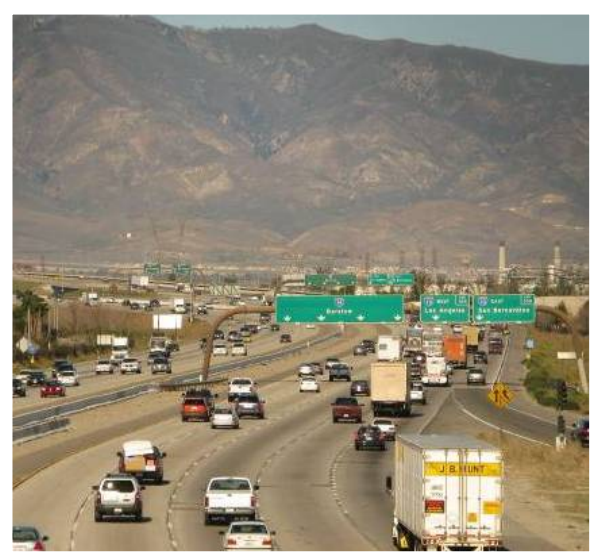

200,000 ADT

I-15, Ontario, CA

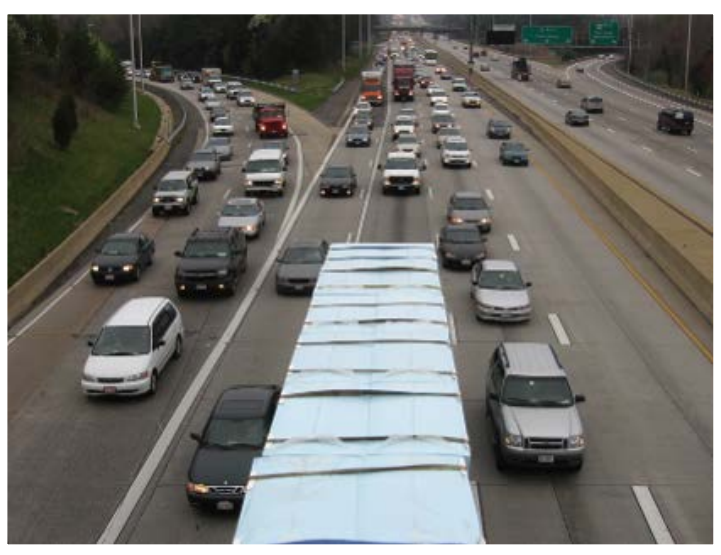

180,000 ADT

I-66, Fairfax, VA

The Fort Miller Co., Inc. 


\section{What Does High ADT's Mean For Pavement Repair \& Maintenance?}

- Heavily-deteriorated pavement

- Too much traffic for long-term durable repairs

- Often repaired with fast-setting non-durable materials

- Very short work windows

$-8-5$ hour night work windows

- 55 hour weekend closures

- Real need for durable repairs

- Summary - Premium pavement required overnight! 


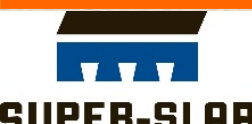

\section{Precast Pavement Emulates Cast in Place}
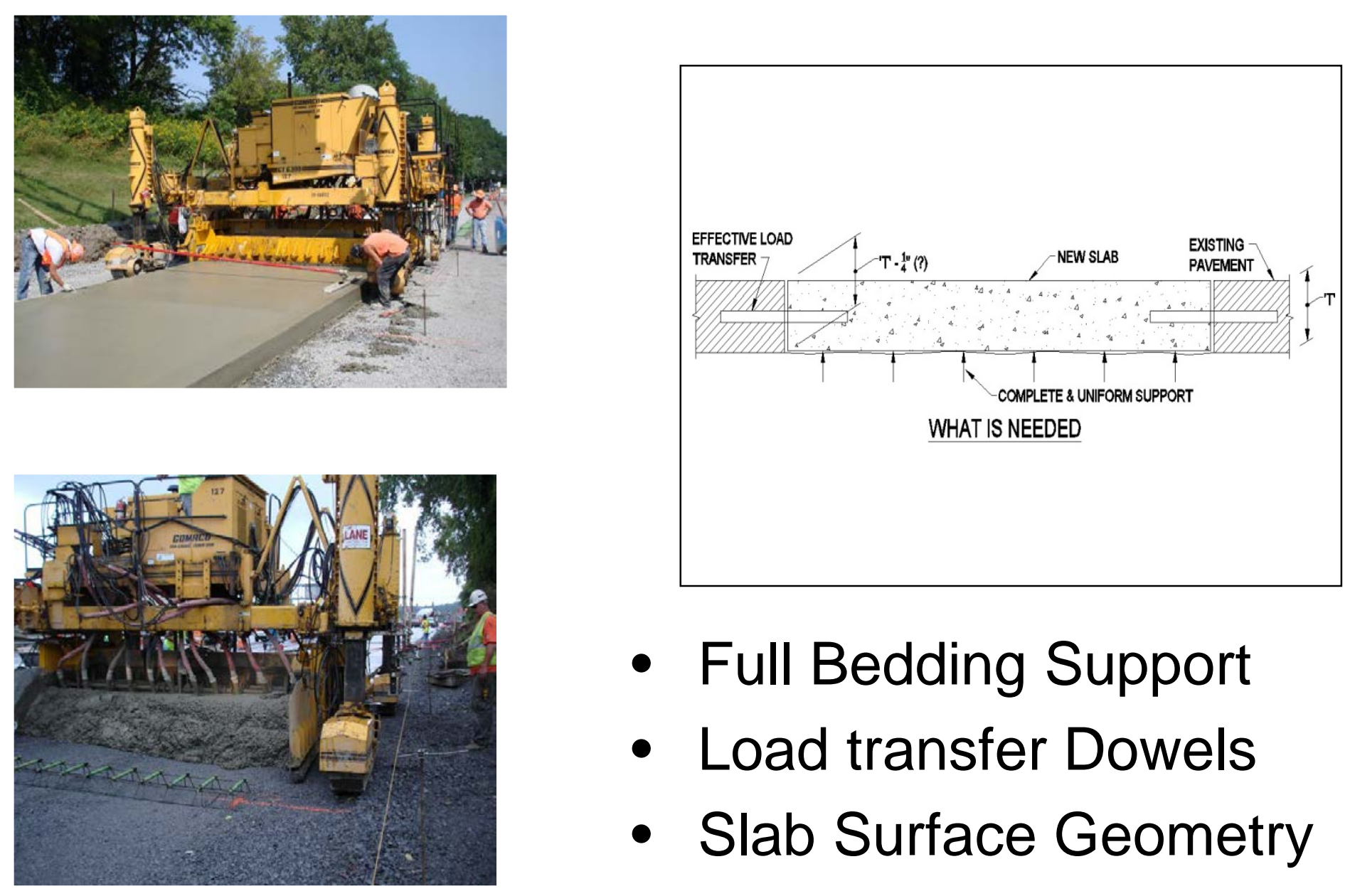

- Full Bedding Support - Load transfer Dowels - Slab Surface Geometry 


\section{Jointed Precast Pavement in the US}

- Full-scale implementation began in 2001 with introduction of the Super-Slab® System

- Can be installed rapidly - overnight

- Versatile

- Intermittent repair, full lane replacement, bridge approach slabs, ramps, intersections

- Proven

- Numerous FWD tests

- Accelerated load (HVS) tests in 2005- 2006

- Cost effective - compared to fast-track concrete repairs 


\section{Super-Slab ${ }^{\circledR}$ System - Bottom Slots}

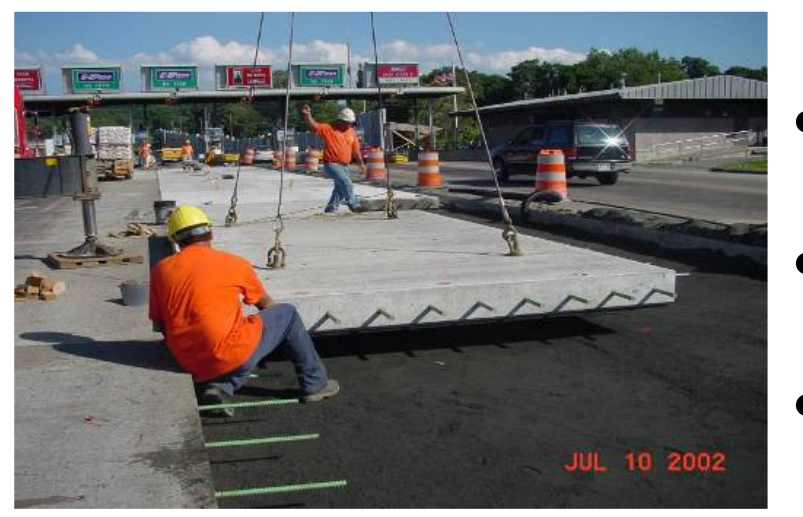

- Simple slab-on-grade system

- Standard dowels and tie bars (JRCP)

- Built-in bedding grout distribution

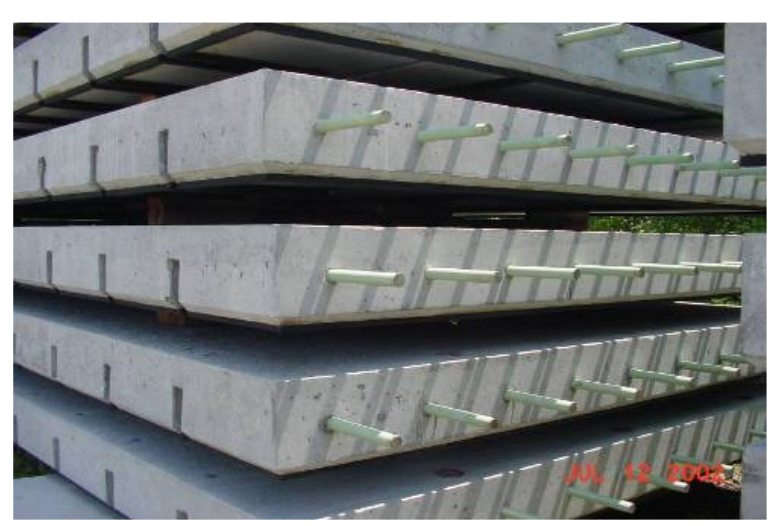

- Precision grading equipment

- Warped and planar surfaces

- $25,000+$ slabs \& $2,800,000+$ SF INSTALLED

100+ projects, 43 lane-miles completed in 17 States + ON \& QC, 29 Owner Agencies 


\section{Cumulative Super-Slab Installations}

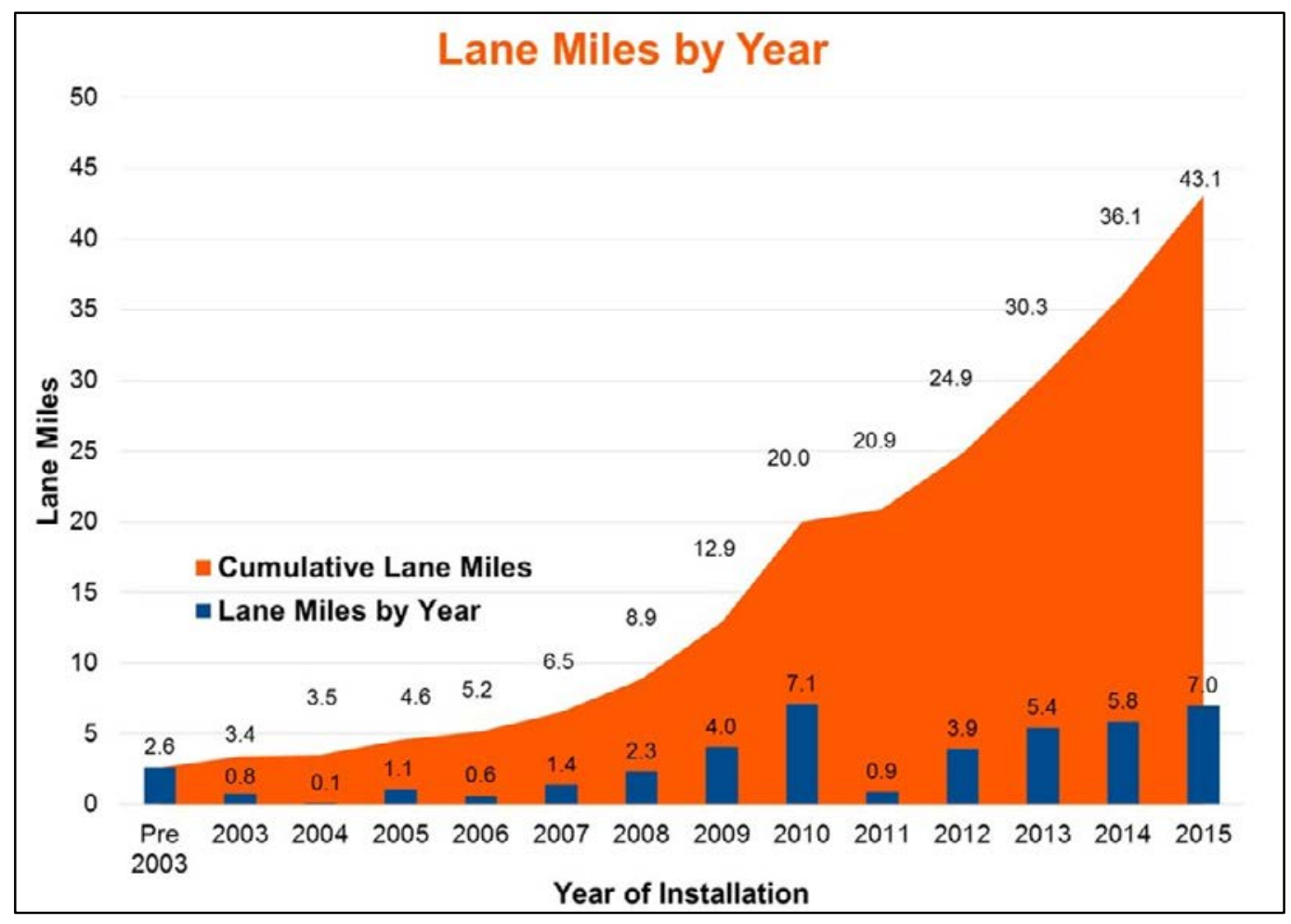

(107 projects, 43 lane-miles in 17 States + ONT \& QUE, 29 Agencies) $(25,000$ Slabs $+/-=311,000$ SY $+/ /-)$

The Fort Miller Co., Inc. 


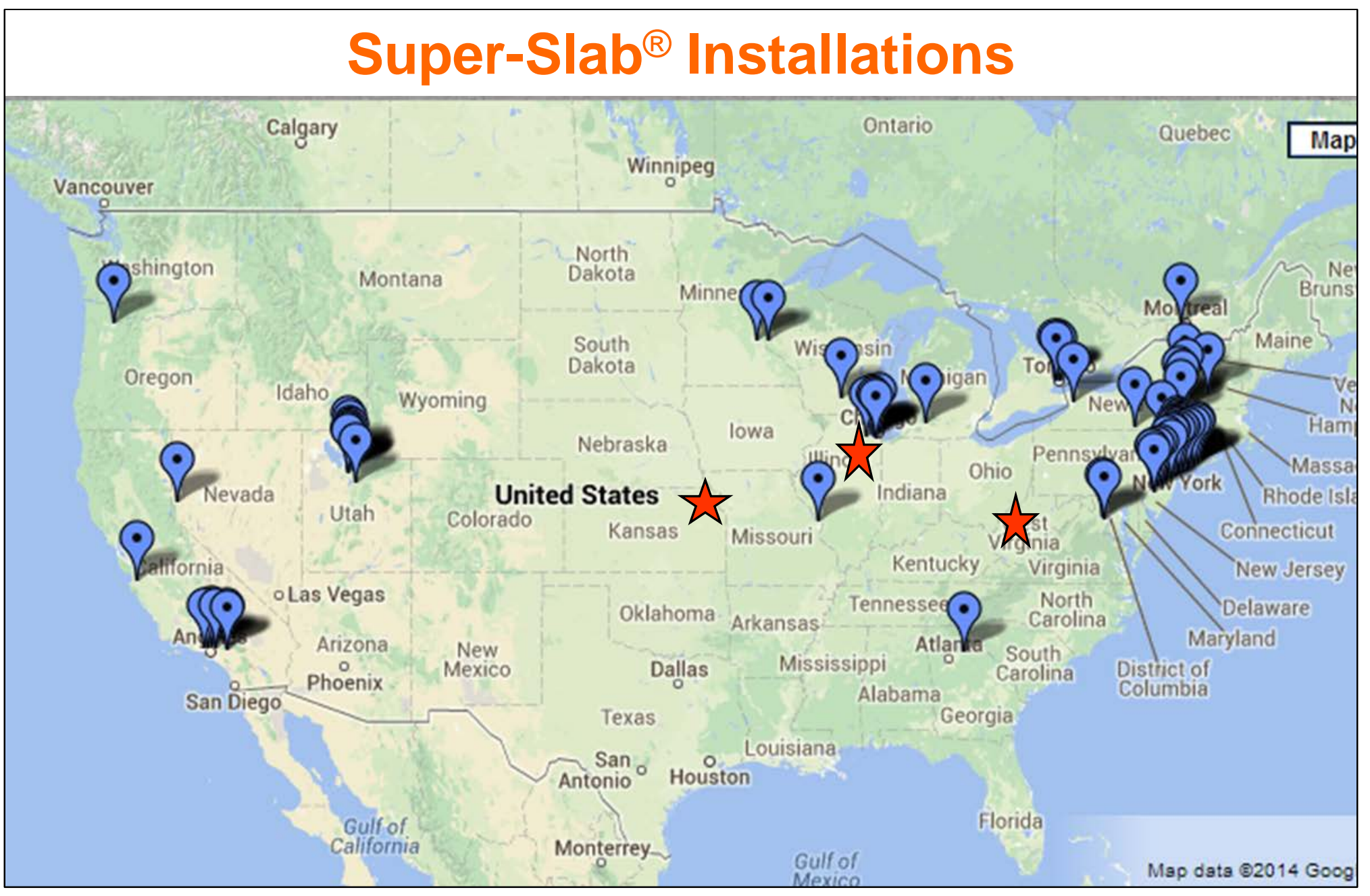

43 Lane Miles , 2.8+ Million Sq Ft, 25,000+ Slabs $100+$ projects in 17 States and 2 Provinces, 29 Agencies 


\section{Super-Slab® Load Transfer Dowel System}

- Dowels engage slots in adjacent slab

- Pump dowel grout into ports

- Grout reaches 2500 psi

in about 2 hours

- Fill slots and joint between slabs

- Dove-tail slot resists bar pop out
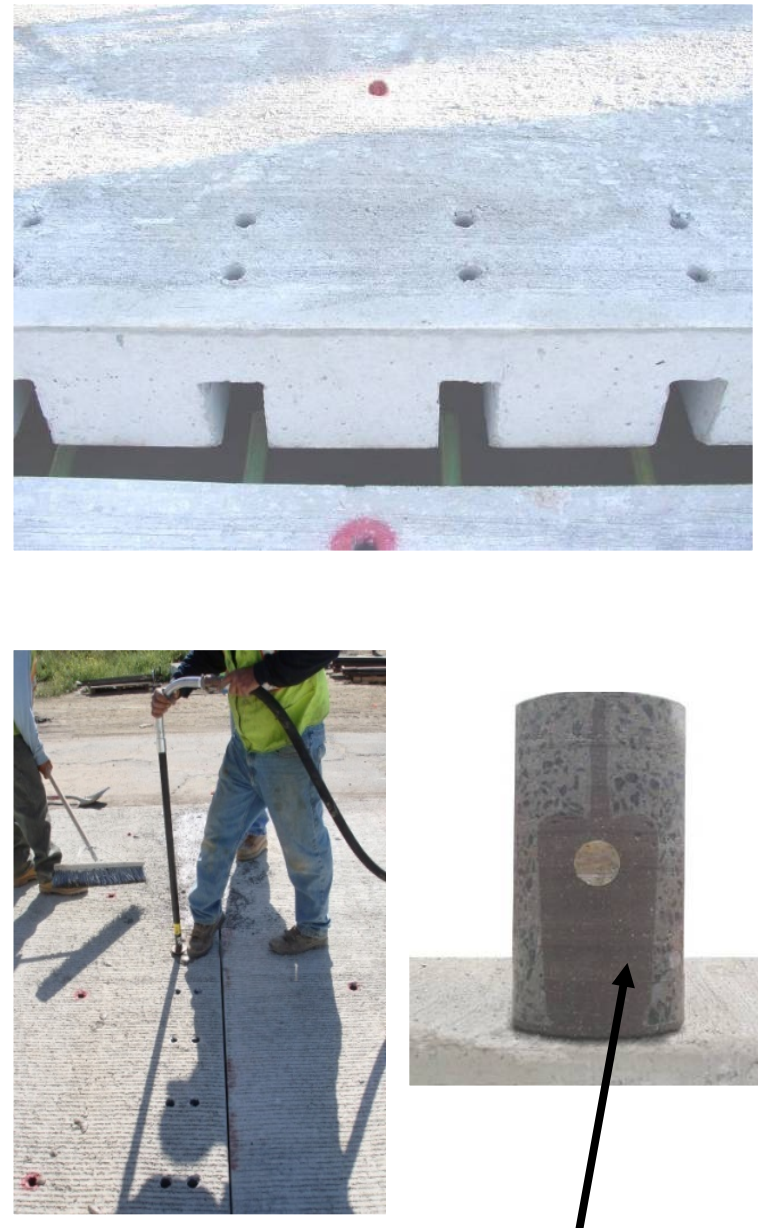

Dove-tail-shaped slot 


\section{Two Slab Types}

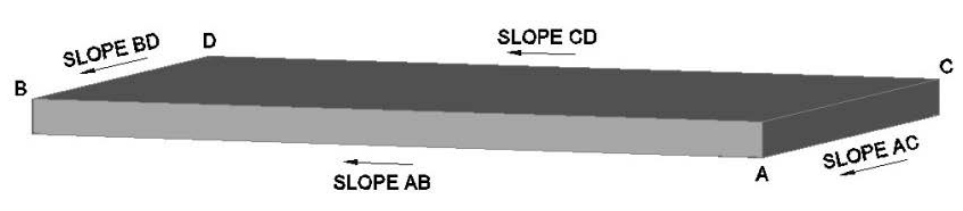

\section{Single Plane}

- Slopes of opposite sides are equal

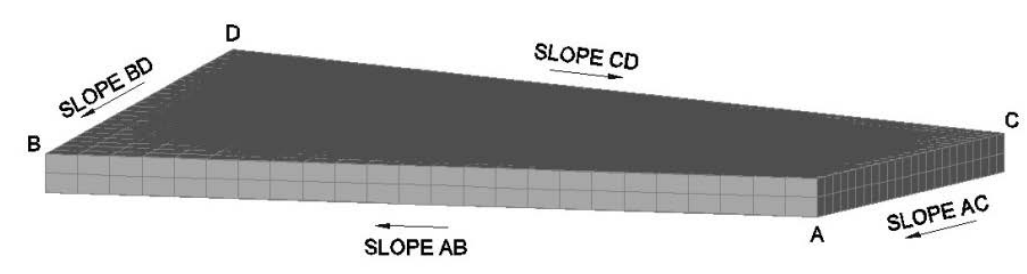

\section{Warped Plane}

- Slopes of opposite sides are not equal 


\section{Controlled Fabrication Conditions}

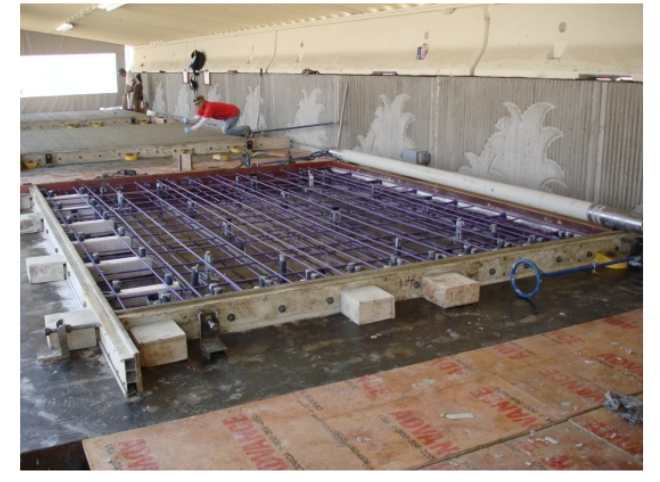

Accurate Forms

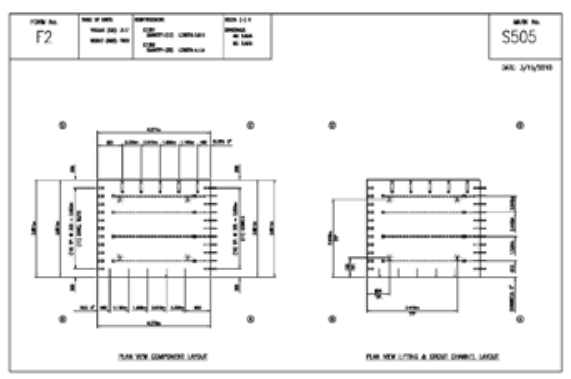

Accurate Piece Drawings

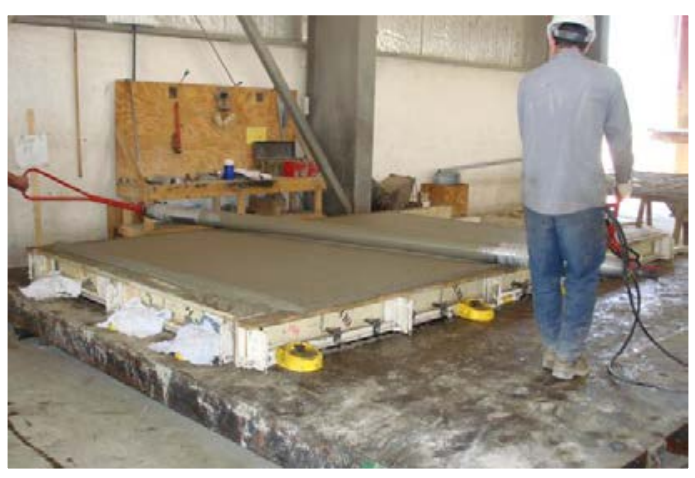

Roller Screed - Accurate Top Surface

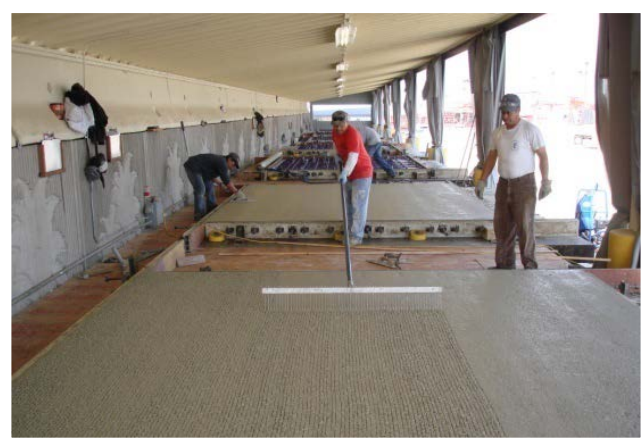

Ideal Finishing (and curing) Conditions 


\section{Achieving Full and Complete Bedding A Two - Step Process}

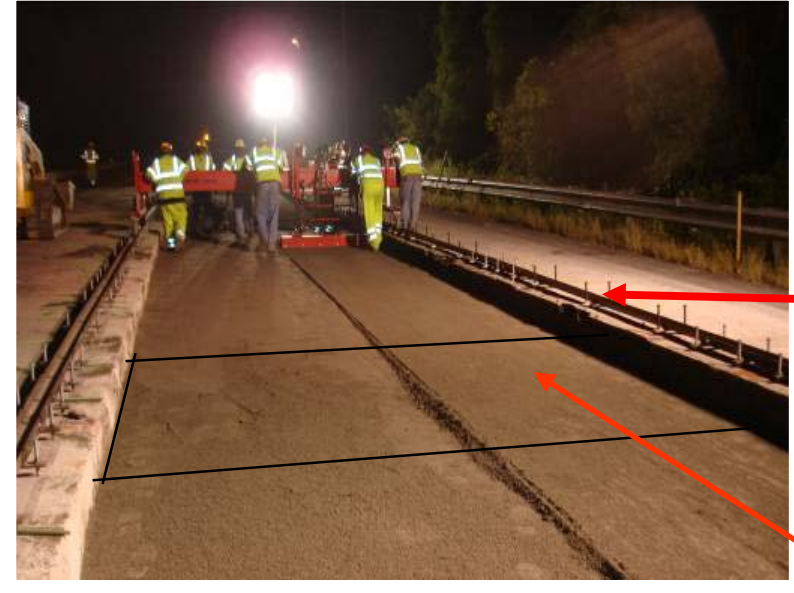

Grade control rails placed to survey marks

Chorded Slab

Precisely-Graded (to $\pm 1 / 8$ ") and Compacted Fine Aggregate Material

Surface

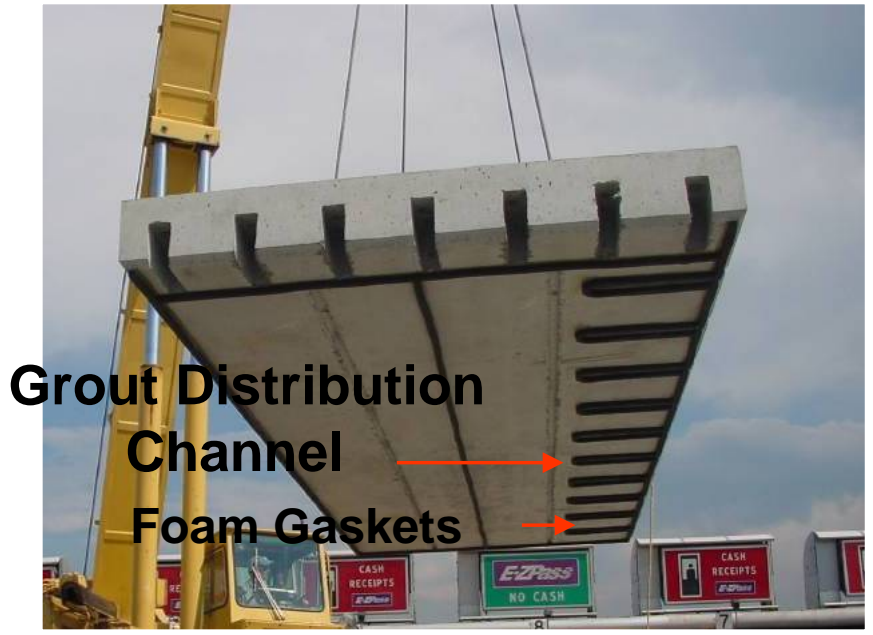

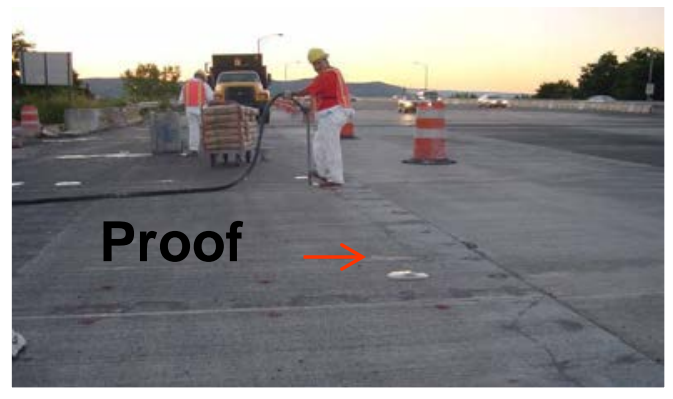

Bedding Grout Fills Any Voids

The Fort Miller Co., Inc. 


\section{Small Scale Grading}

\section{Rail Supported and Hand Operated}

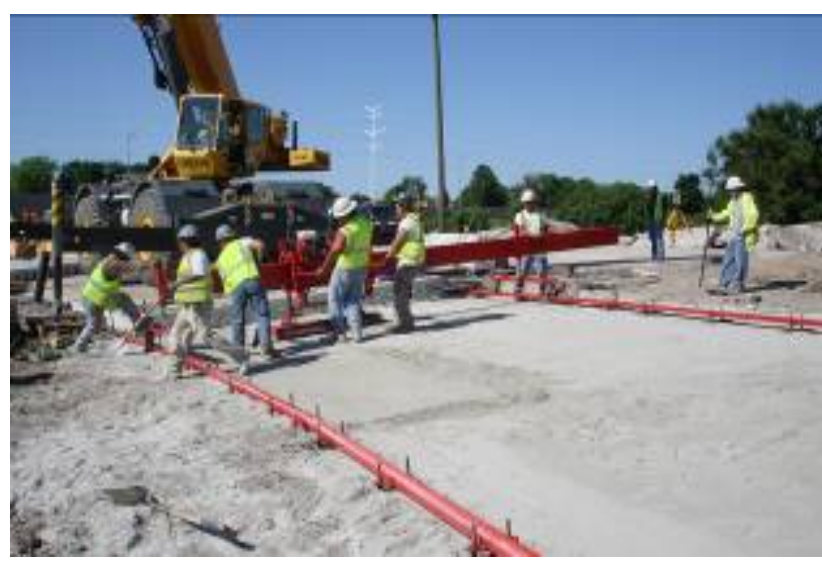

Auger H.O.G.

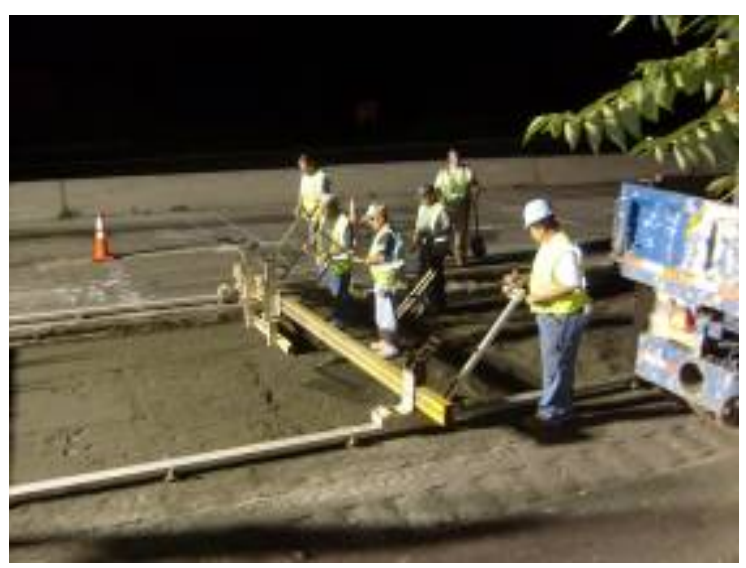

Mini-H.O.G

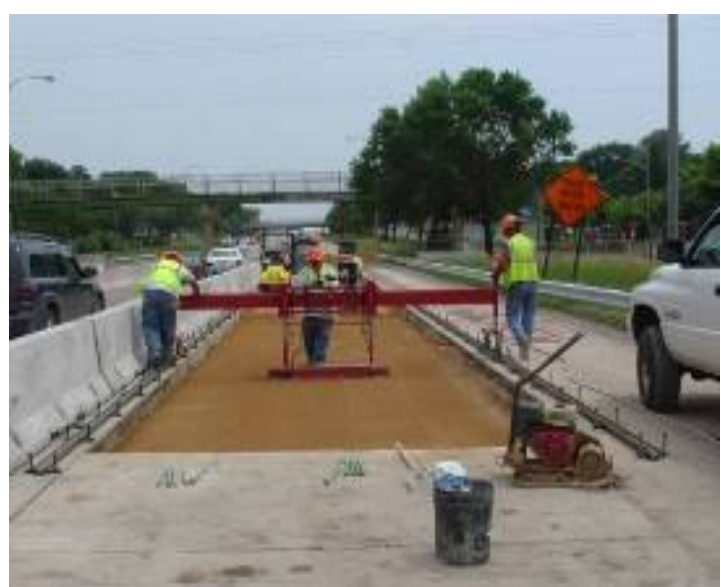

Hand Operated Grader (H.O.G.)

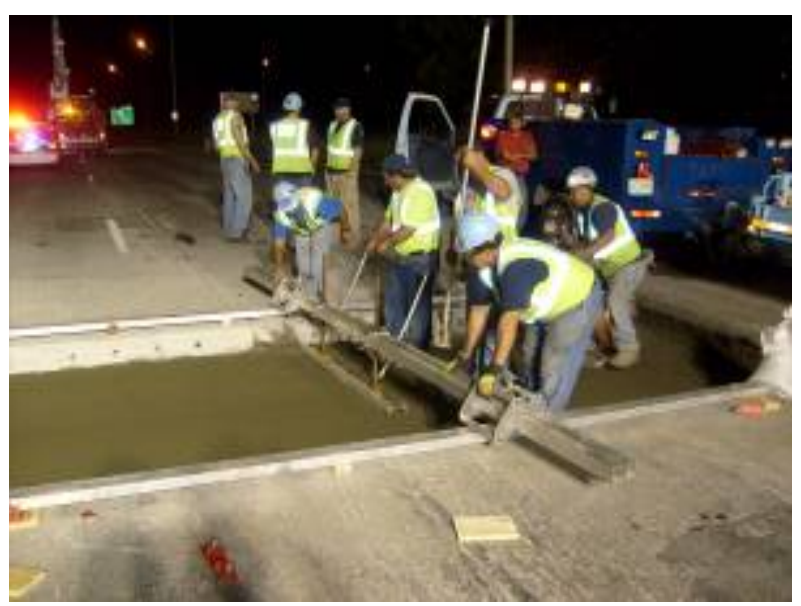

Shutter Screed

The Fort Miller Co., Inc. 


\section{Large Equipment Precision Grading Laser/Robotic Controlled Planar and Non-Planar Slabs}
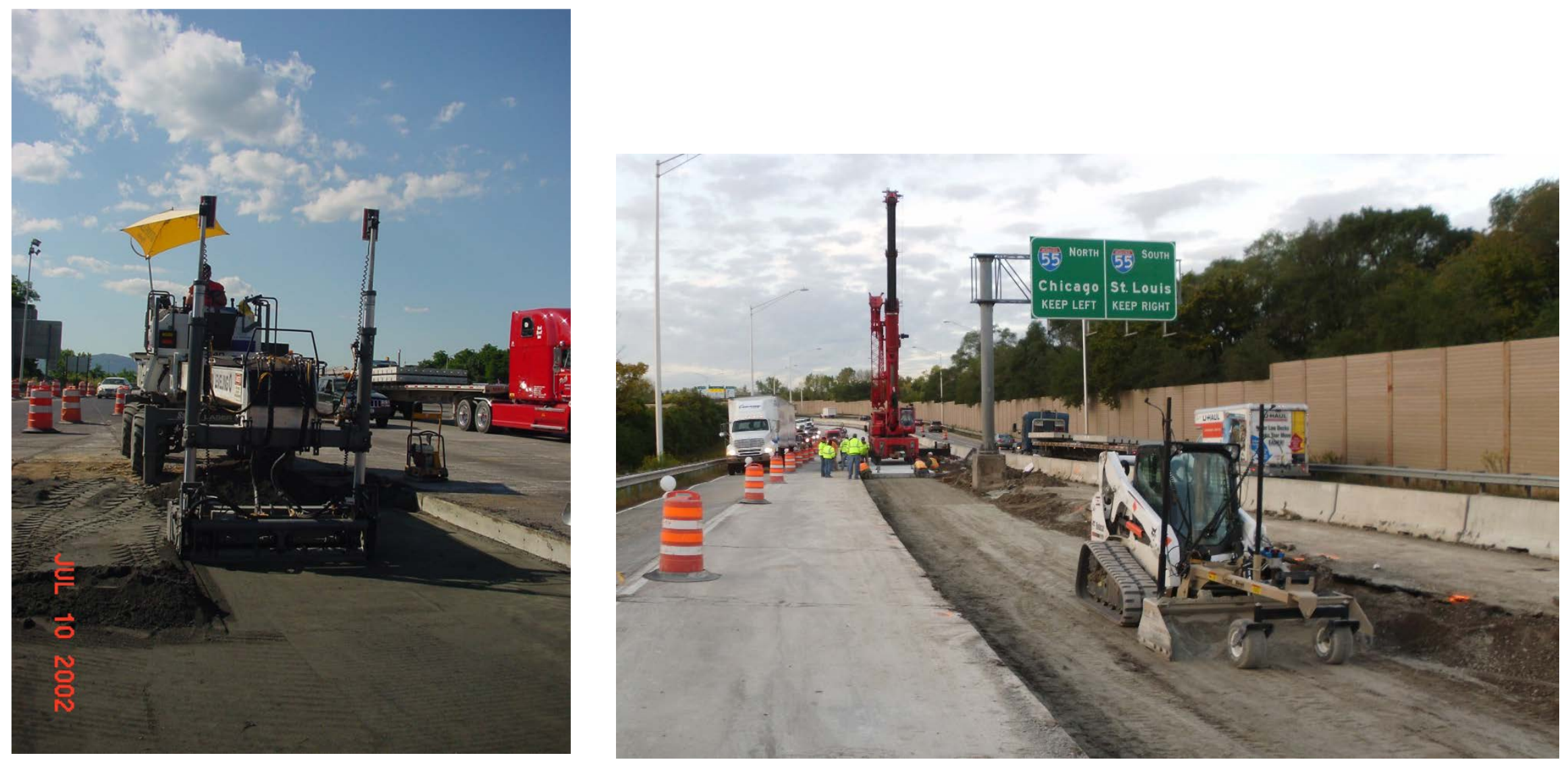

The Fort Miller Co., Inc. 


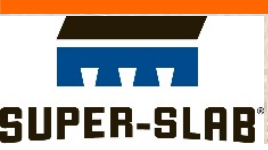

\section{I-78 Interchange 14C Toll Plaza - NJTA Jersey City, NJ - Baker / GPI}
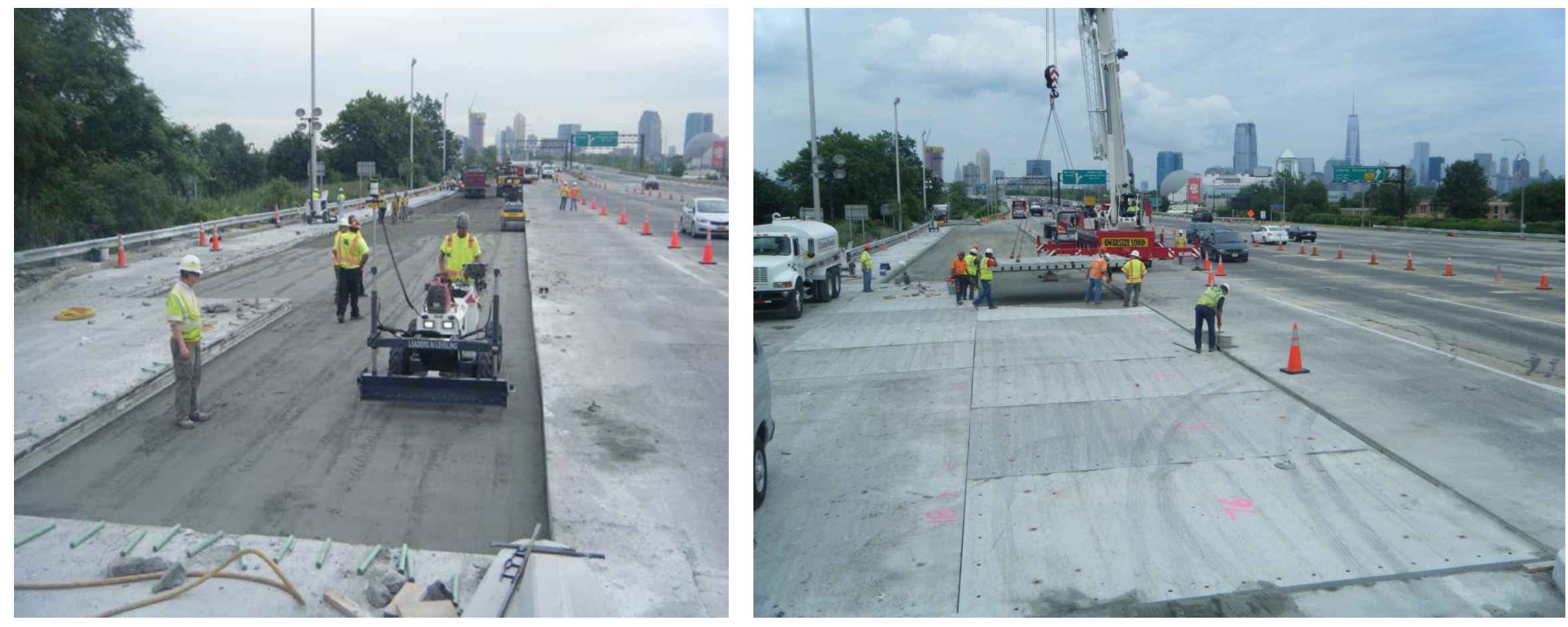

The Fort Miller Co., Inc. 


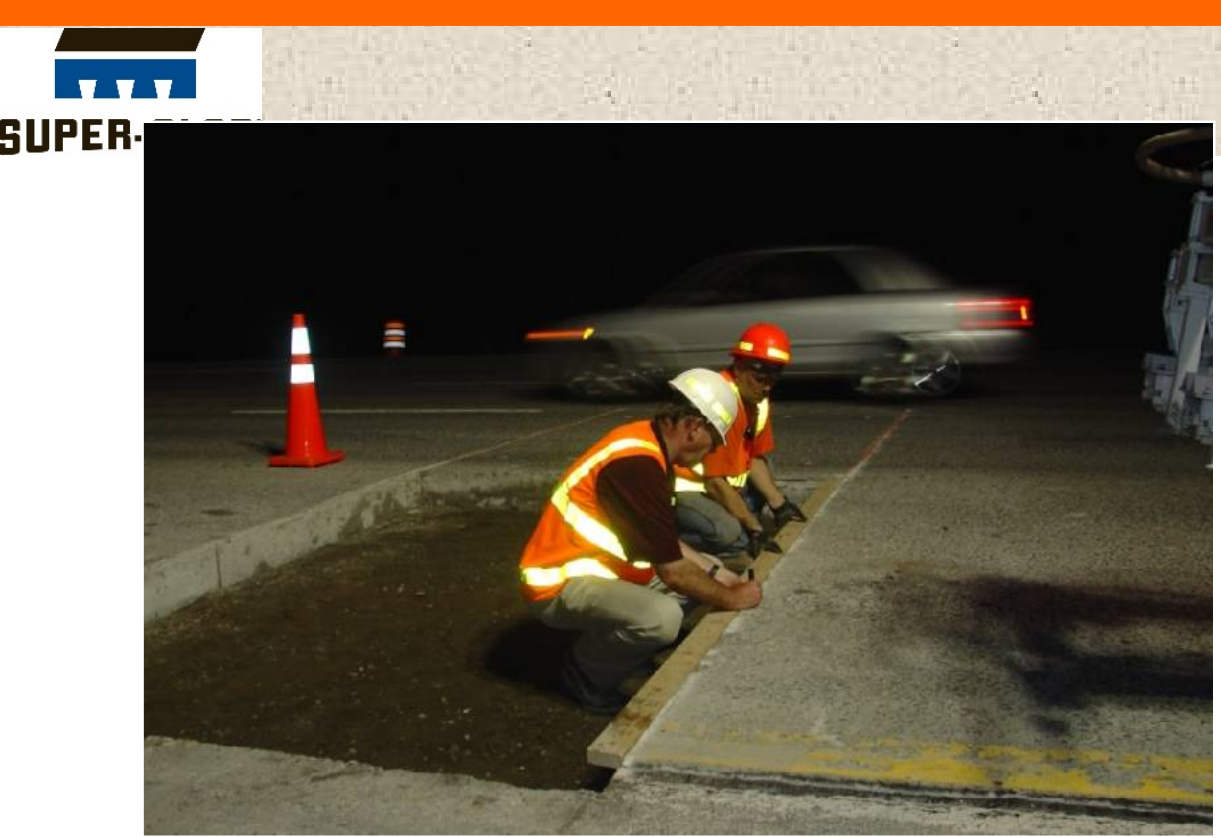

Use Correct Template

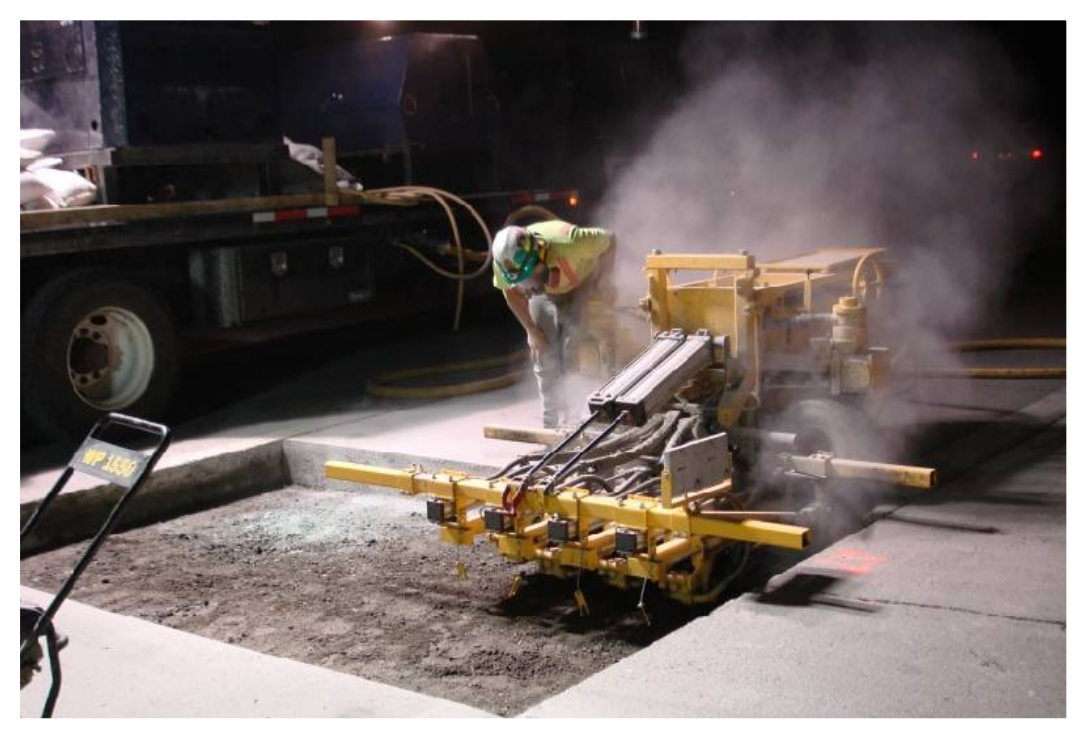

16 holes - 12 minutes

\section{Drilling for Dowels}

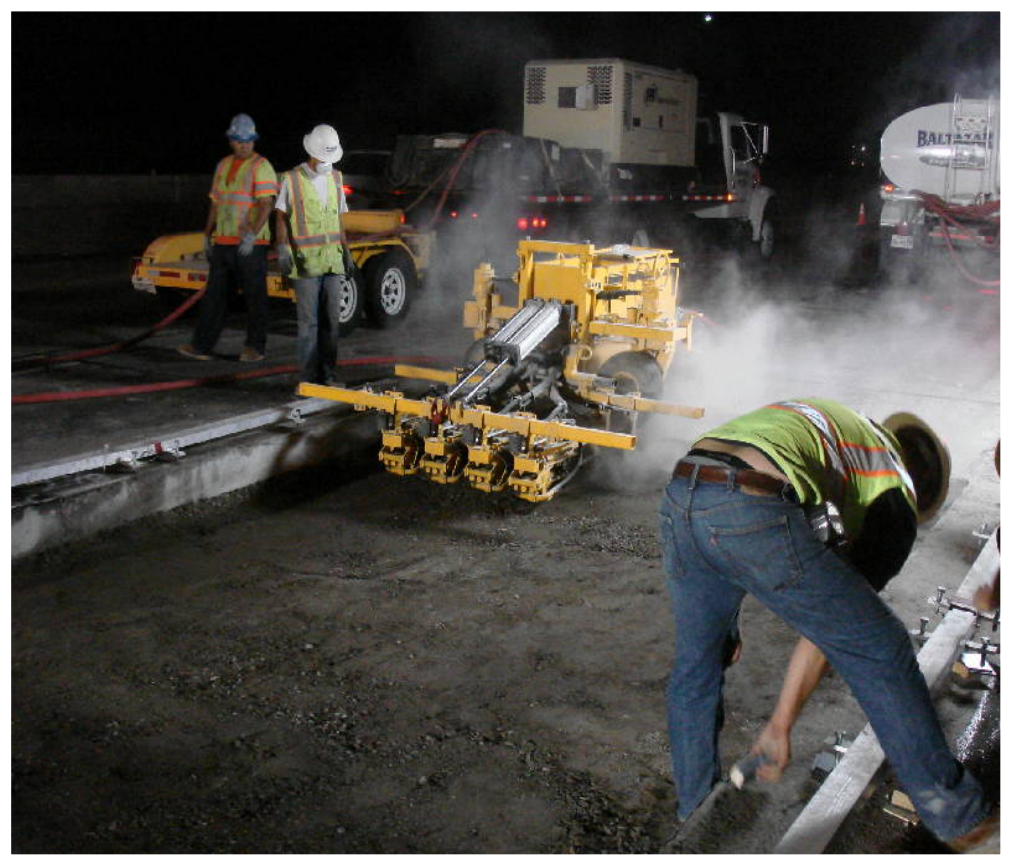

Drilling and Setting Rail

The Fort Miller Co., Inc. 


\section{Shipping and Placing}

- Size slabs for shipping

- 12' Max. width

- Special permits

- Slabs delivered in adjacent lane

- One man in each corner

- Set slabs to panel point mark

- Check for match (the SuperSlab Shuffle)

- Average setting rate $\mathbf{- 1 0}$ slabs per hour

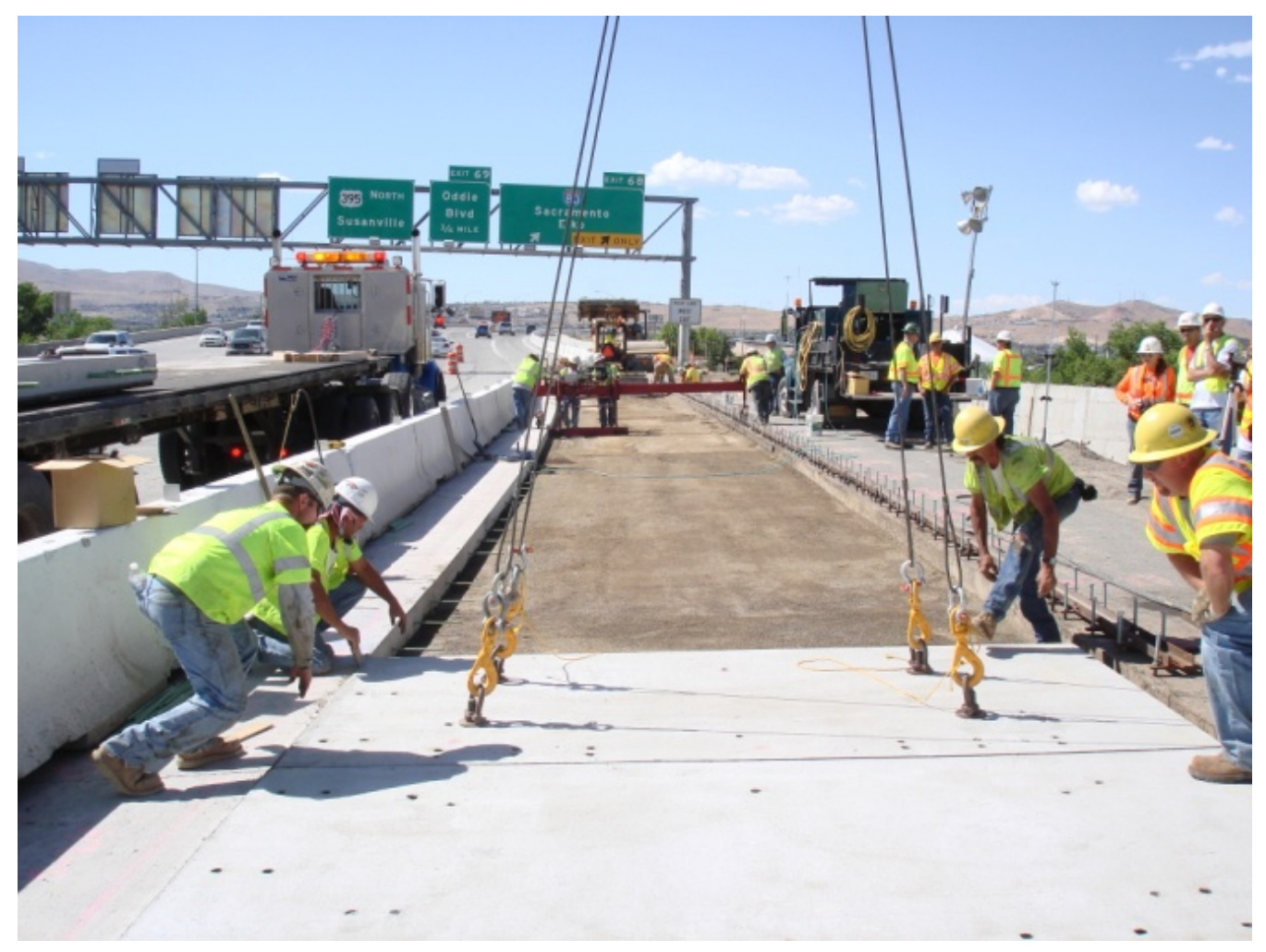




\section{Installing Dowel Grout}

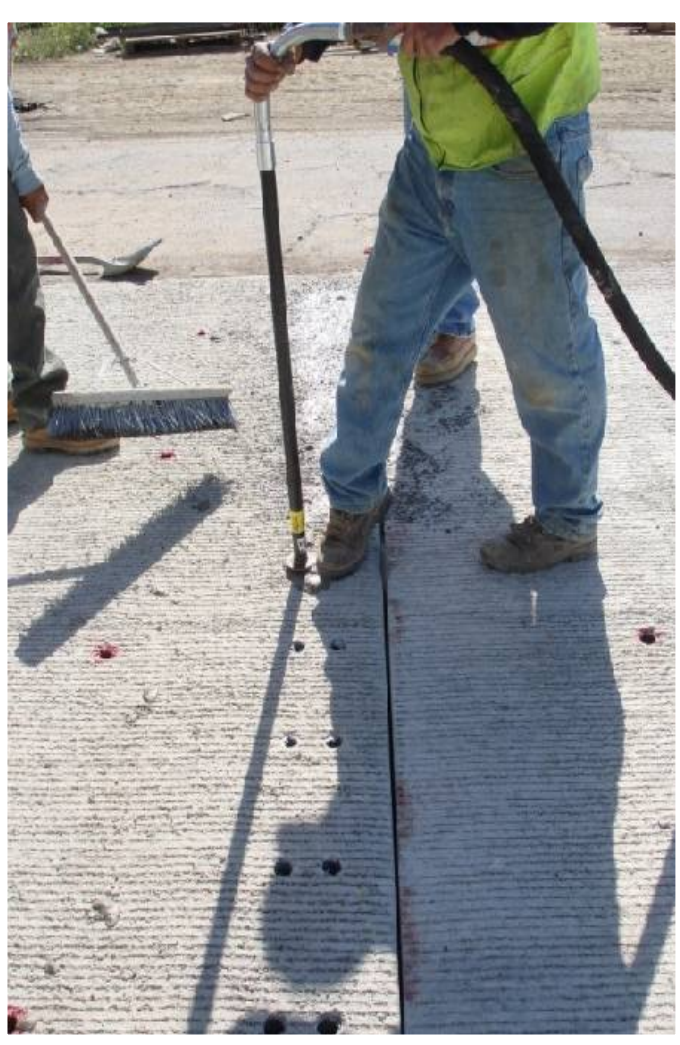

Fill Dowel Slots and Joints

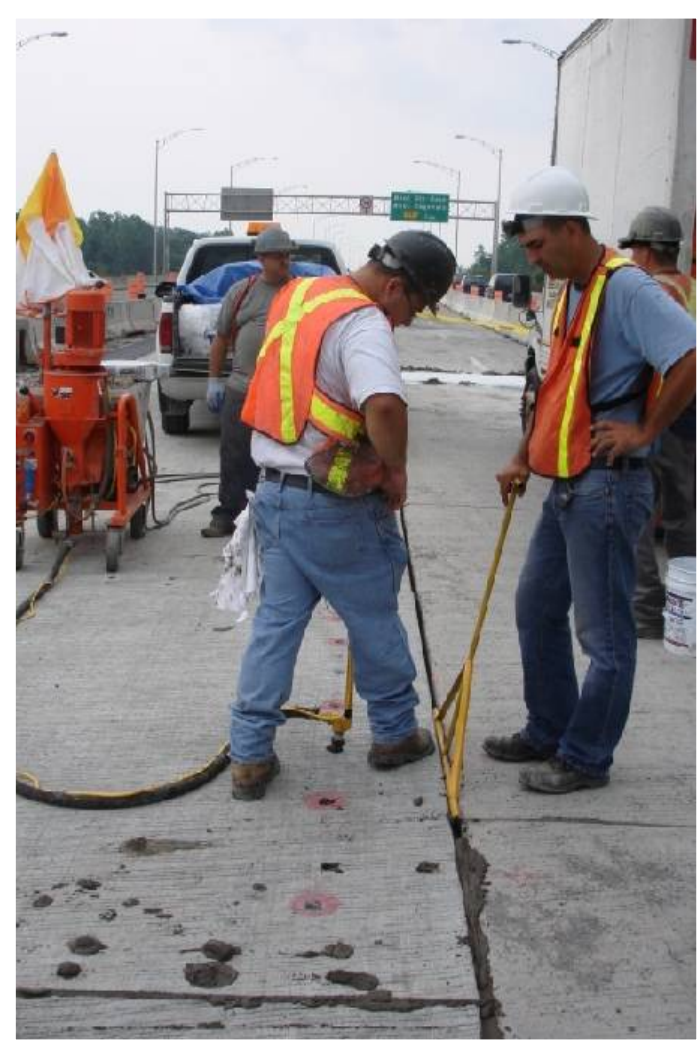

Contractor-Designed Joint Dam 


\section{Intermittent Repairs (CPR)}
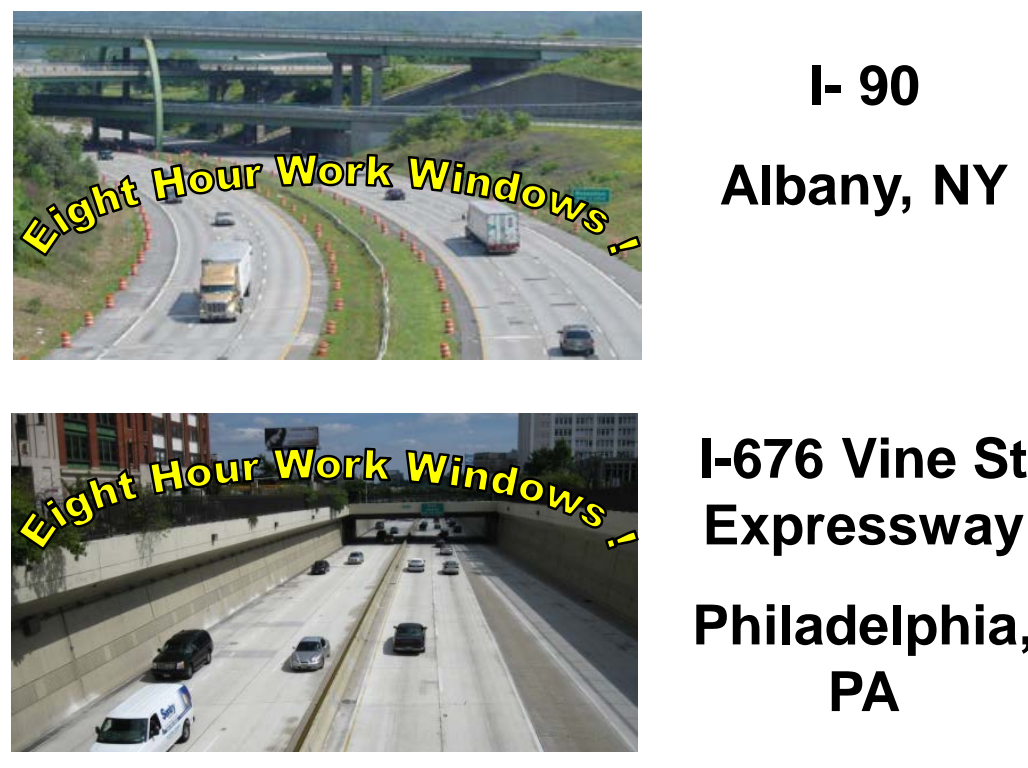

I-676 Vine St Expressway

Philadelphia, PA
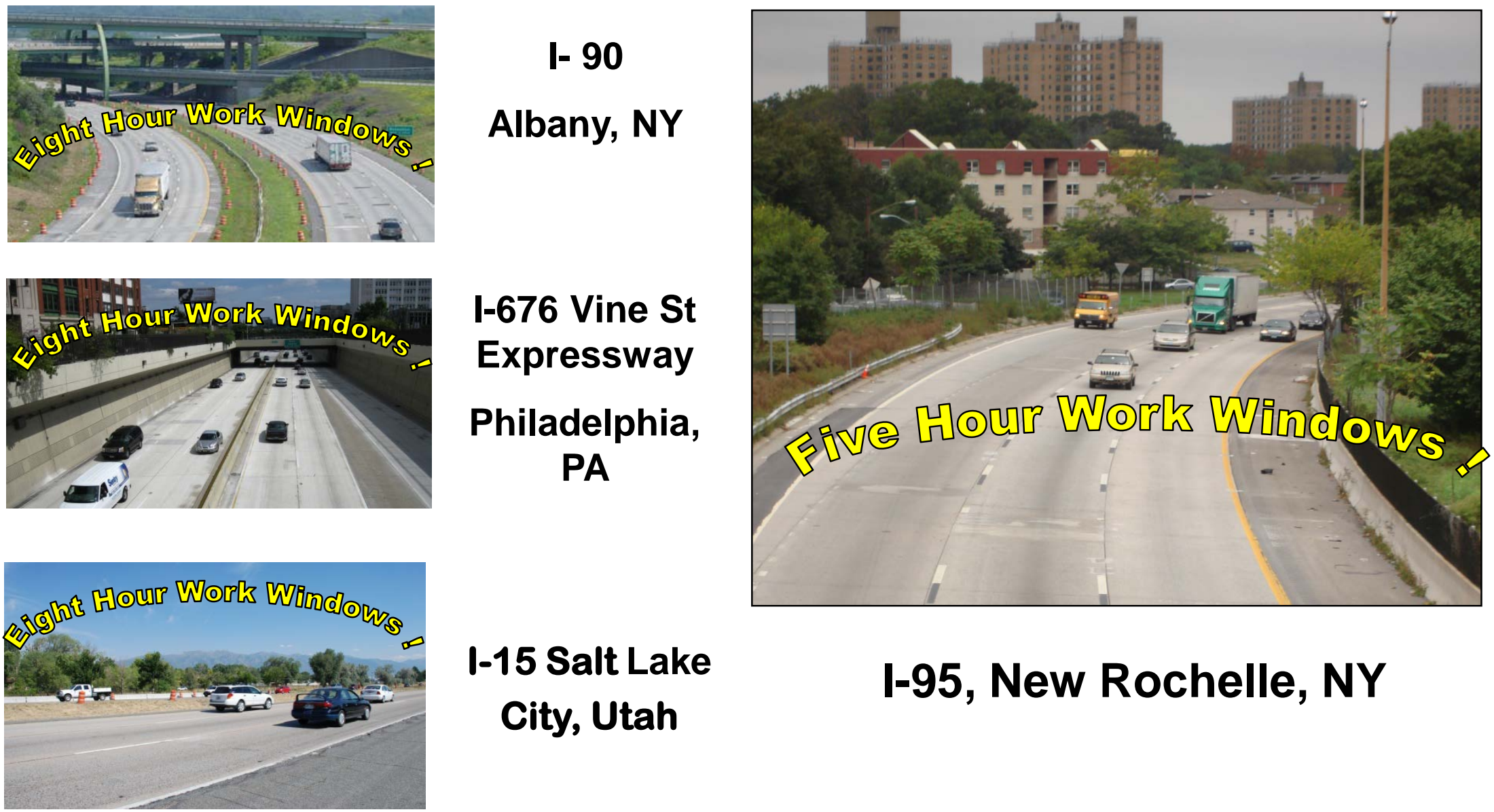

I-15 Salt Lake City, Utah

I-95, New Rochelle, NY

The Fort Miller Co., Inc. 


\section{I-295 Pav't Repair, Burlington Co., NJ NJDOT 2007 to date: 14 jobs $=4500+$ slabs}
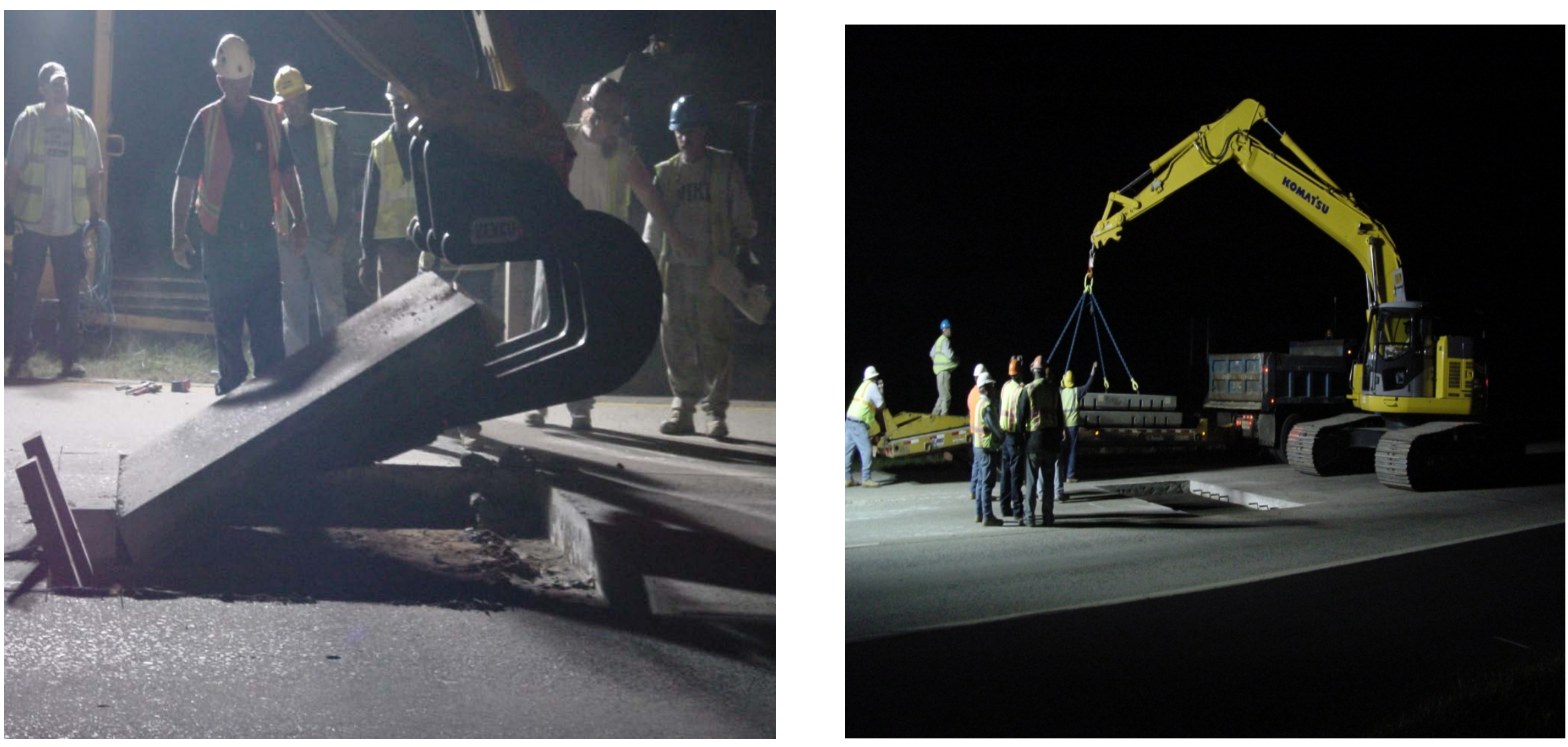

The Fort Miller Co., Inc. 


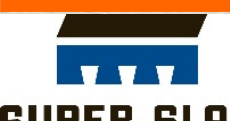

\section{Continuous - Tappan Zee Bridge Toll Plaza}

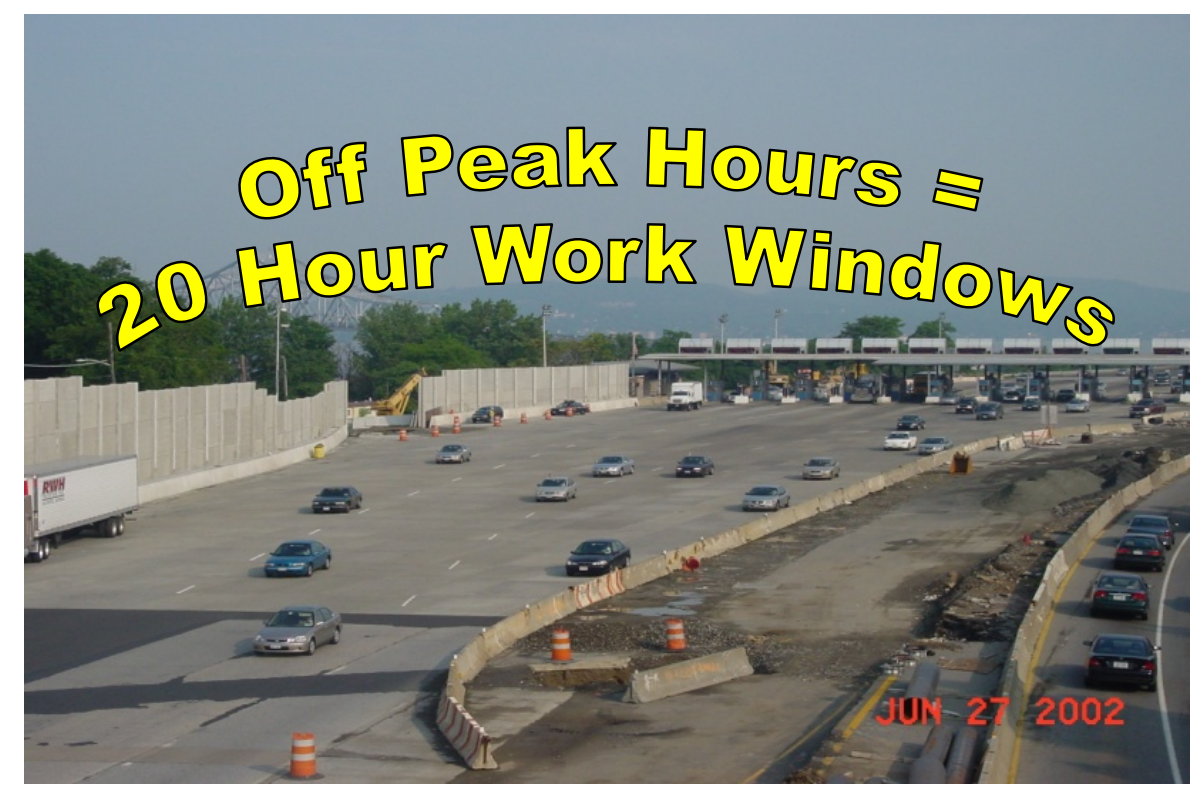

3,000 SF I 8 Hour Shift

(Within $\pm 1 / 8 ")$

2001 - 2002

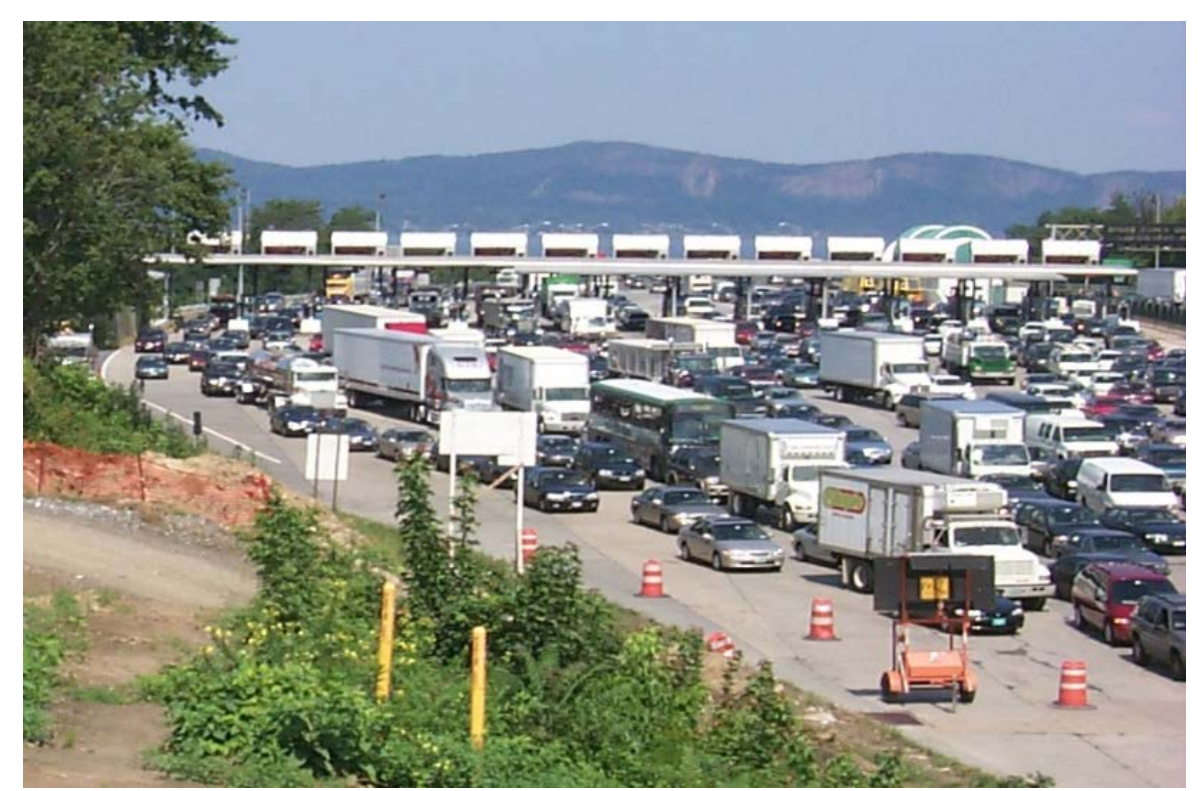

Open for Rush

Hour

(135,000 ADT)

The Fort Miller Co., Inc. 


\section{Continuous - Mainline Placement}
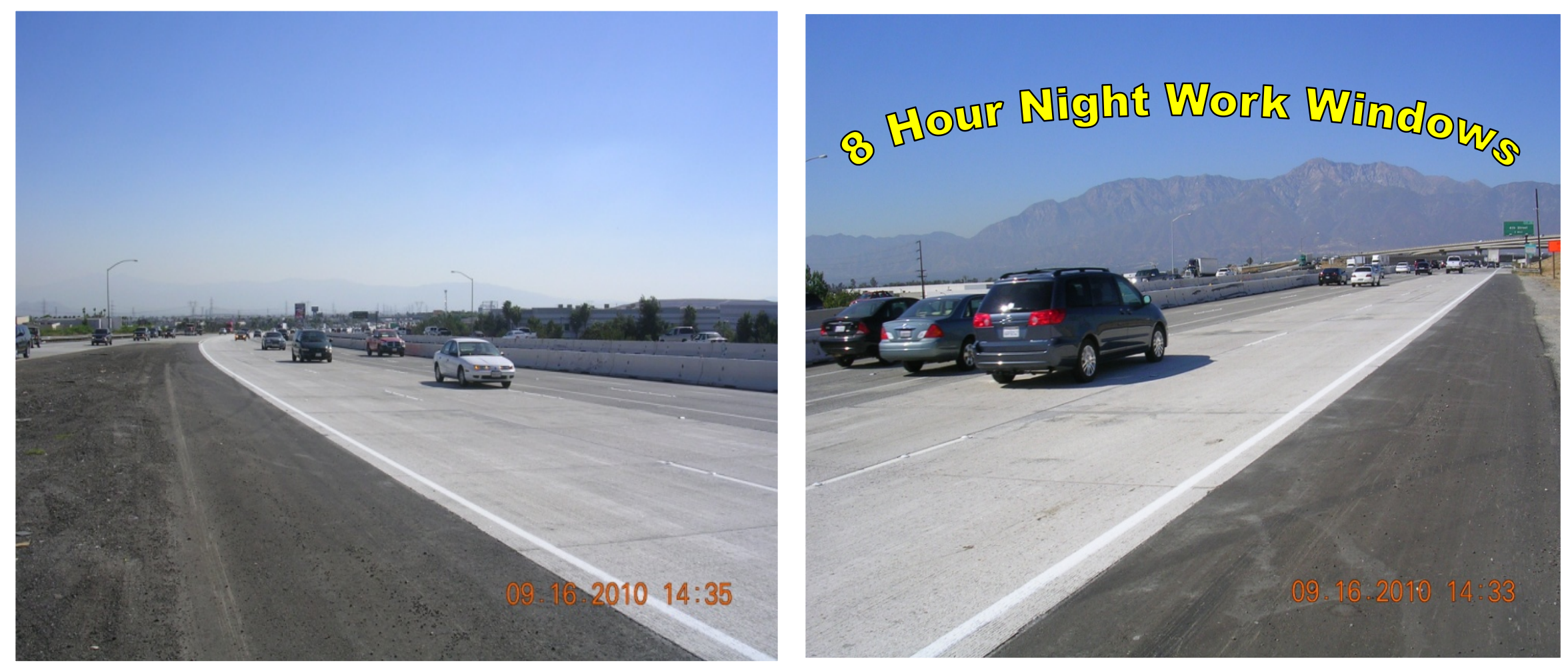

\section{Mainline I-15, Ontario, CA} (200,000 VPD) 


\section{Ramps}
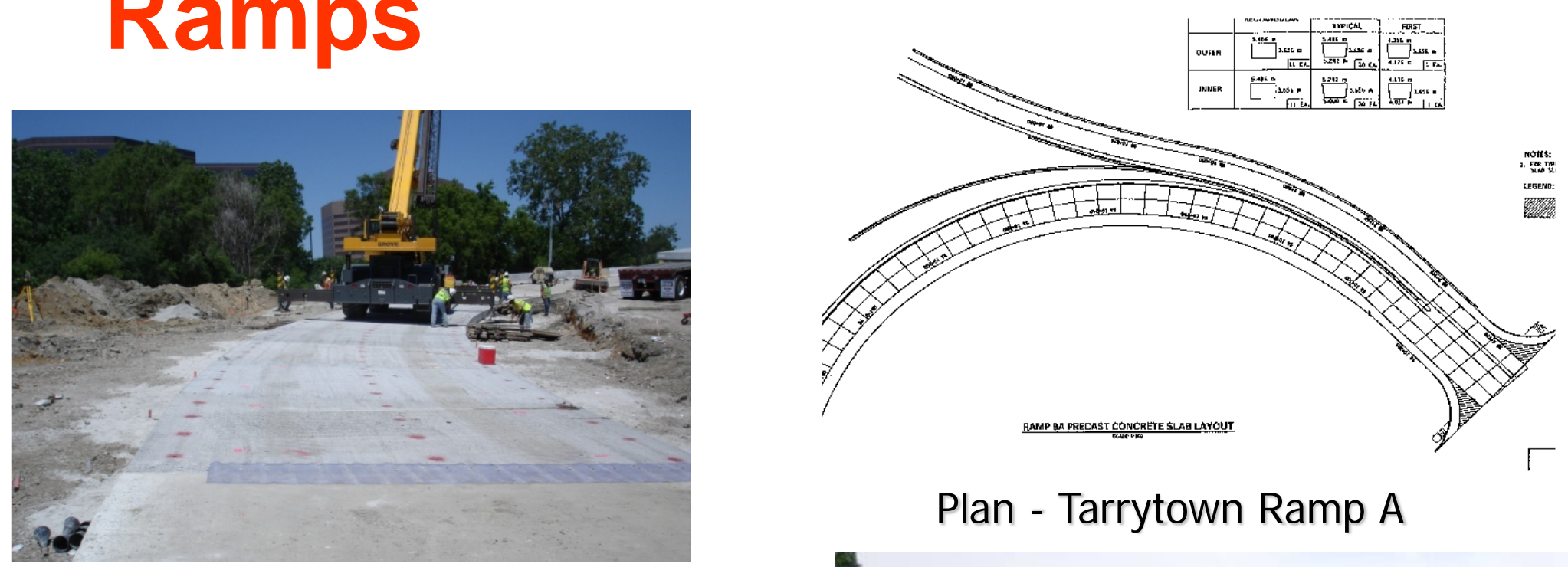

Oak Brook, IL

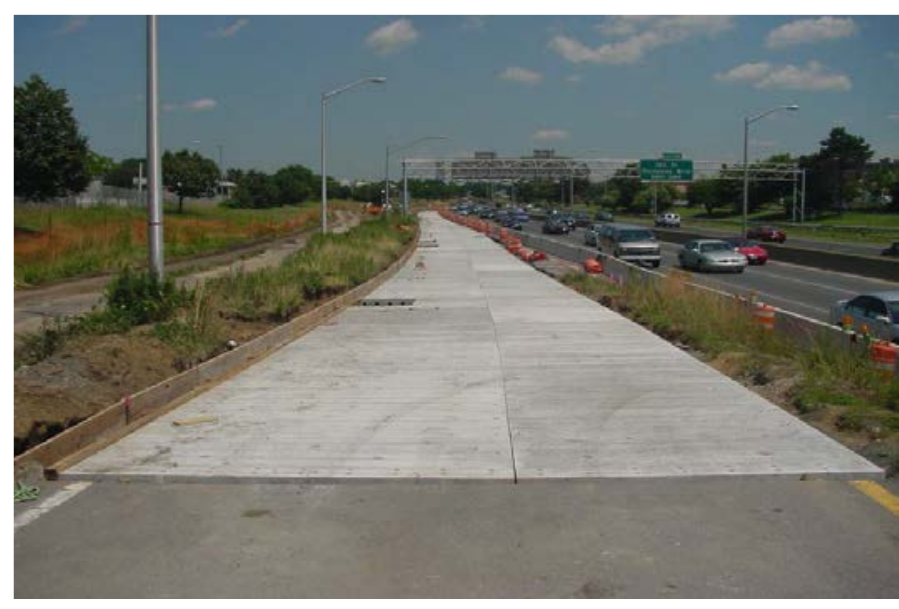

Brooklyn, NY

Plan - Tarrytown Ramp A

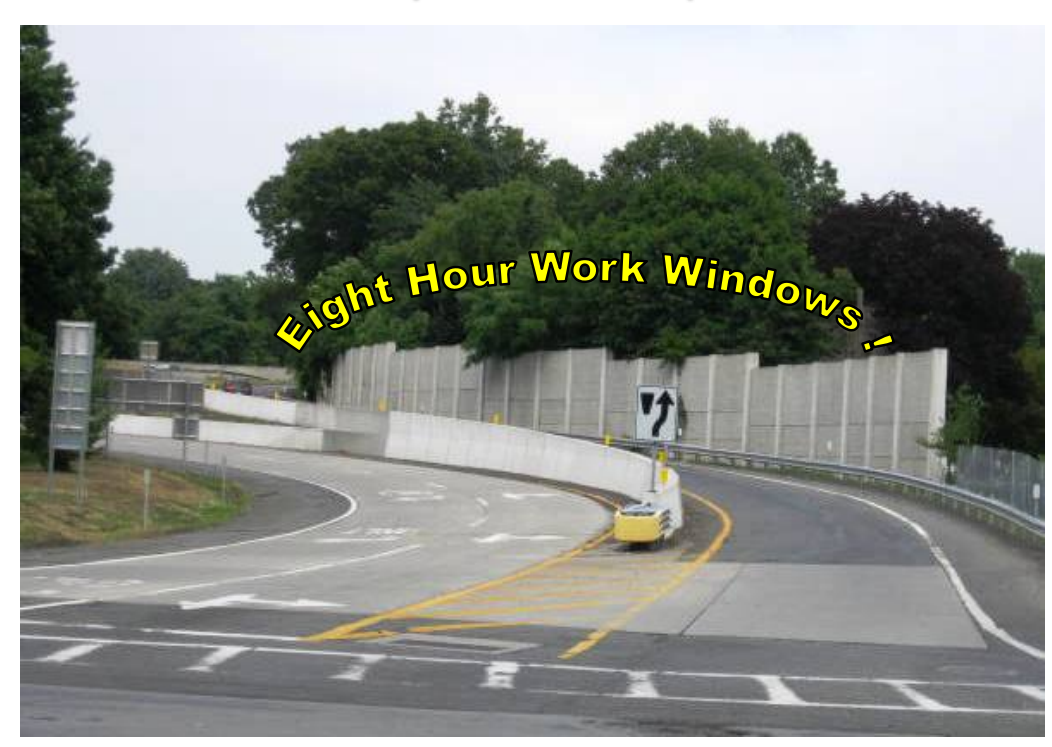

Tarrytown, NY 


\section{NJDOT Bridge \& Approach Slabs US 46 Over Broad St. - Clifton, NJ}

- Bridge replaced over two weekends - April 2011

- Two-span (40.2', 40.2') continuous, $28.76^{\circ}$ skew

- Precast Approach Slabs - tied to prefabricated bridge units
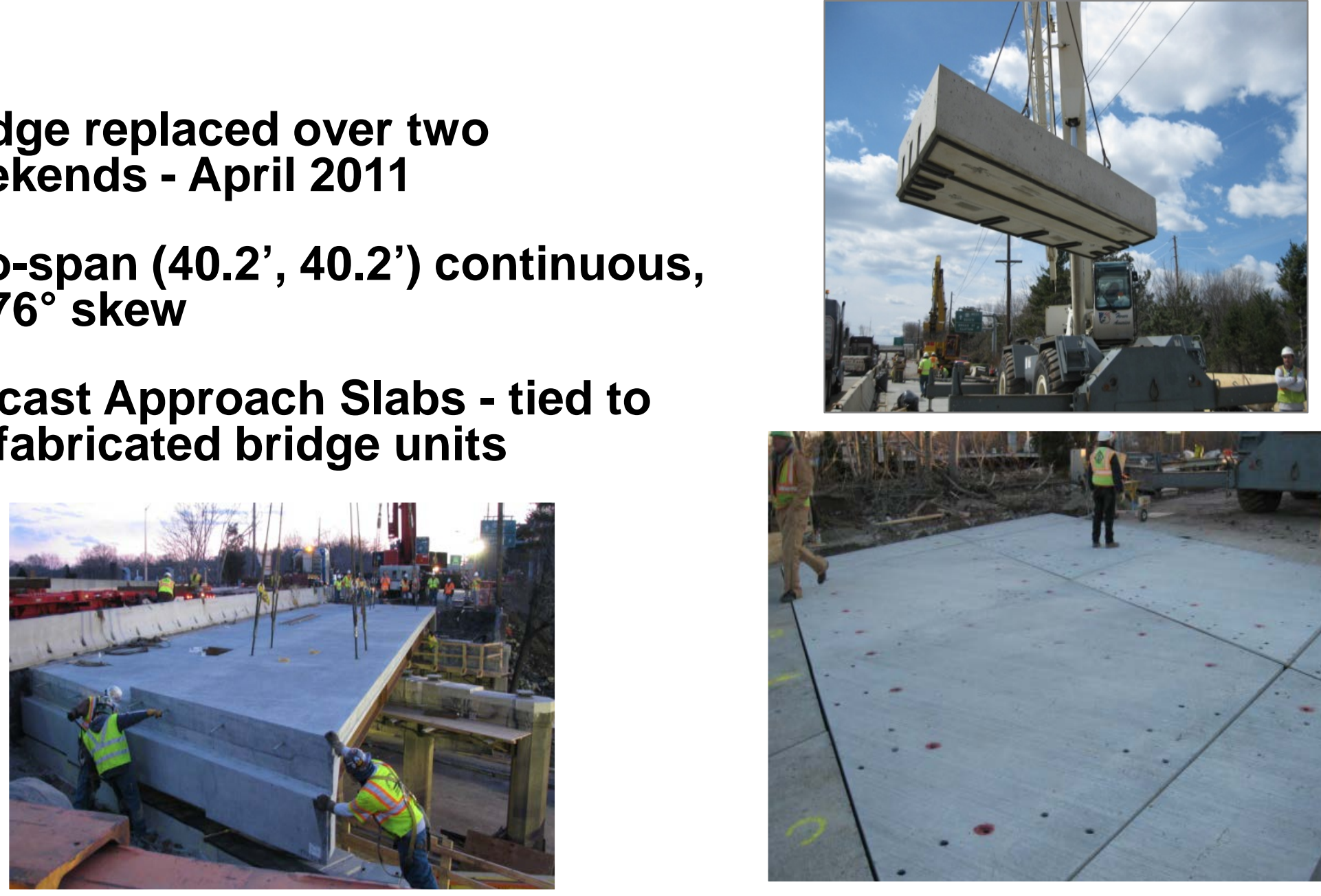

The Fort Miller Co., Inc. 
Brooklyn Bridge Approaches $2010-2013$ URS \& Weidlinger
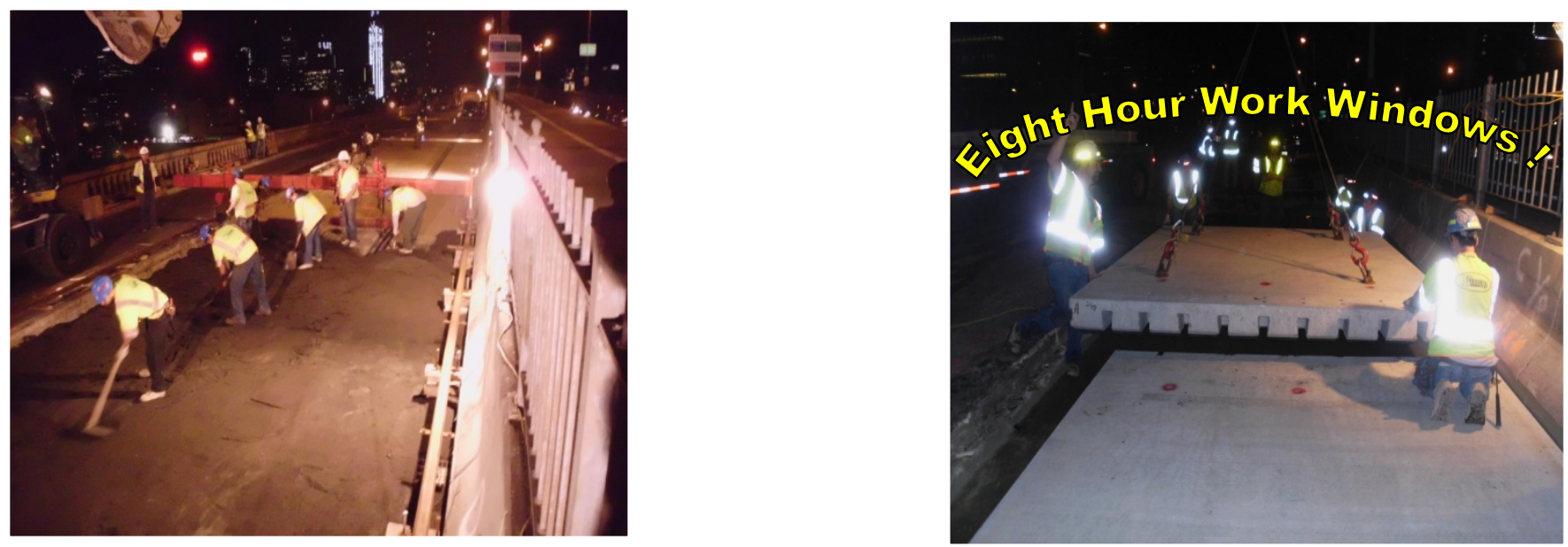

Grading

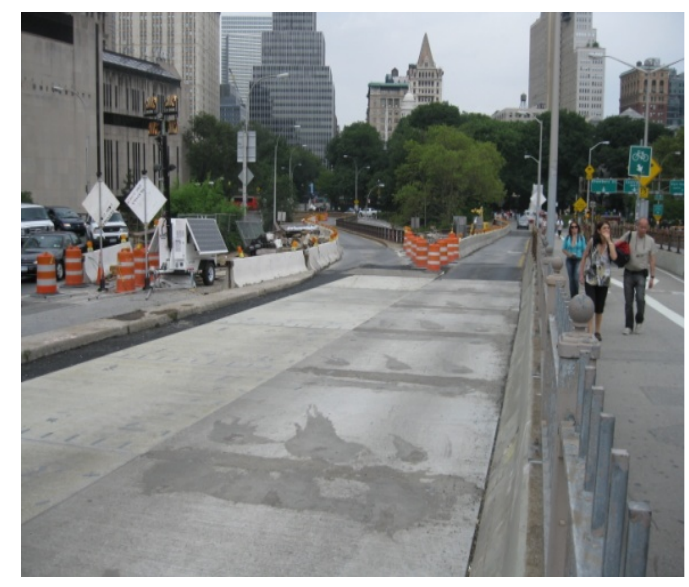

Looking toward Manhattan

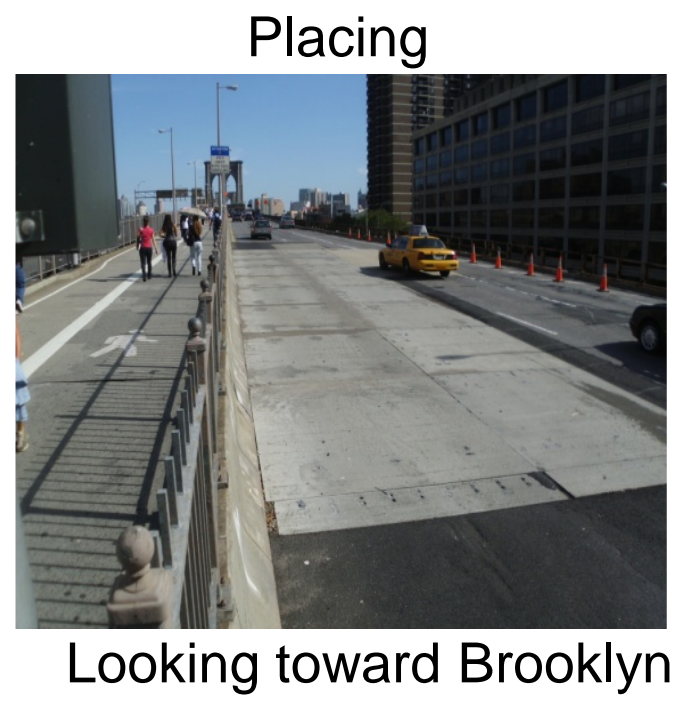

The Fort Miller Co., Inc. 


\section{Alexander Hamilton Bridge W. Approach, 2011 - 2013 Jacobs}

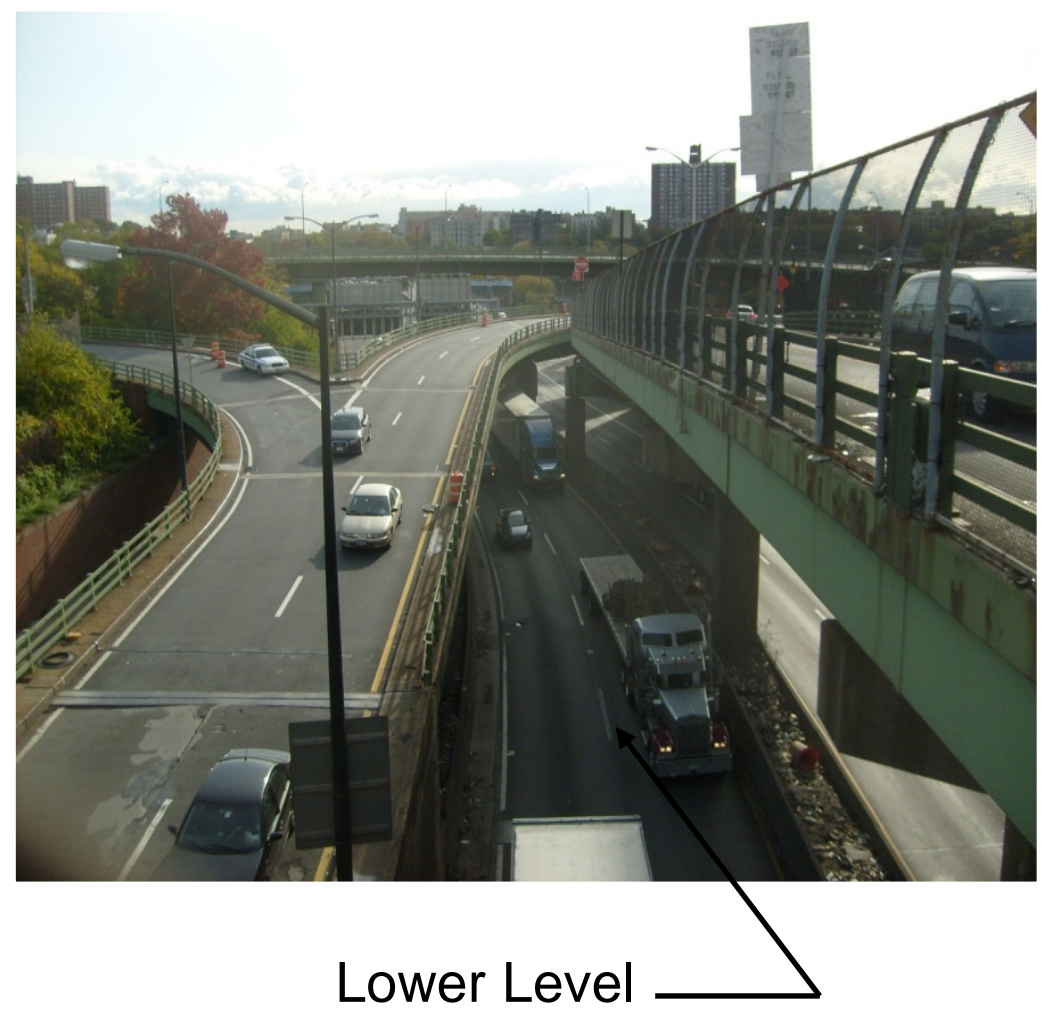

Contractor Gets One Lane To Replace The Same Lane
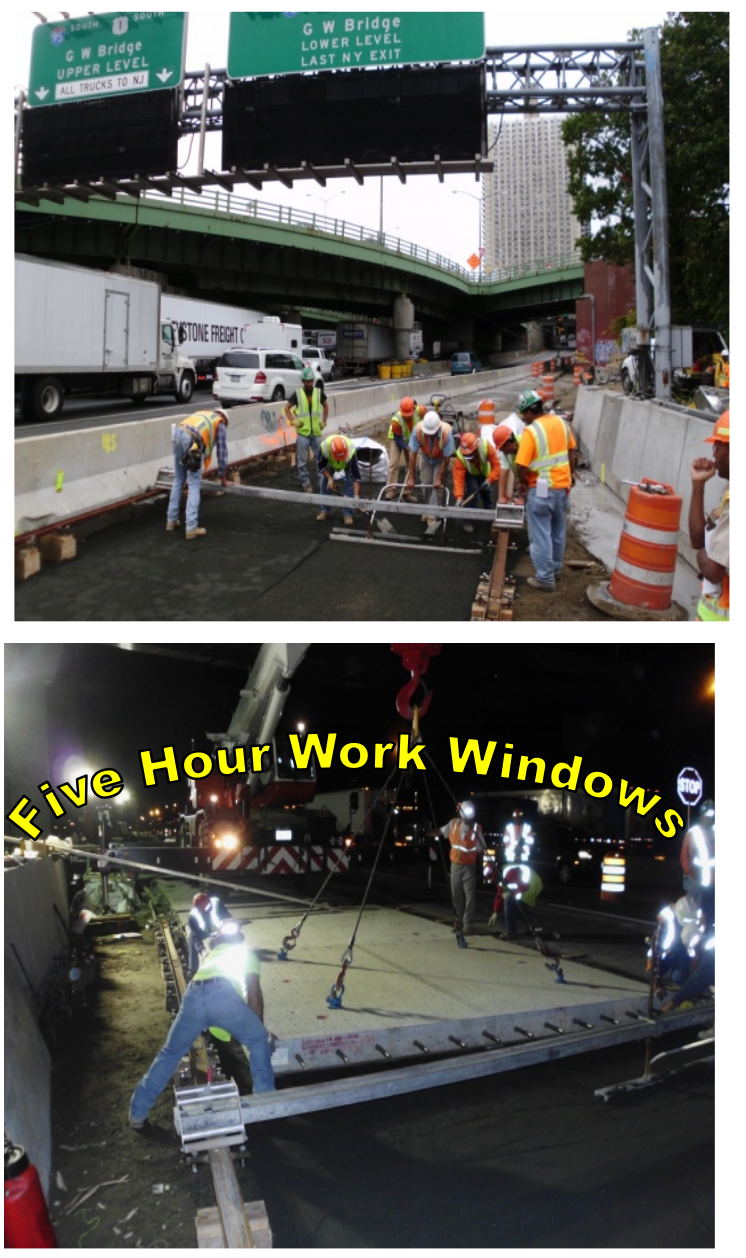

The Fort Miller Co., Inc. 


\section{I-94 MDOT Low-Clearance Bridges, Kalamazoo, MI}
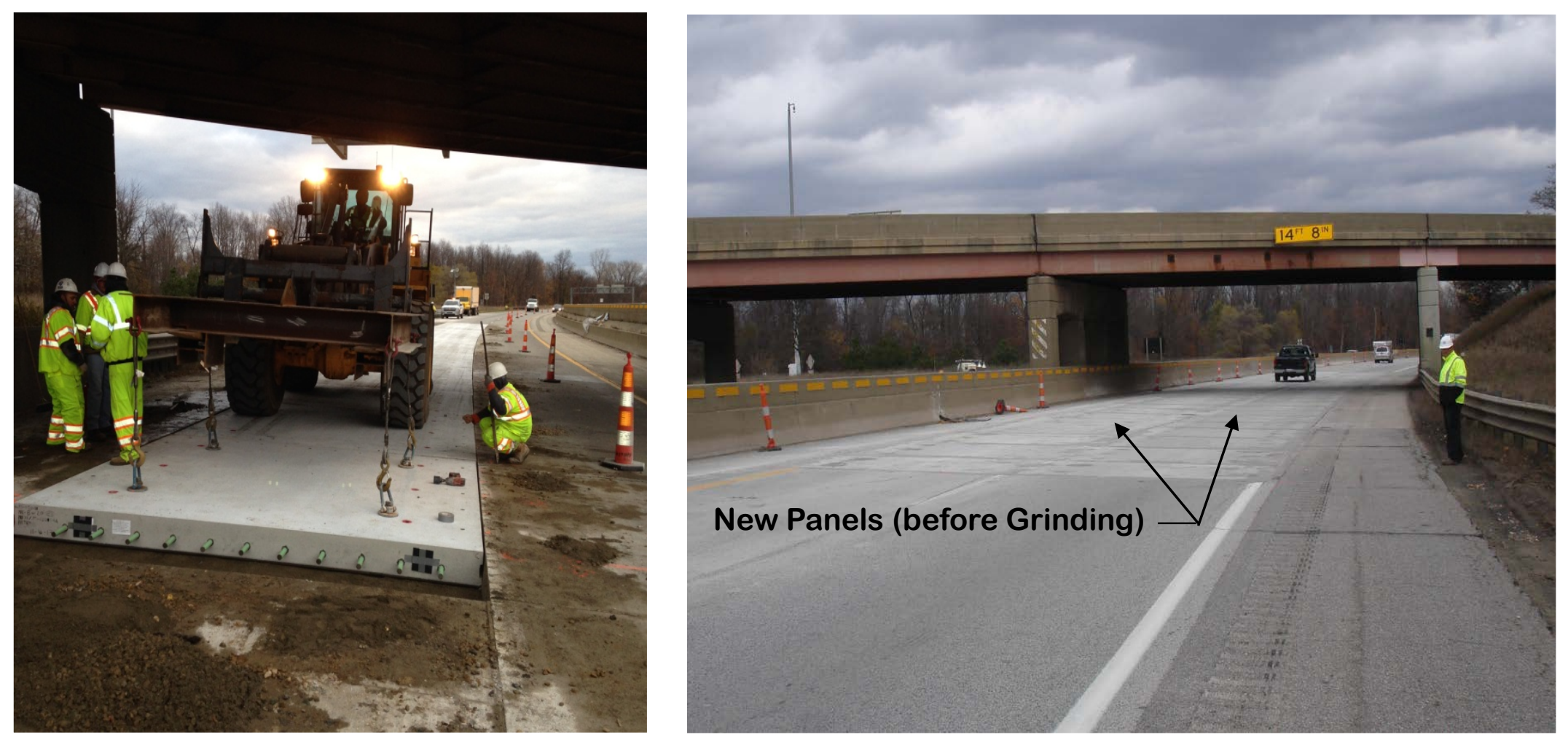

Installation

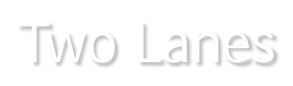

The Fort Miller Co., Inc. 


\section{Bus Pad, Hollywood \& Santa Monica Blvd. North Hollywood, CA}

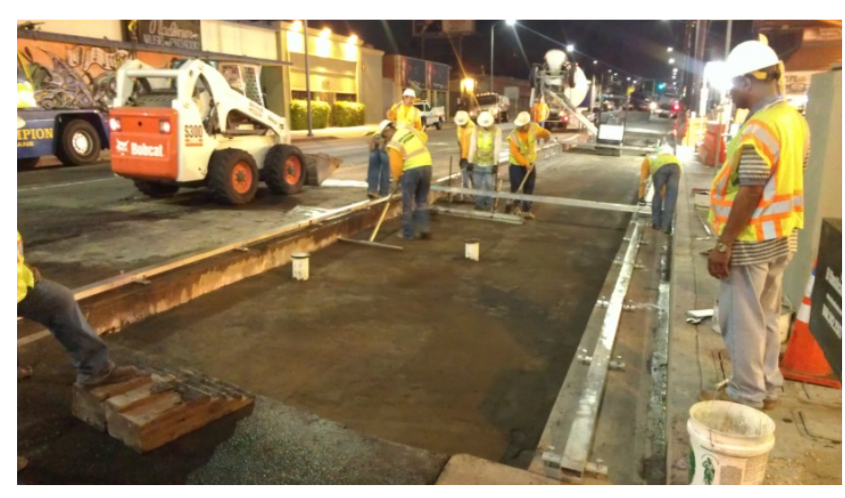

Grading

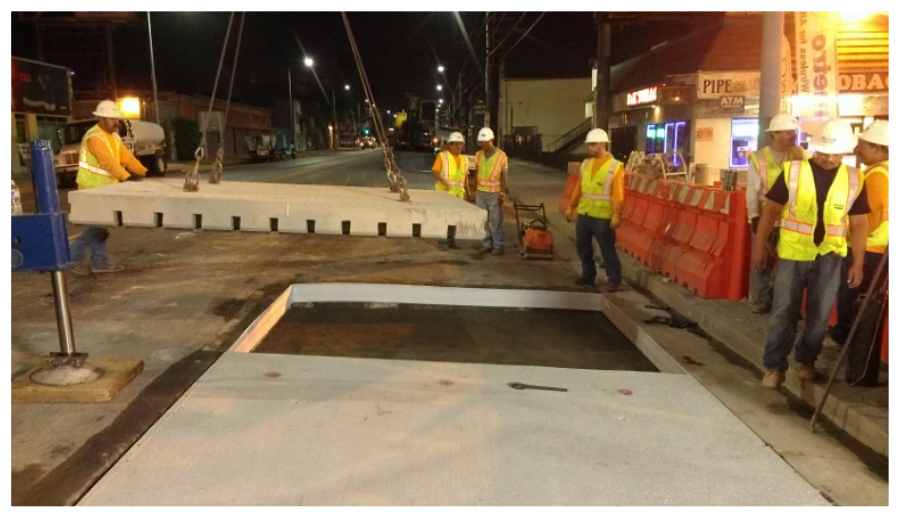

Last Slab

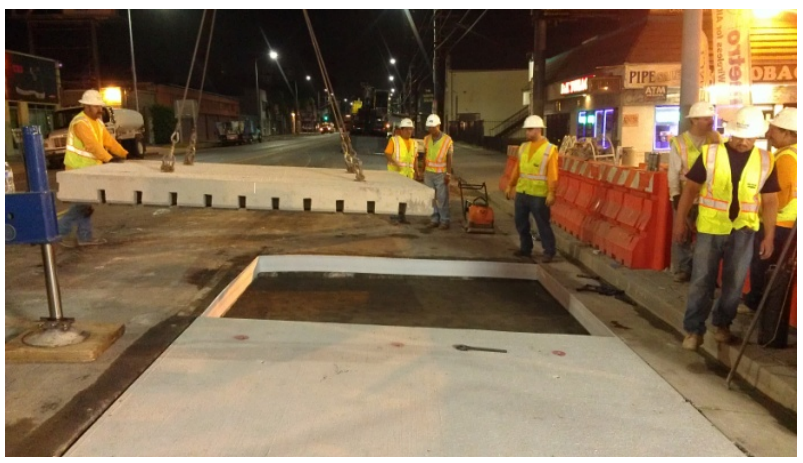

\section{Placing}

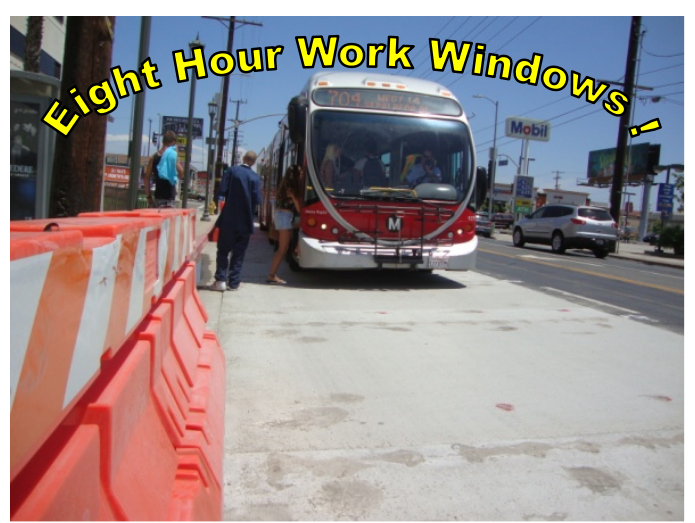

Finished, Next Day

The Fort Miller Co., Inc. 


\section{VDOT I-66 WB Ramp to US 50 WB FHWA Highways for LIFE - 2009}

- 184,000 ADT, 5\% Trucks

- (3) Repair Types:

CIP, JPCP \& PPCP

- Rt. Lane Super-Slab® 224 Slabs: 12 'x16'x8.75"

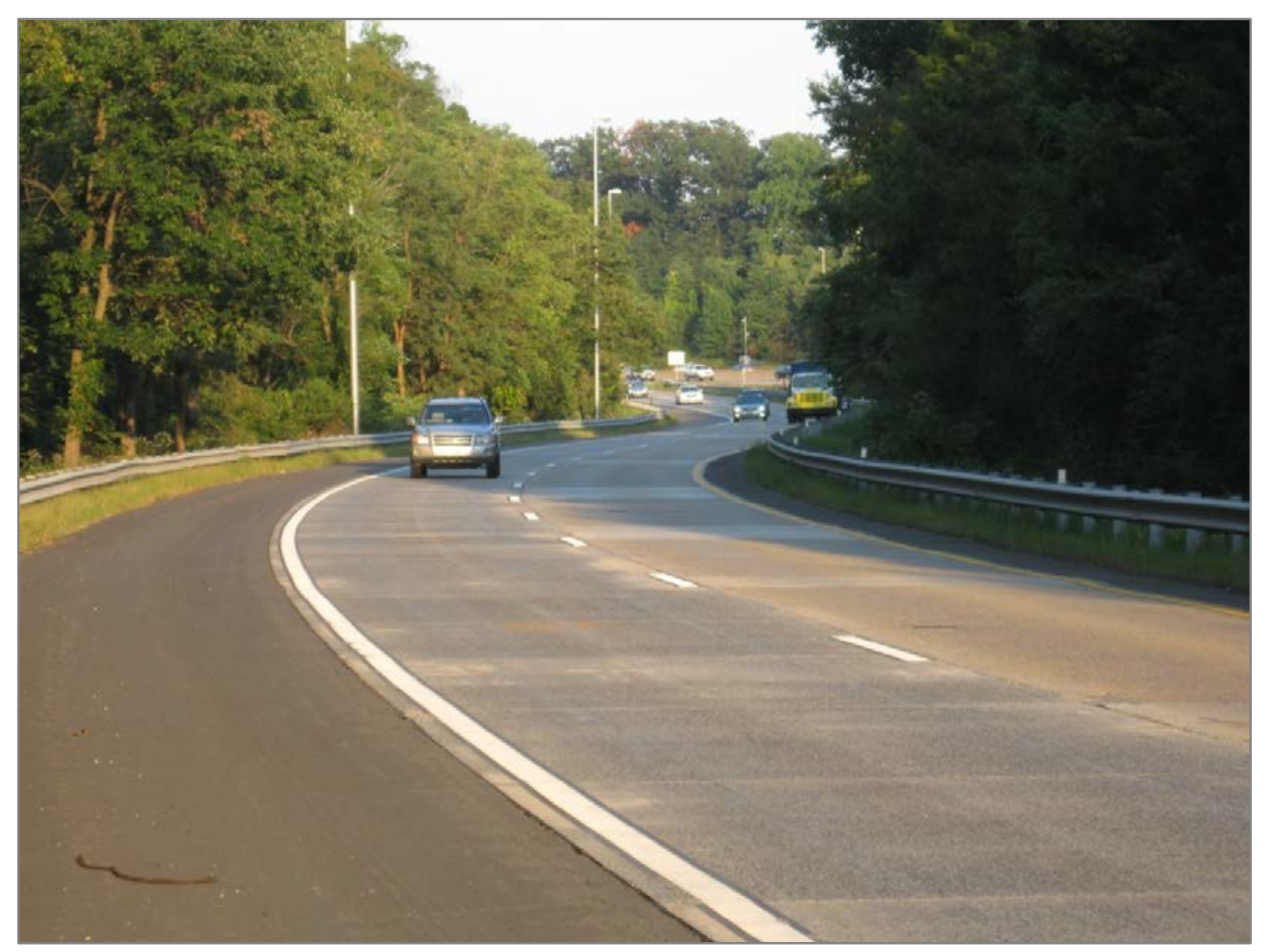




\section{I-676 Vine St. Expy. Philadelphia, PA - 2009 PennDOT District 6-0 85 slabs}
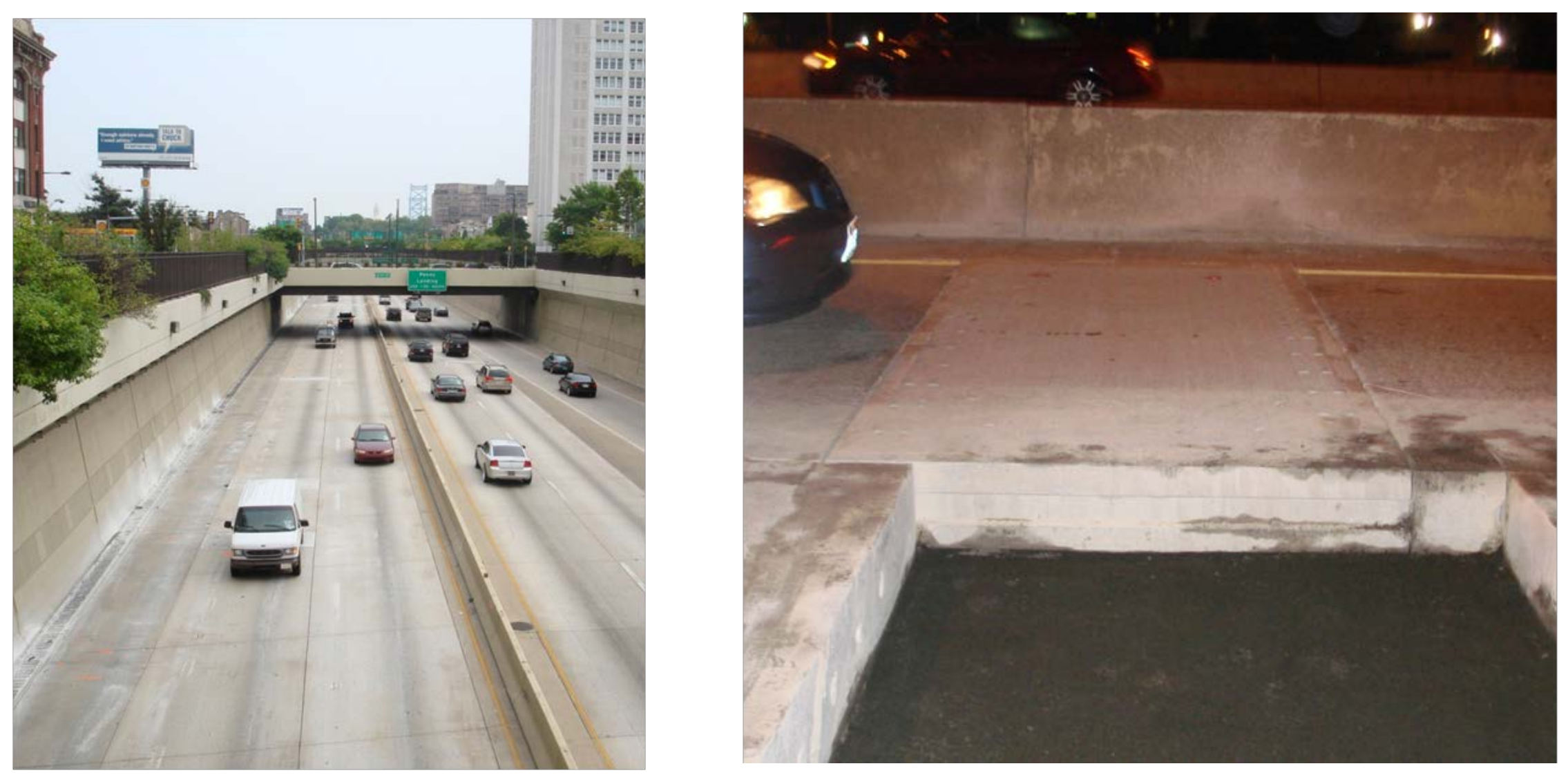

The Fort Miller Co., Inc. 


\section{Challenge - Maintaining Quality Pavement on Heavily-Traveled Urban Streets and Arterials Over Multiple Utilities}
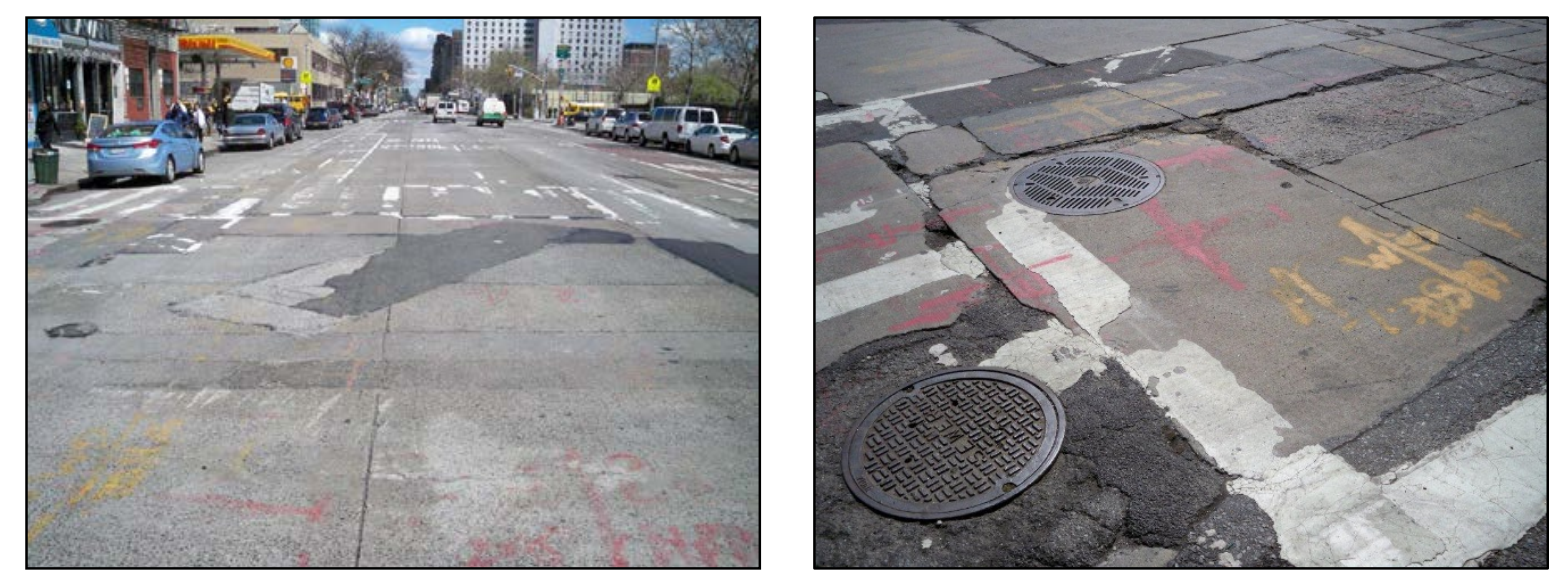

First Avenue, New York City

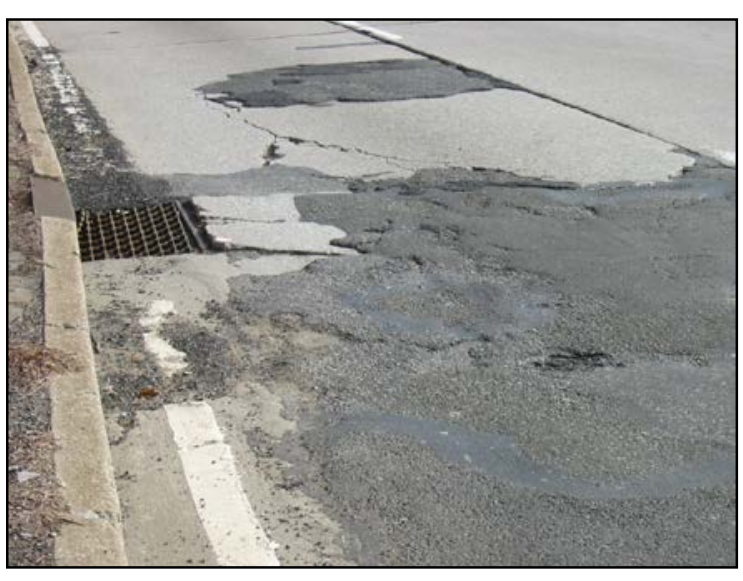

Cross Bronx Expressway, NYC

Non-durable materials - no load transfer - poor workmanship

The Fort Miller Co., Inc. 


\section{Goals}

- Up-grade subgrade and subgrade drainage

- Install long-lasting durable concrete pavement materials (concrete)

- Maintain traffic during the process

- Use a modular pavement system or materials that are easily removed and replaced to maintain utilities below

- If concrete, to use dowels for load transfer

- Be able to restore pavement to original (equivalent or better) condition after a utility repair event

- In appearance and functionality 


\section{Removable Urban Pavements (RUP) - A New Tool For Consideration}

- Pavement that can be removed and replaced rapidly

- To original condition (in appearance \& functionality)

- Durable concrete precast concrete pavement slabs

- Slabs may be (relatively) light weight

- For ease of handling

- To keep disturbed footprint to a minimum

- Vertically-removable (and replaceable) units

- Full load transfer between slabs 


\section{Two Approaches to Servicing Underlying Utilities}
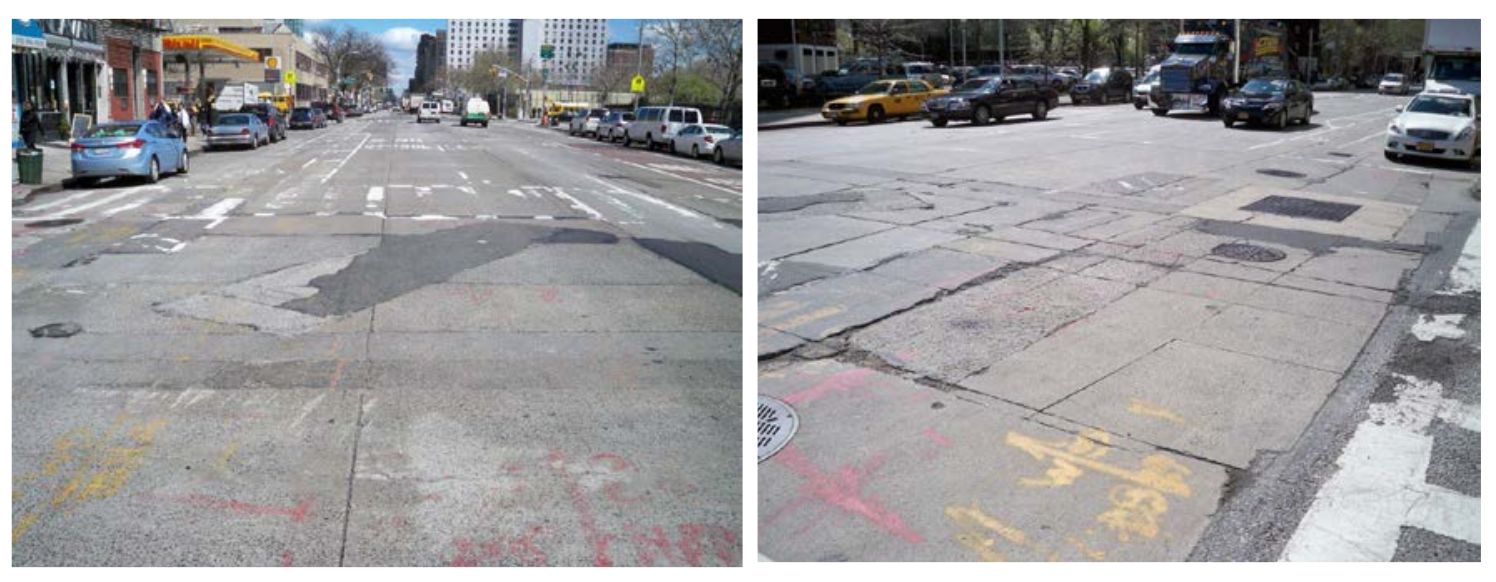

Cut, Remove and Replace Randomly

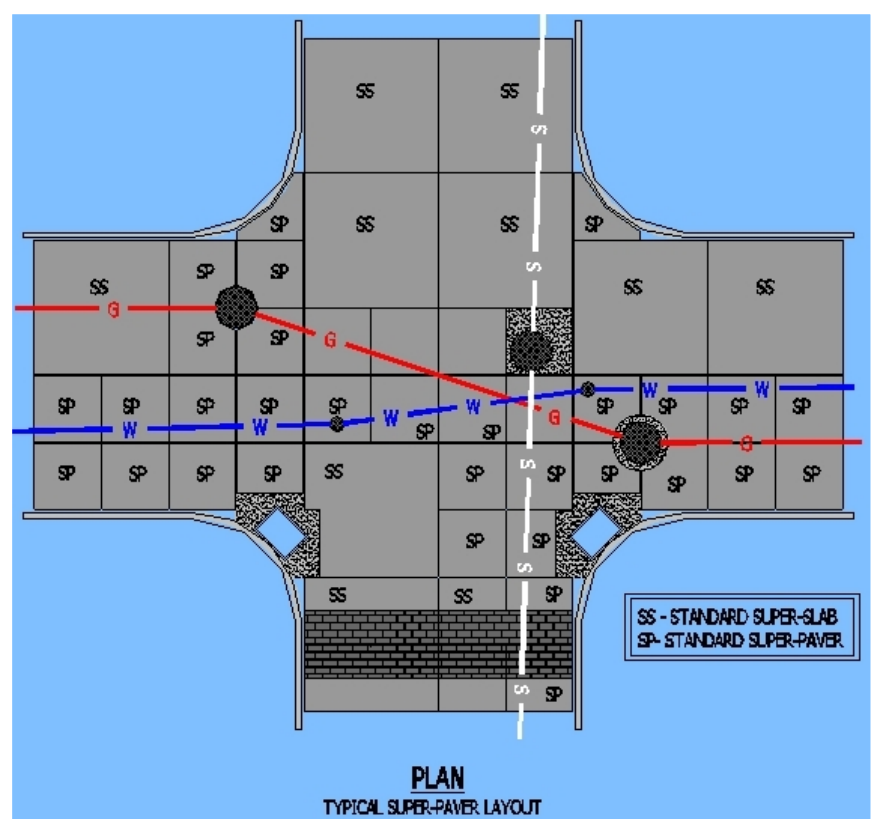

Size Slabs to Access Utilities Below - Cut at Joints for Access Below 


\section{Replacing Pavement}

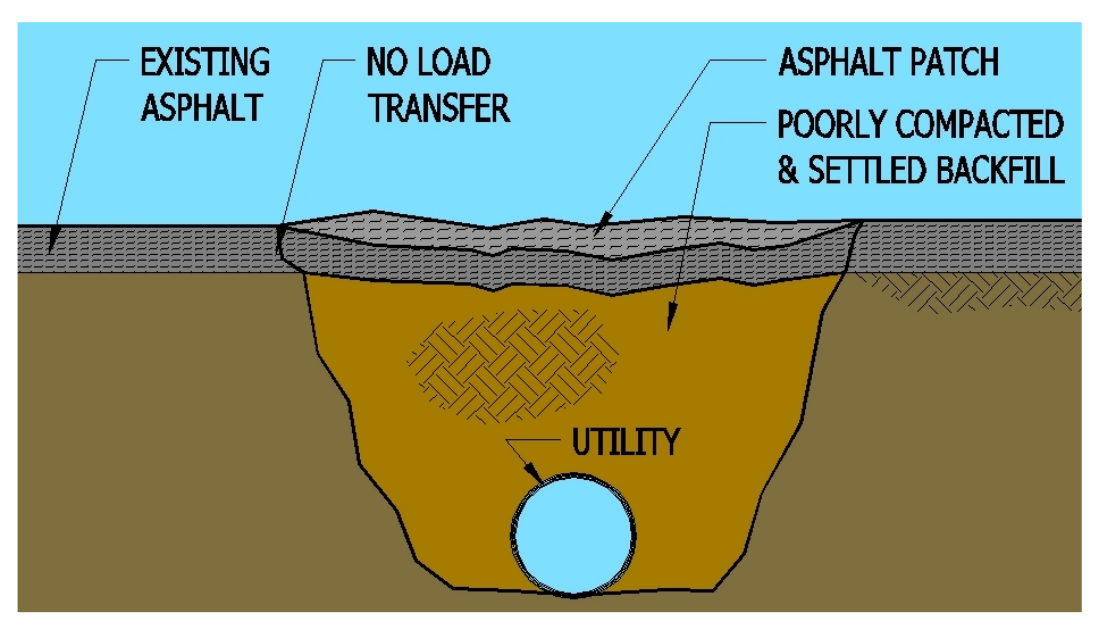

Asphalt Repair

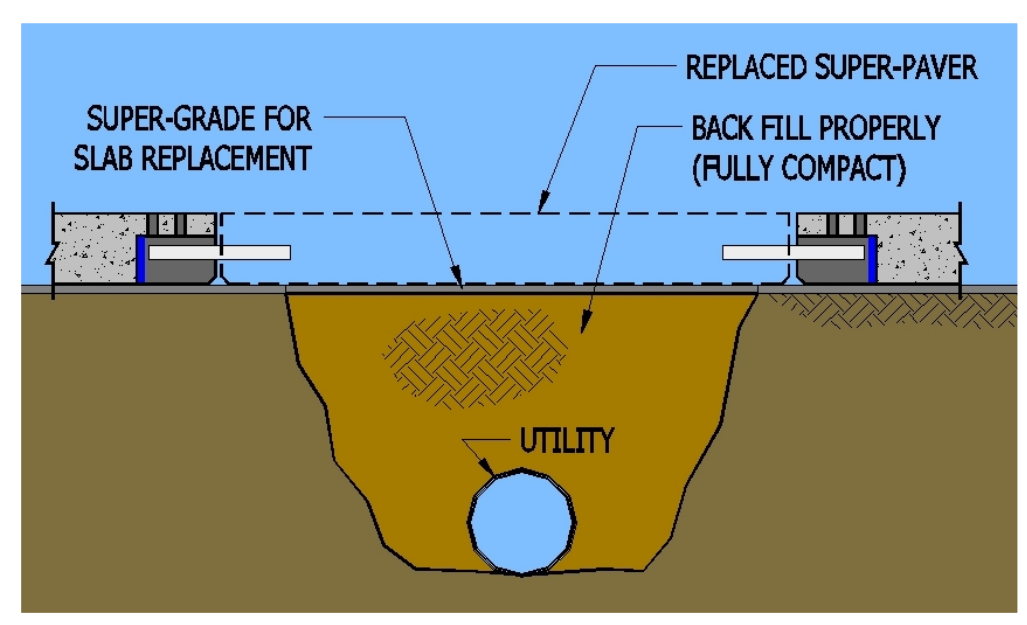

Precast Pavement

- a Better Repair

The Fort Miller Co., Inc. 


\section{Case Studies of Urban Arterials Replaced with Precast Pavement}

- NYSDOT Route 7 - Nott Street Intersection, Crosstown Connection, Rotterdam, NY - 2006

- Nassau-Queens Expressway, Rockaway Boulevard, Jamaica, NY - 2009

- GDOT Broad Street, Winder GA - 2013

- Kansas DOT Route 73, Leavenworth, KS - 2015 


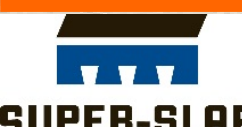

\section{NY 7 Crosstown Connection Nott Street Intersection}
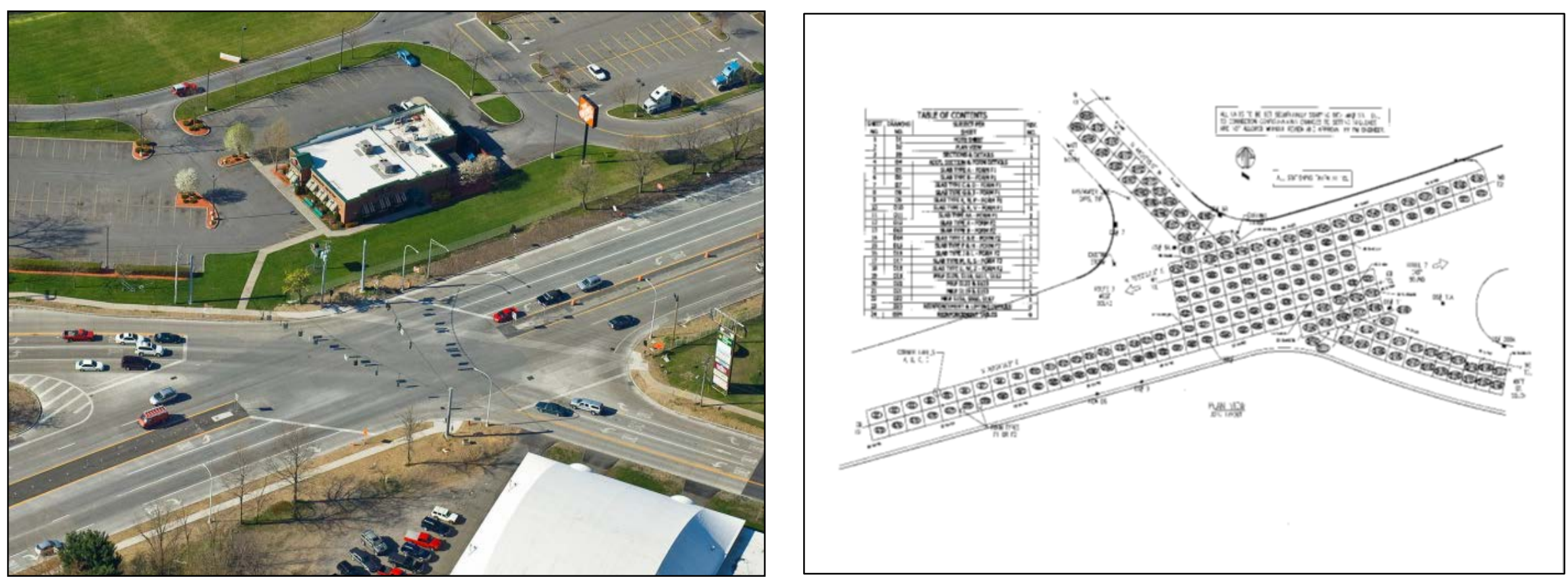

Precast Pavement - Center Part of Intersection Only

The Fort Miller Co., Inc. 


\section{Undercut and Replace with Dense Aggregate Base}

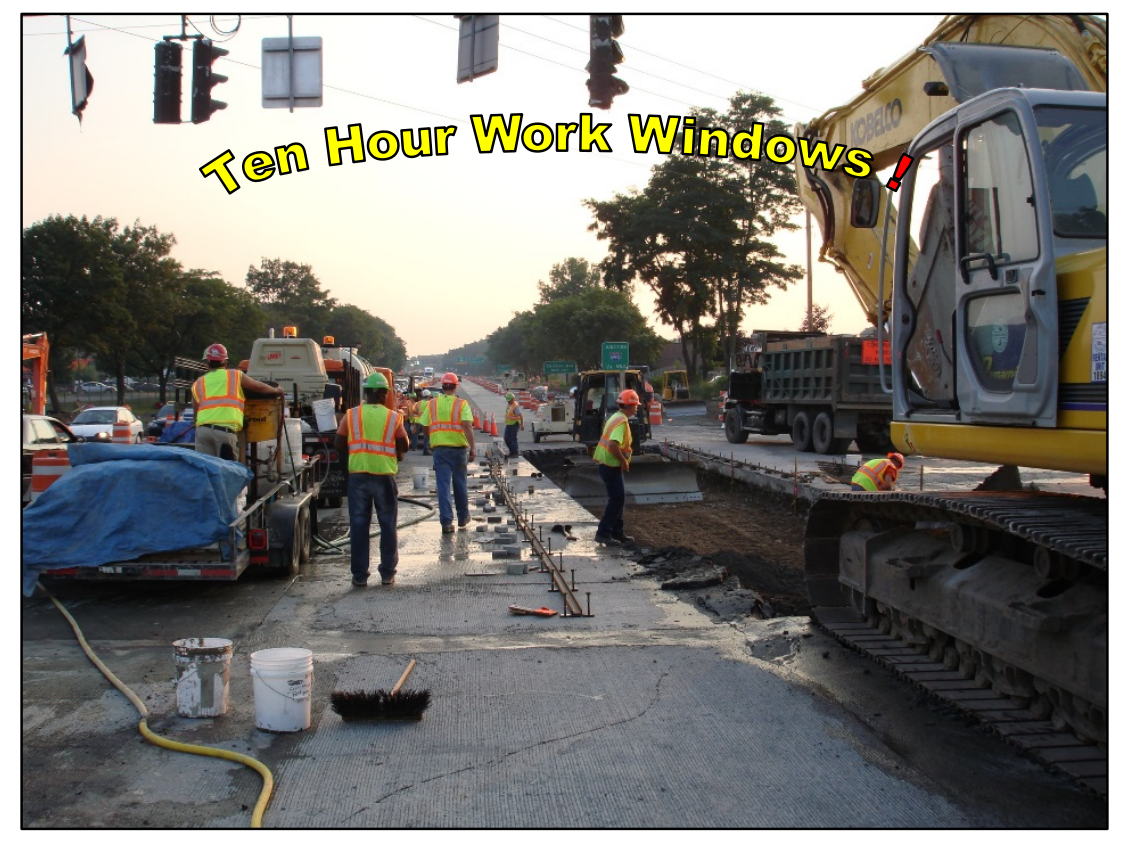

Undercut 1' - Backfill with Dense Aggregate Base

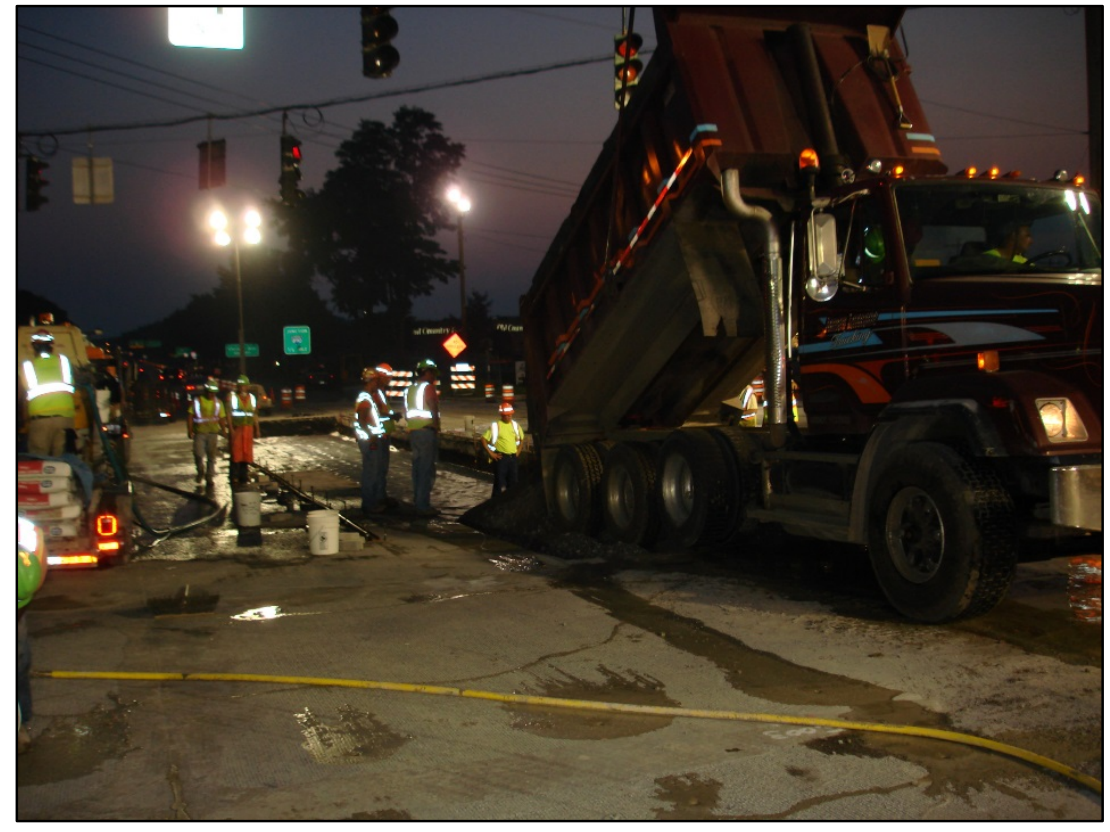

Geofabric Separation Layer

The Fort Miller Co., Inc. 


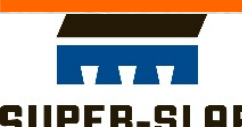

\section{Grading Bedding Material and Placing Slabs}

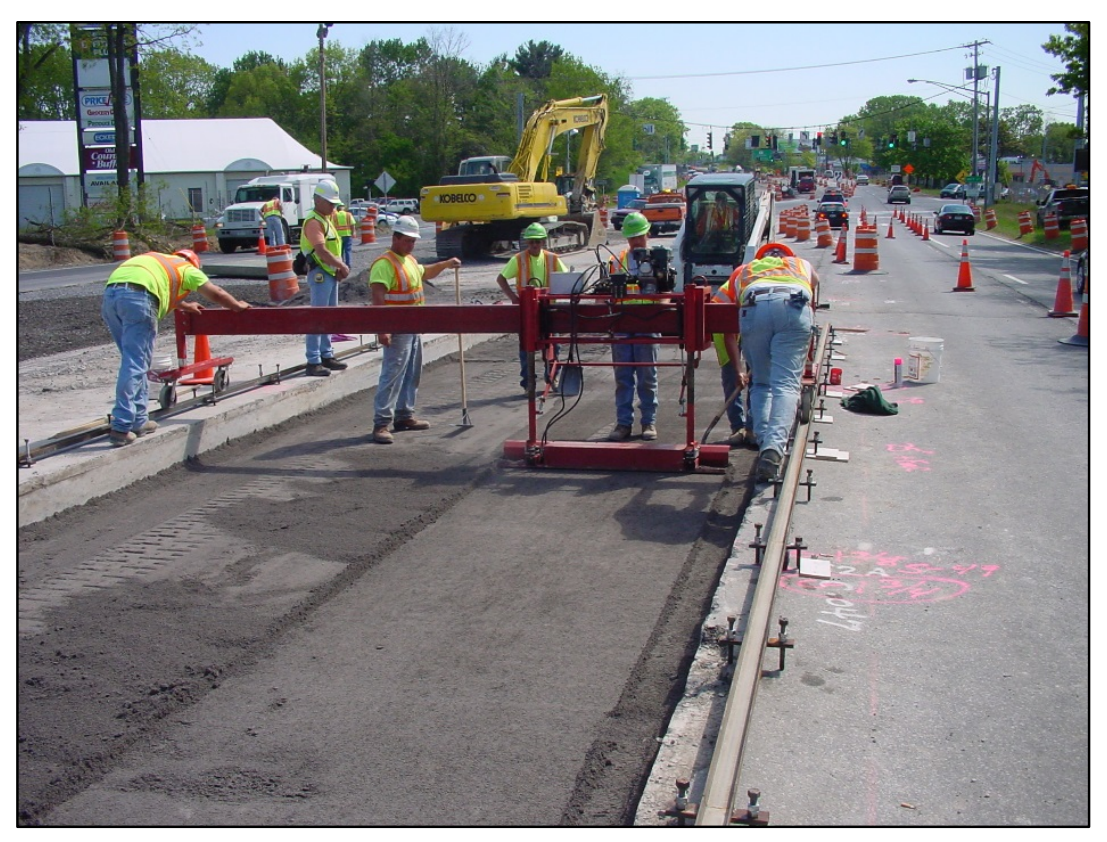

Grade Controlled by Rails

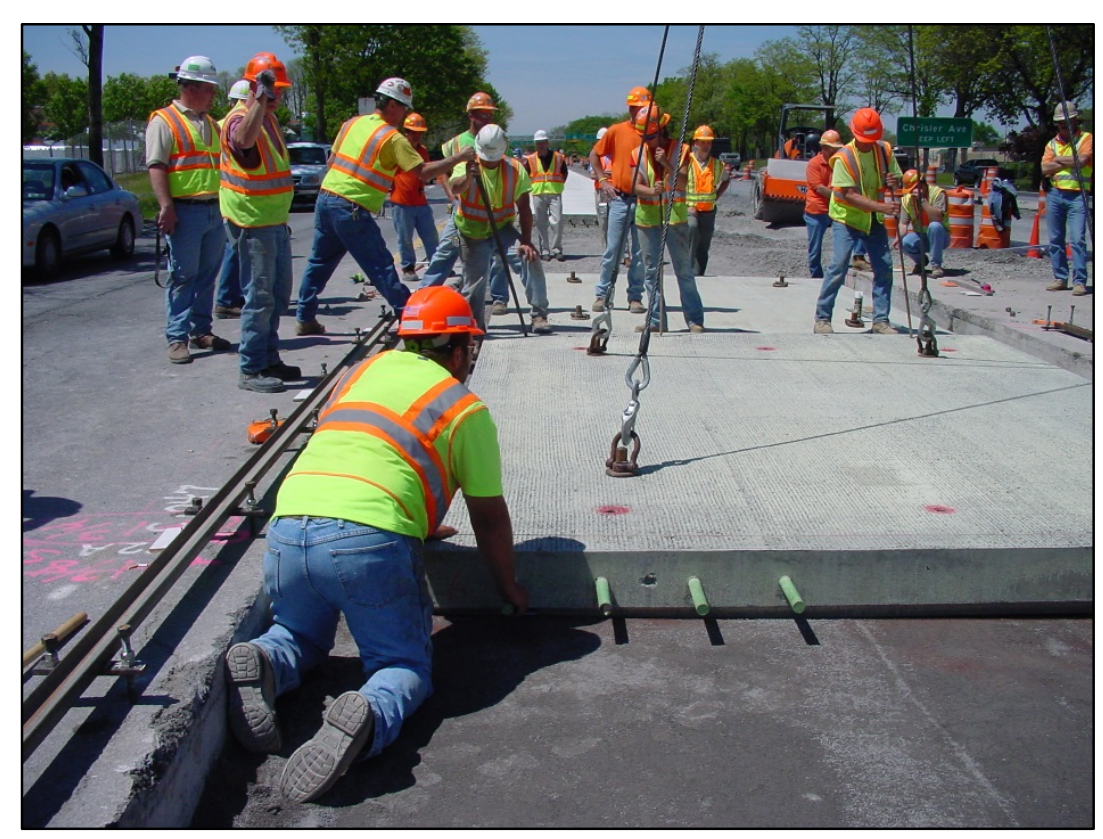

Each Slab Set To a Mark

The Fort Miller Co., Inc. 


\section{Maintenance of Traffic}

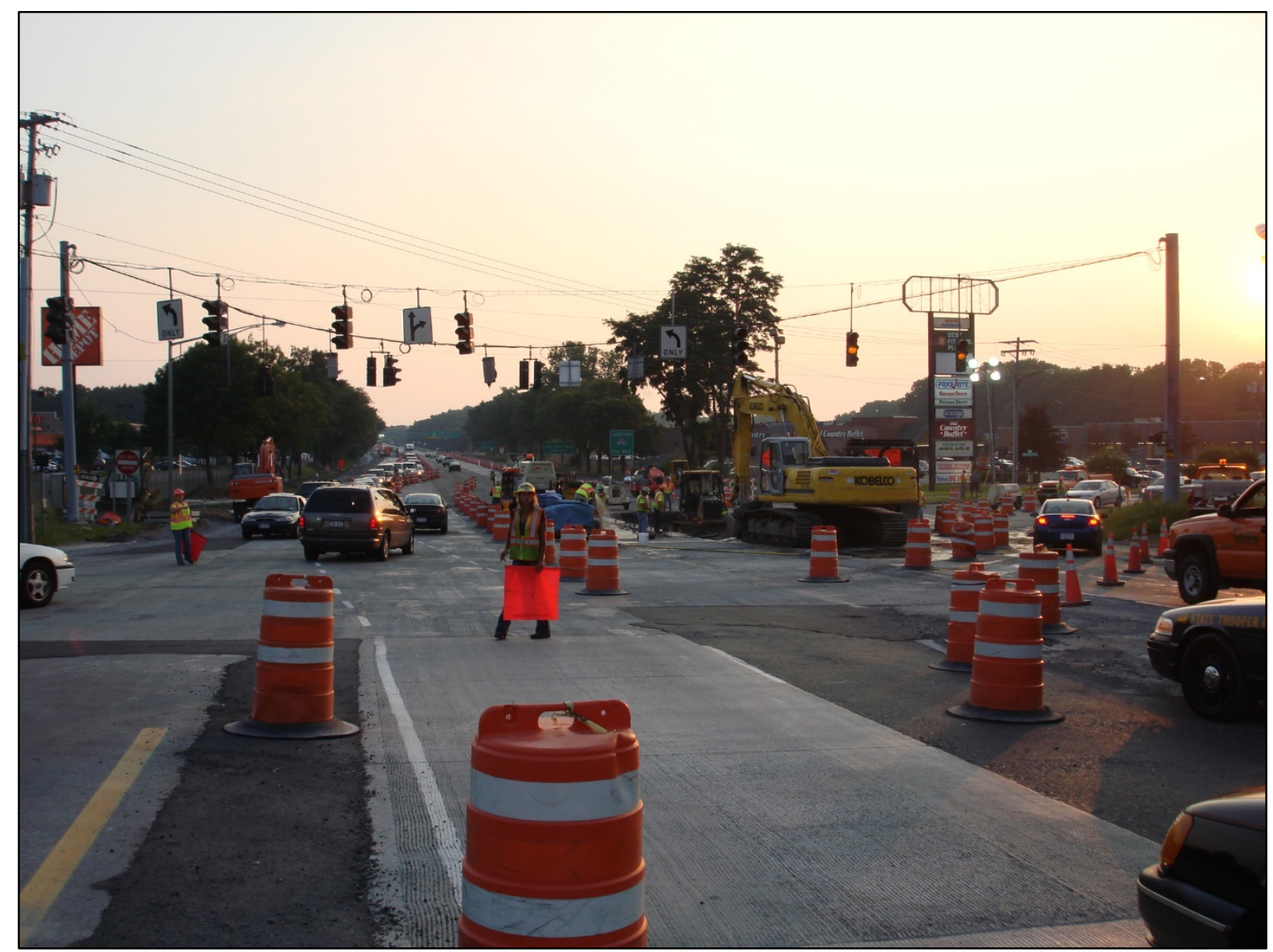

Undercuts

Traffic Never Stopped

Replaced in 17 Nights

The Fort Miller Co., Inc. 


\section{Finished Street View}

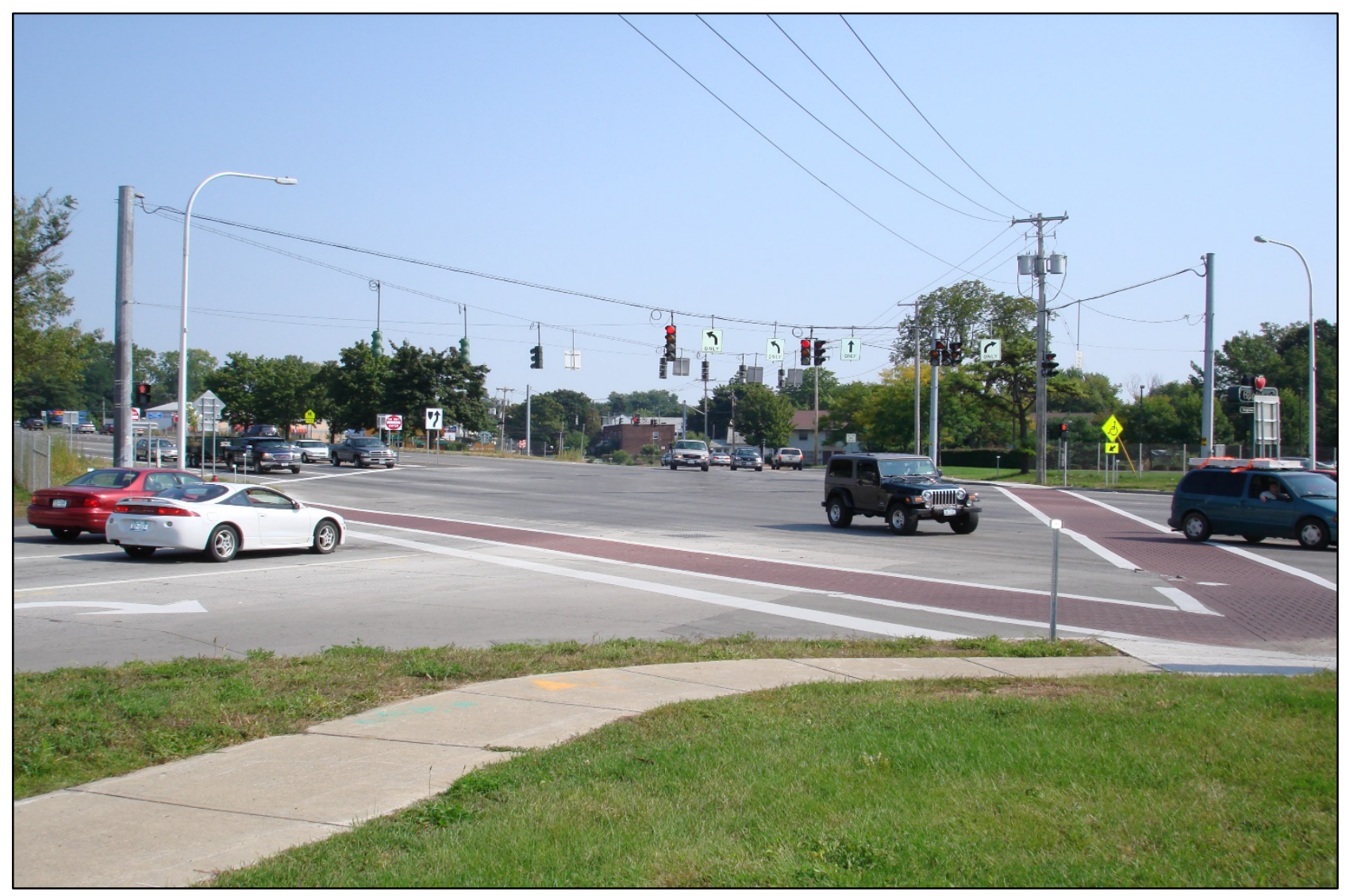

Completed in 17 Nights 158 Slabs - 28,500 SF

The Fort Miller Co., Inc. 


\section{Rockaway Blvd., Jamaica - Queens, NY 2009 - 2010 Installation}

- 2390 slabs

$\cdot 29,000 \mathrm{SY}$

-Replaced fulldepth asphalt

-300 lane-ft in 8hour shift

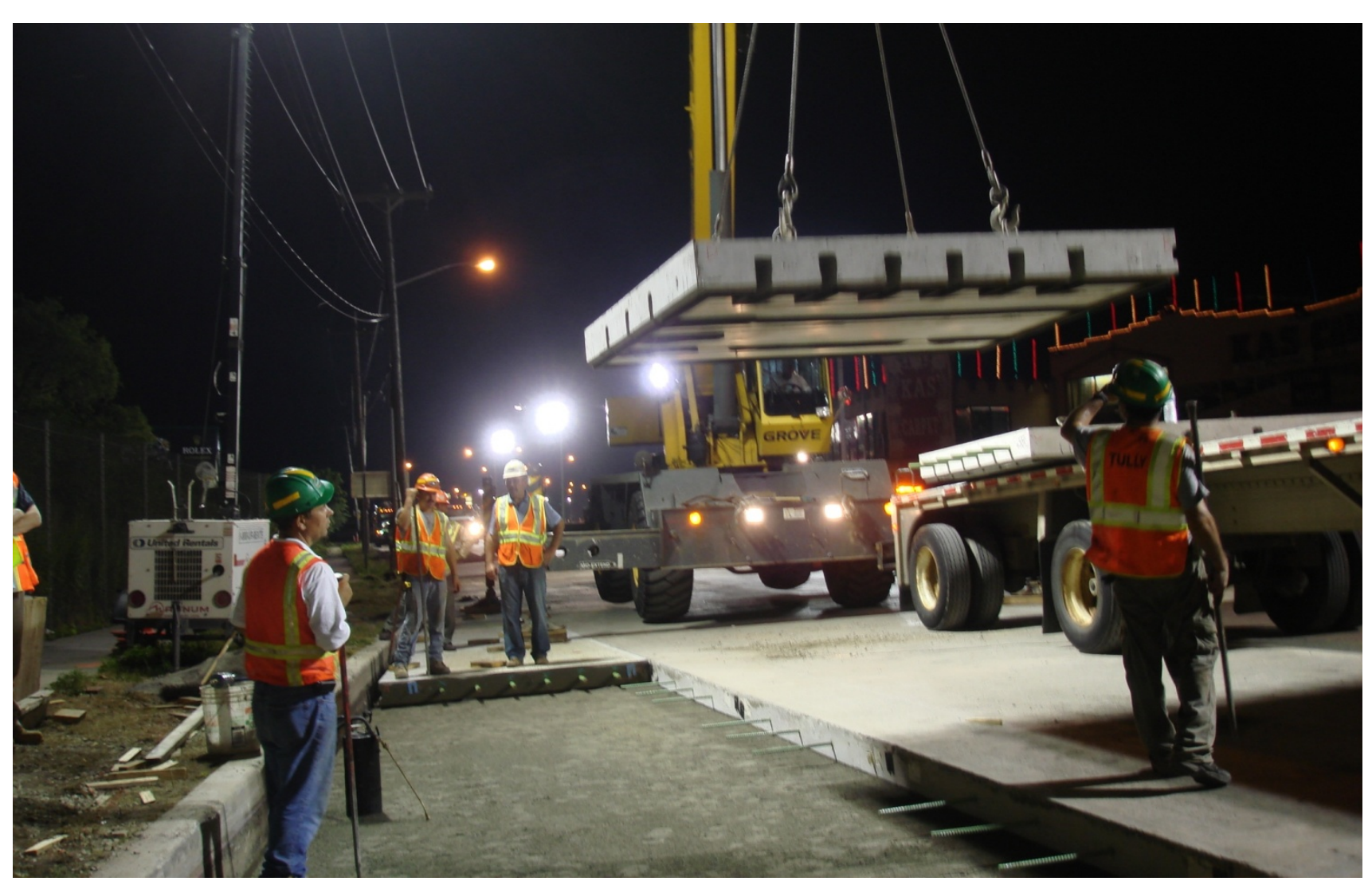

The Fort Miller Co., Inc. 


\section{Intersection Approaches}

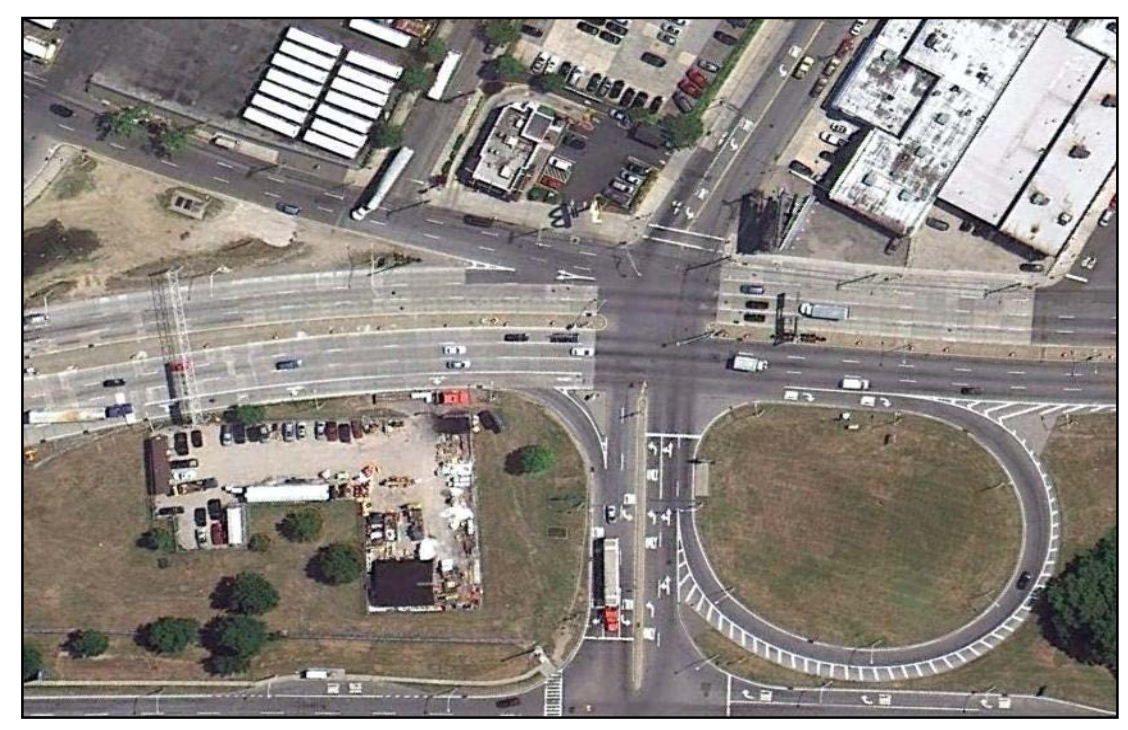

Farmers Blvd.

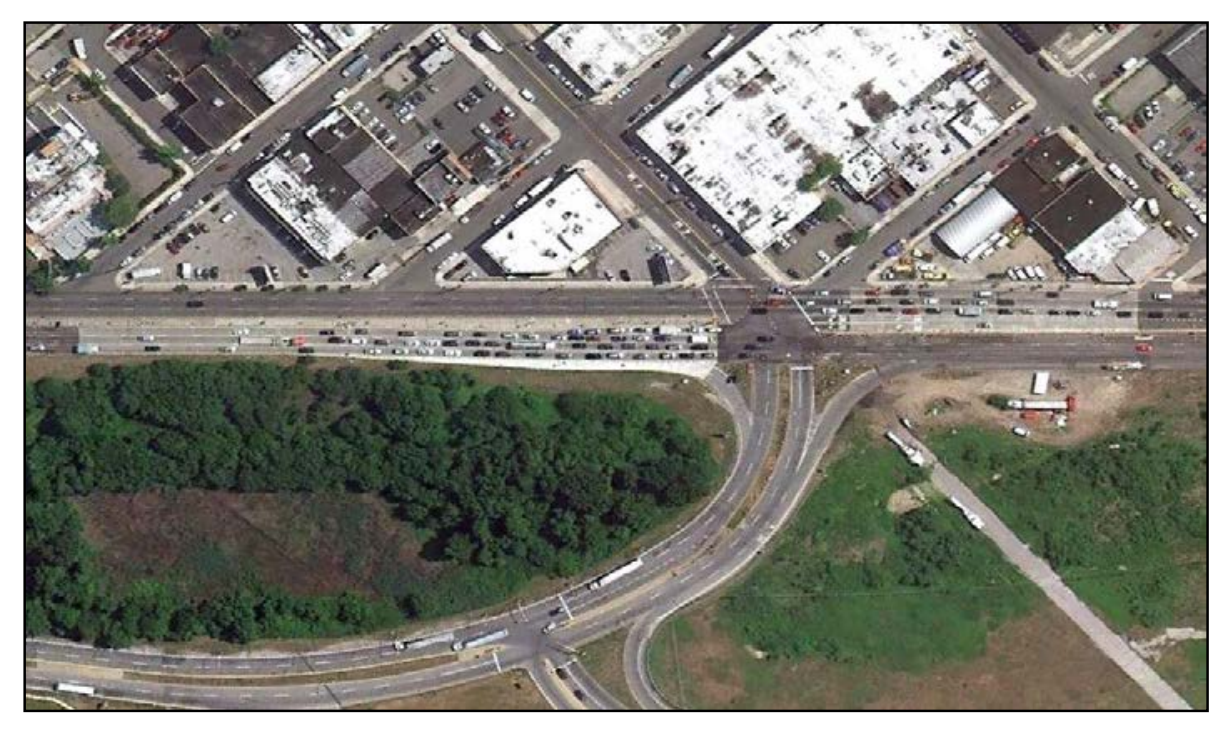

Guy R. Brewer Blvd.

\section{Gannett Fleming}

Excellence Delivered As Promised

The Fort Miller Co., Inc. 


\section{rre}

SUPER-SLAB

\section{Brookville Blvd. to Eastern Project Limit}

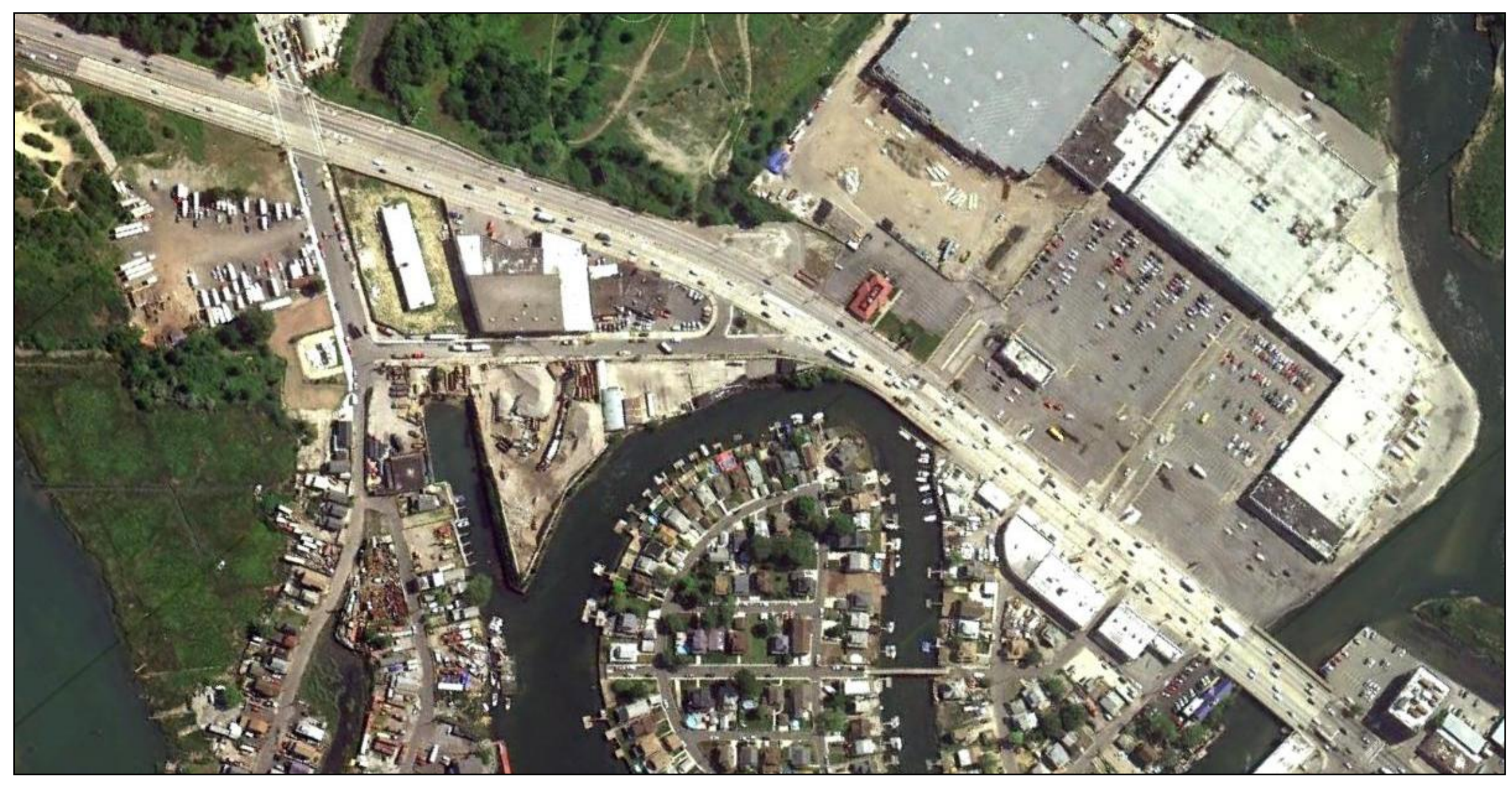

$1 / 2$ Mile of Rockaway Blvd. - Full Depth Asphalt Replaced with Precast Concrete

Gannett Fleming

Excellence Delivered As Promised

The Fort Miller Co., Inc. 


\section{Night Construction}

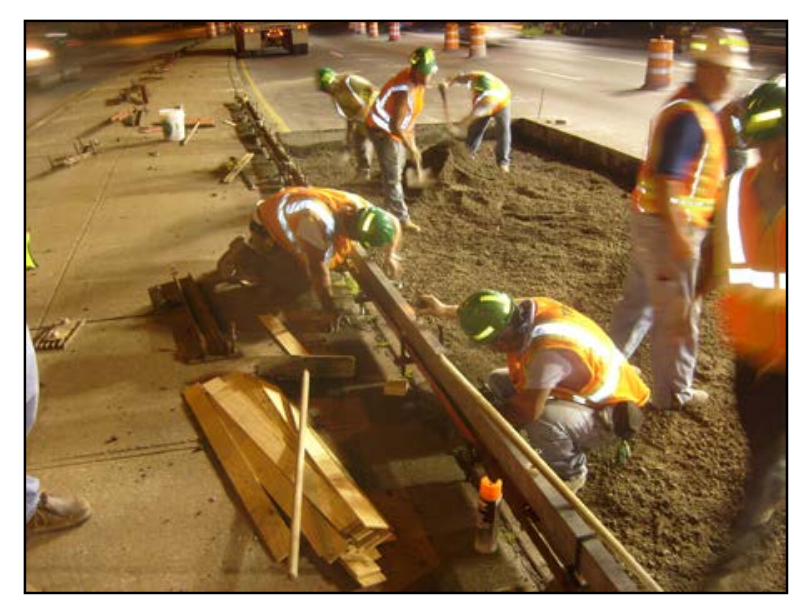

Setting Grading Rails
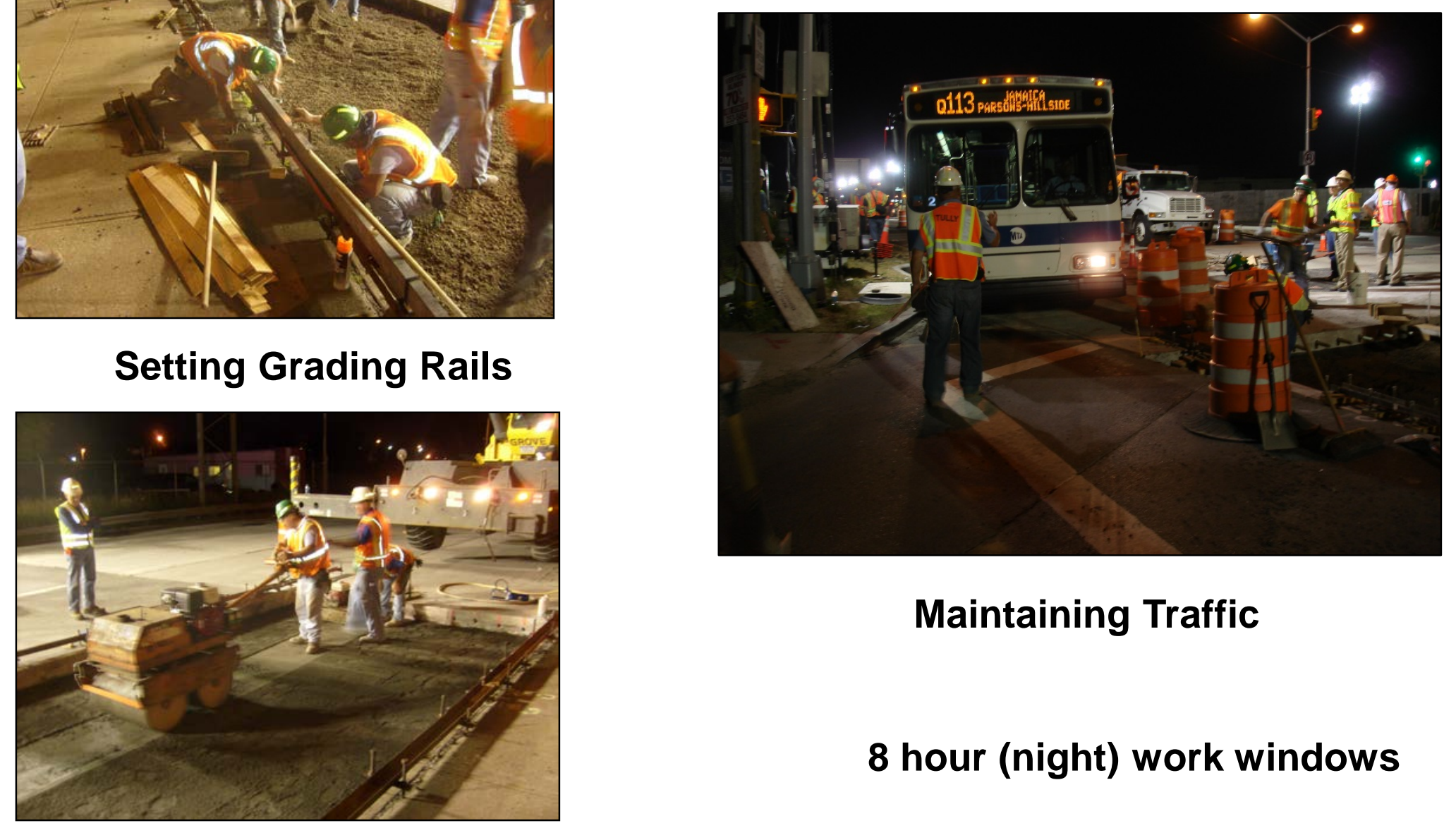

Maintaining Traffic

8 hour (night) work windows

DGB Compaction

The Fort Miller Co., Inc. 


\section{Rockaway Blvd. - Two Years Later (2011)}

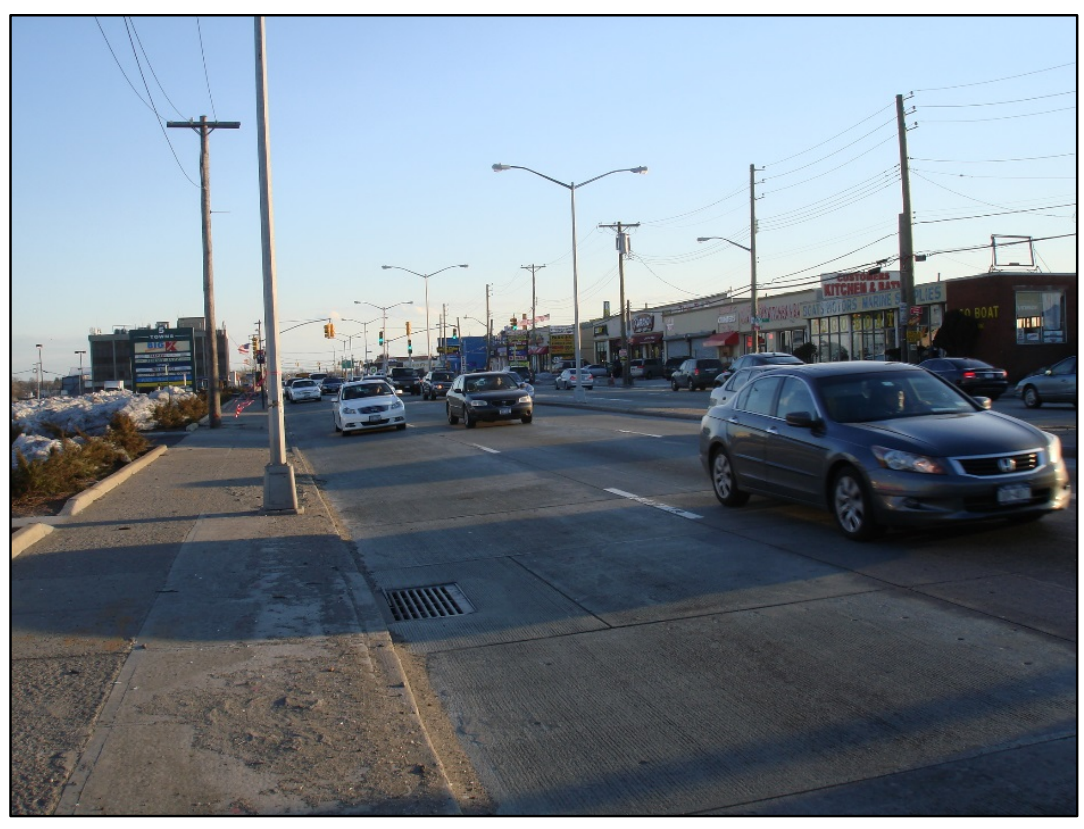

One-Half Mile Stretch - Two Lanes in Each Direction

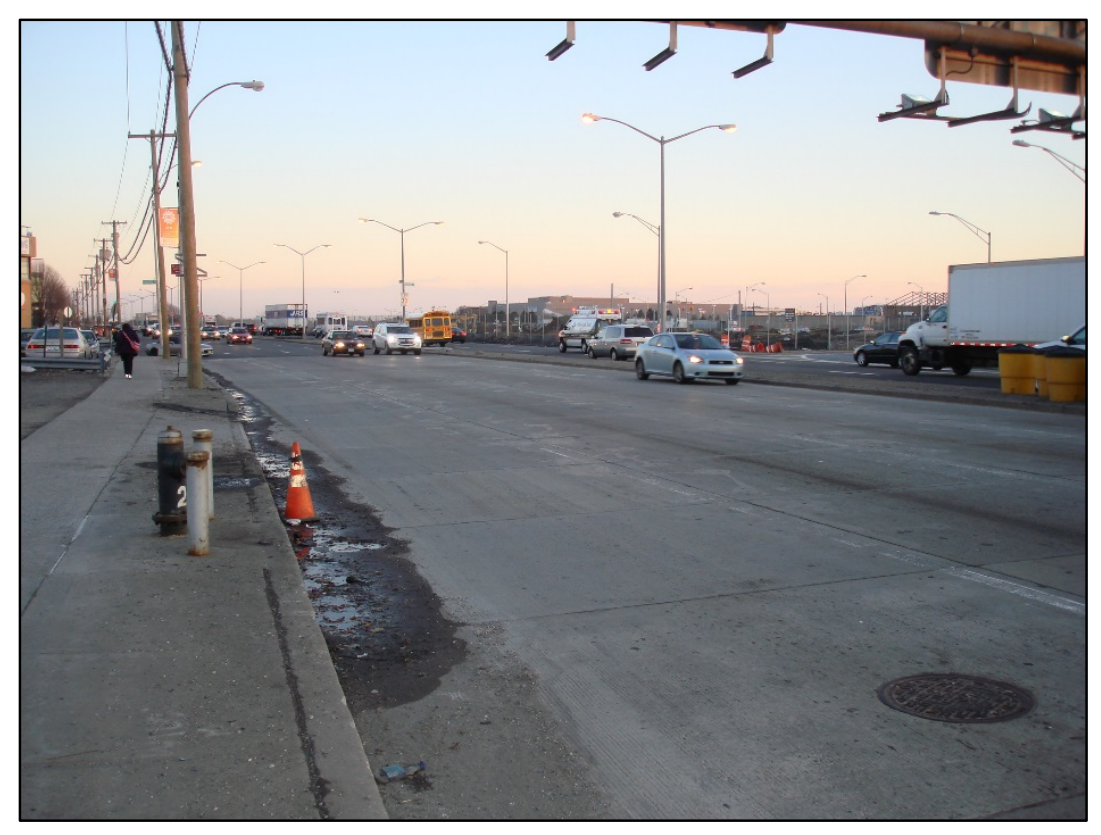

Guy R. Brewer Intersection Approach

The Fort Miller Co., Inc. 


\section{GDOT Reconstruction Broad Street Winder, GA - 2013}

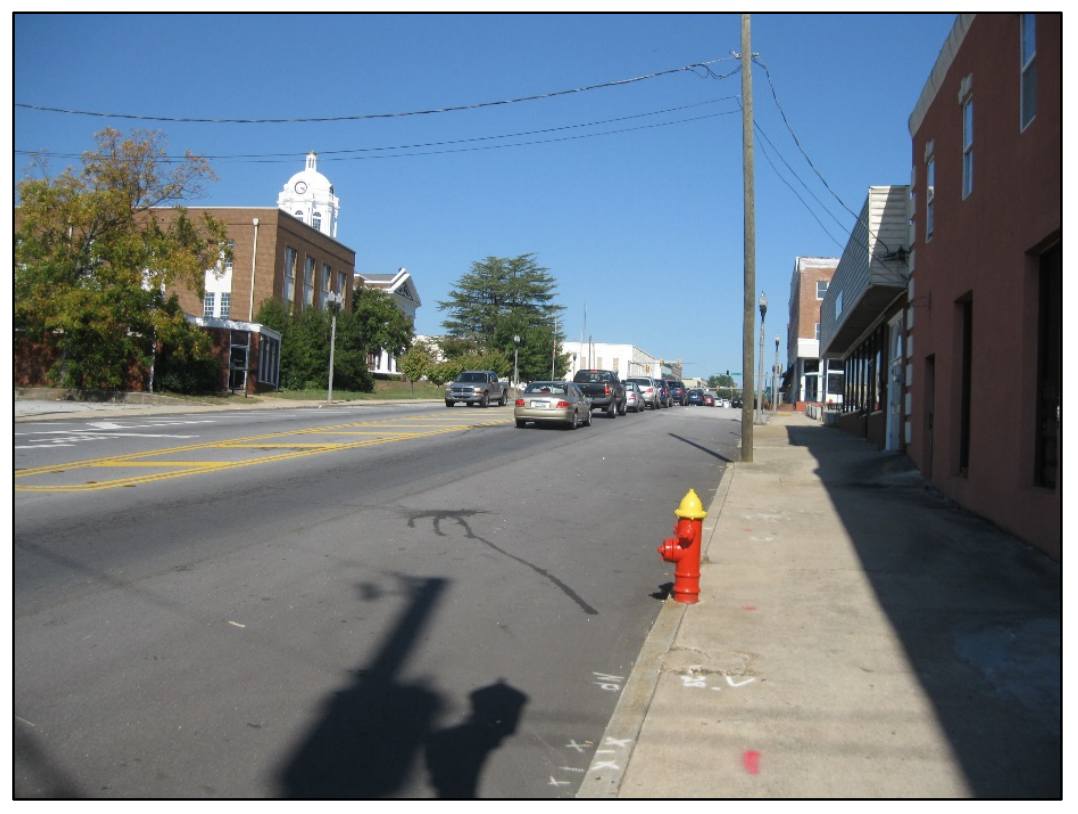

Hills and Curves

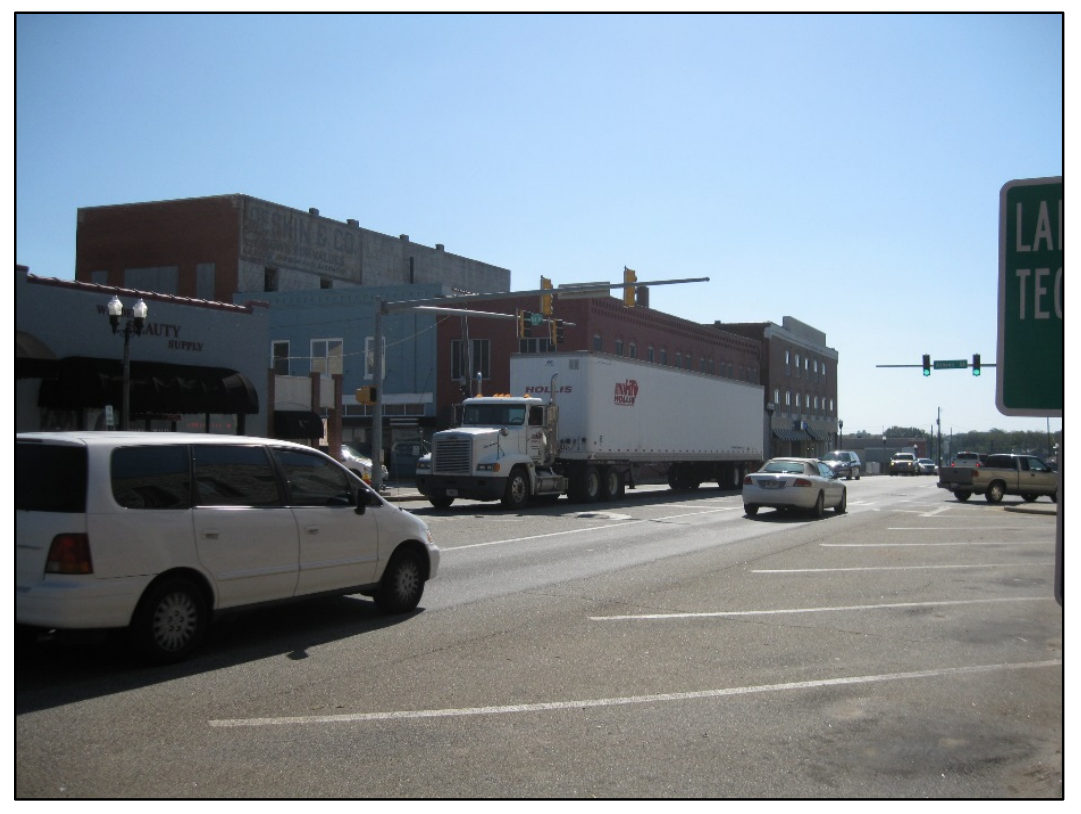

Heavy Truck Traffic

The Fort Miller Co., Inc. 


\section{Pavement Removal \& Subbase Preparation}

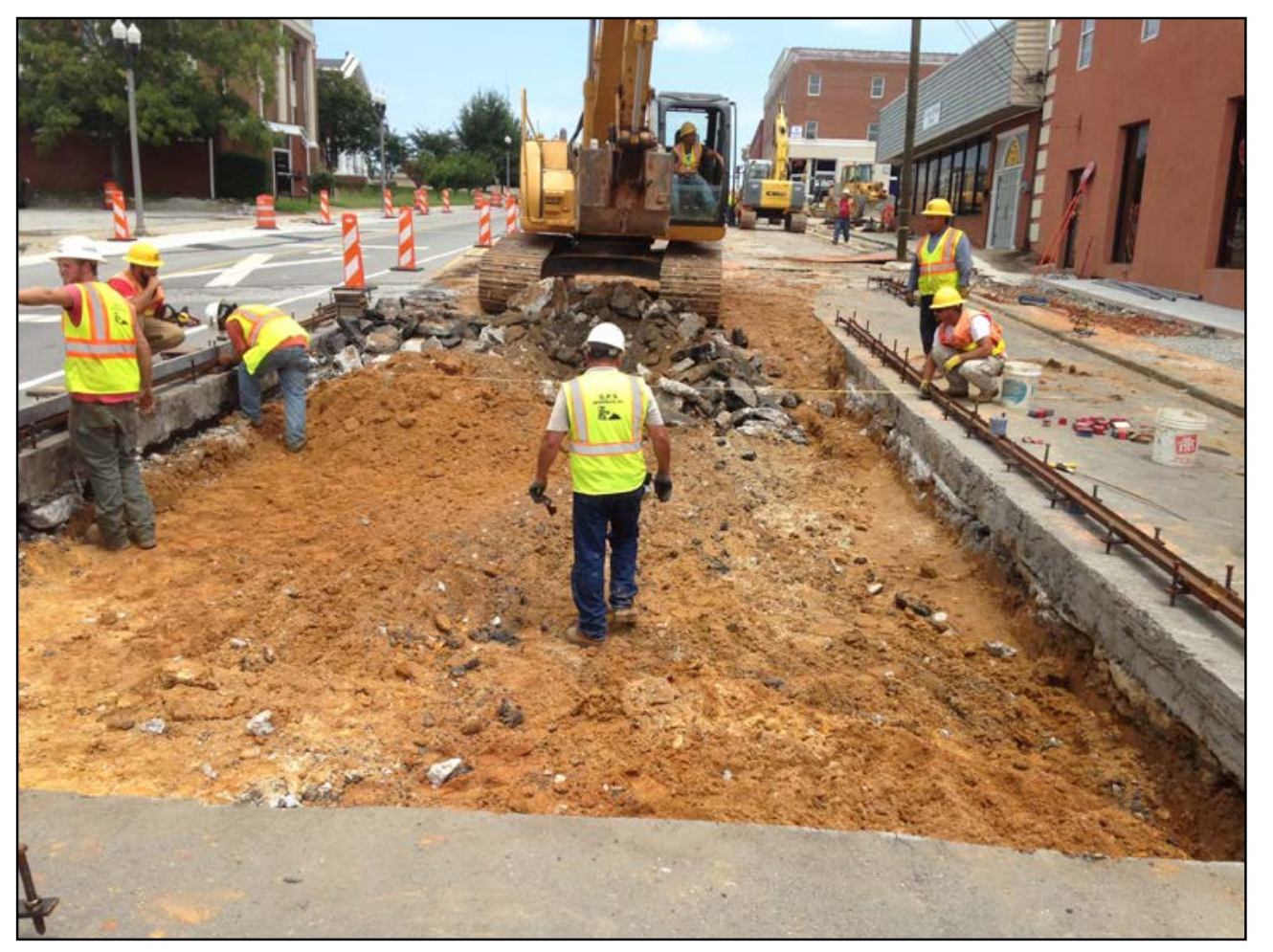

Removing Multiple Layers of Old Pavement

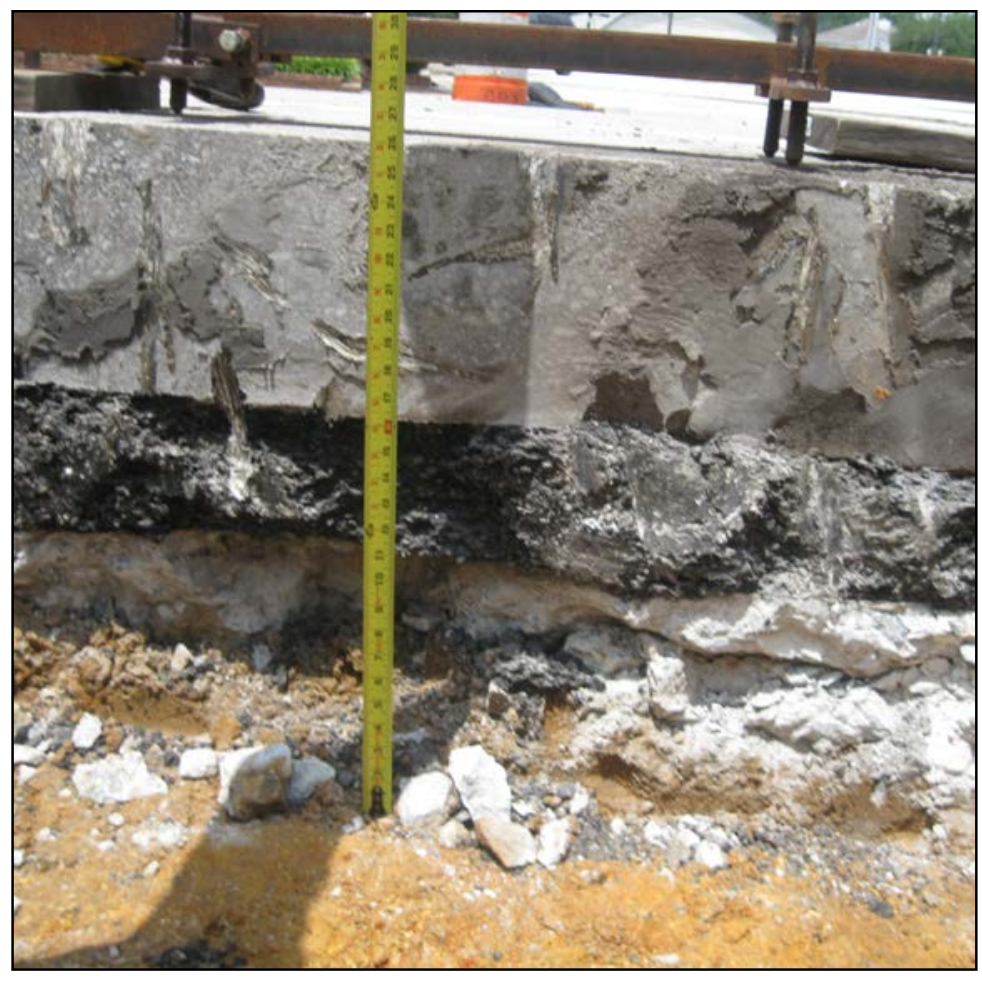

26 Inches

The Fort Miller Co., Inc. 


\section{Installing Aggregate Subbase}

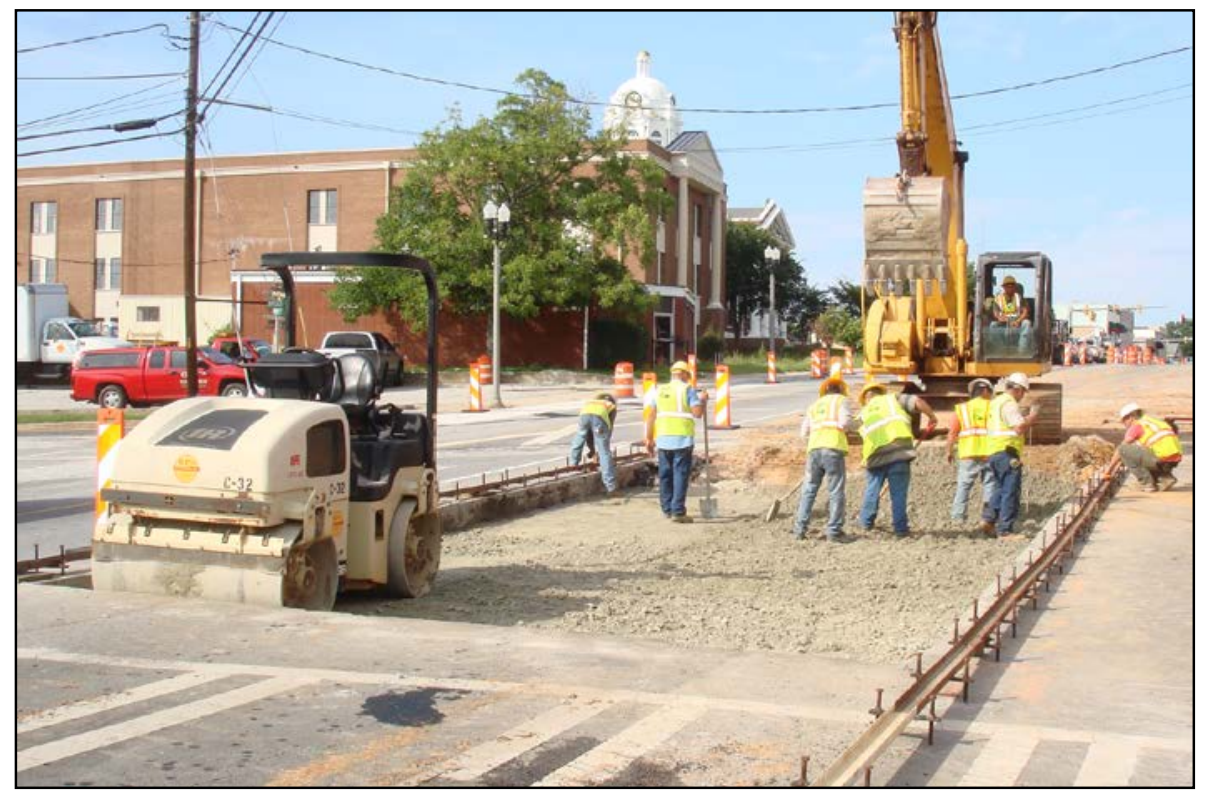

Grading and Compacting

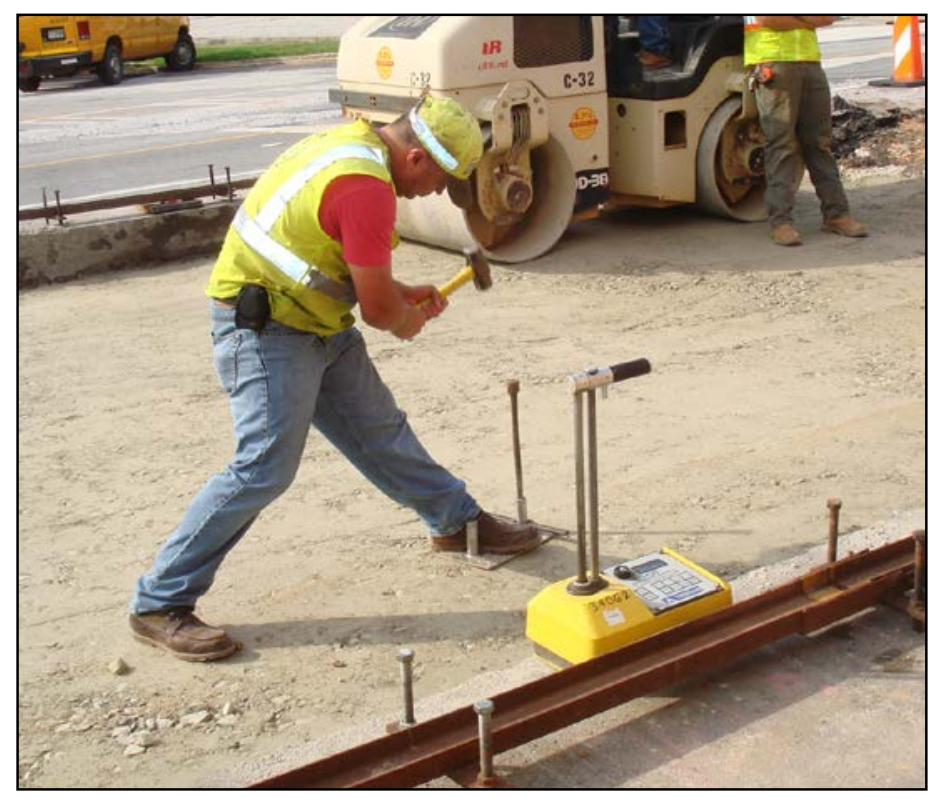

Compaction Test

\section{New Aggregate Subbase}

The Fort Miller Co., Inc. 


\section{Installing \& Super-Grading Bedding Material}

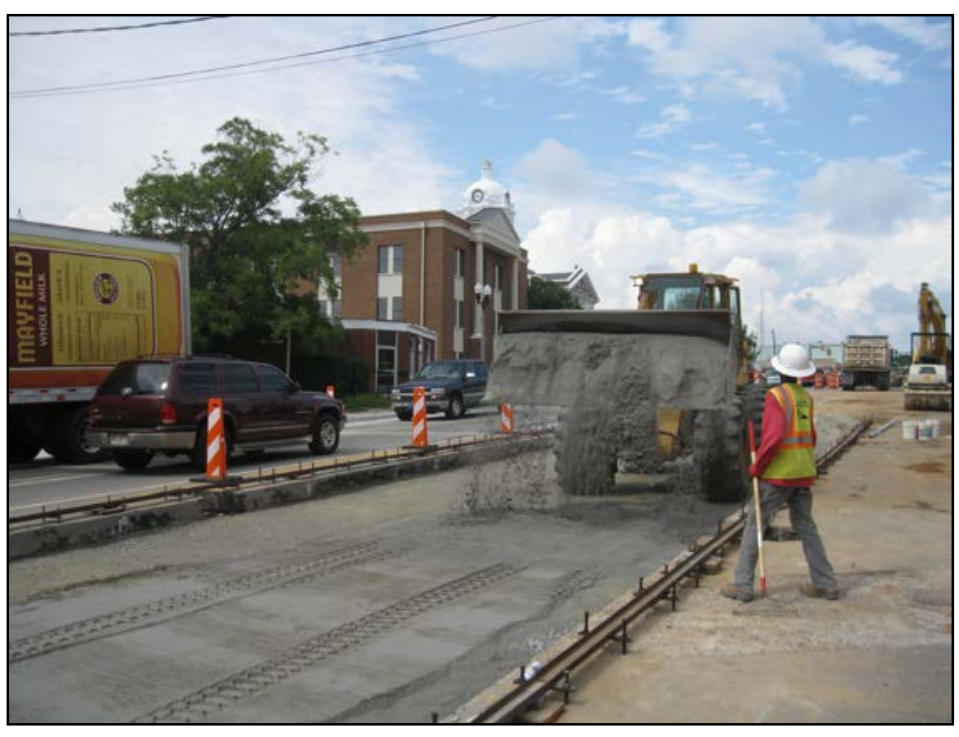

Installing Bedding

Material Over

Aggregate Base

(1" max. thickness)

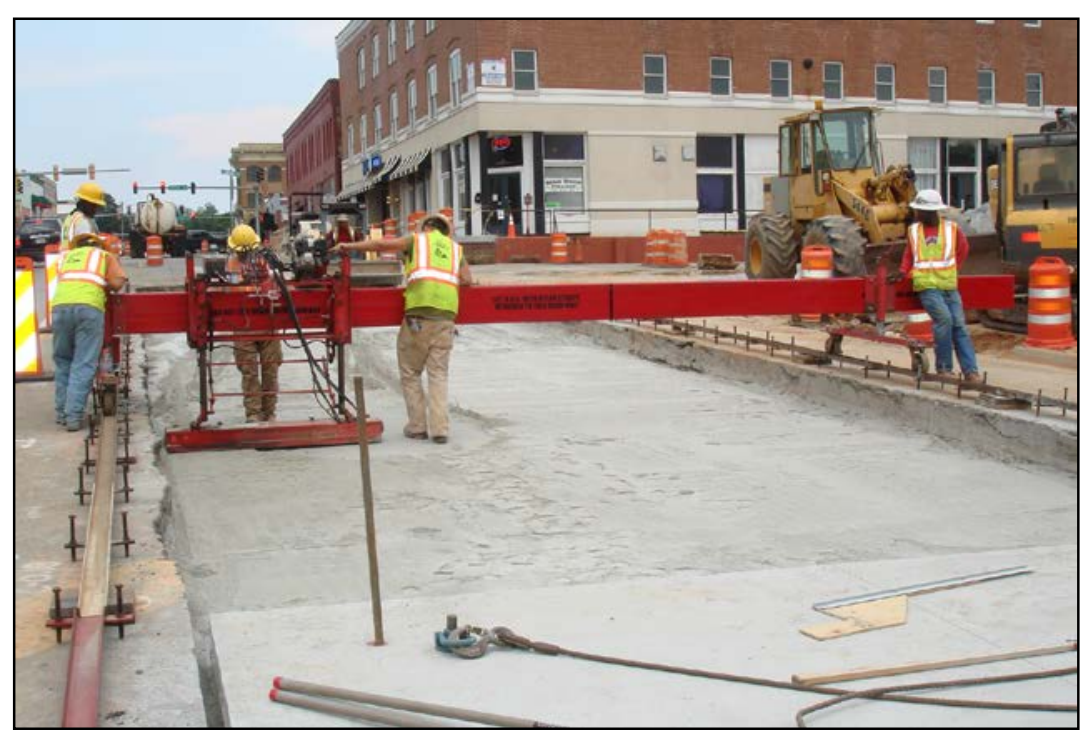

Super-Grading With Hand Operated Grader (H.O.G.) to +/-1/8" Accuracy

Key Operation!

The Fort Miller Co., Inc. 


\section{Installing Slabs - At Night}

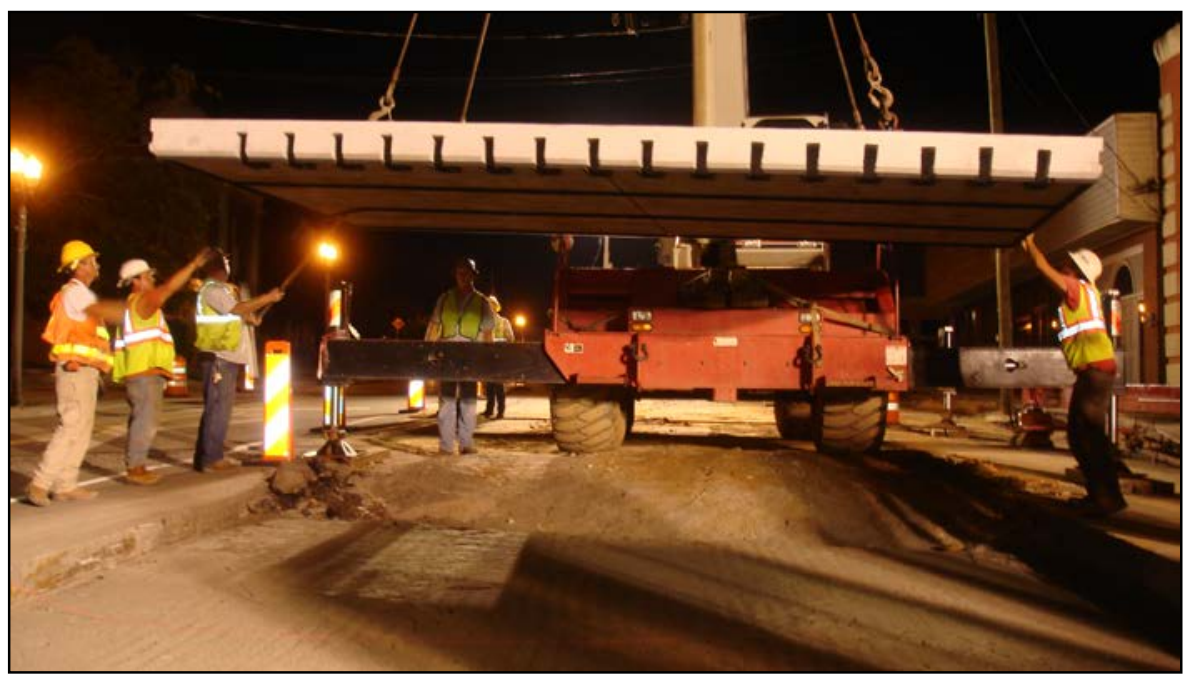

Placing First Slab - Notice Gaskets on Bottom of Slab

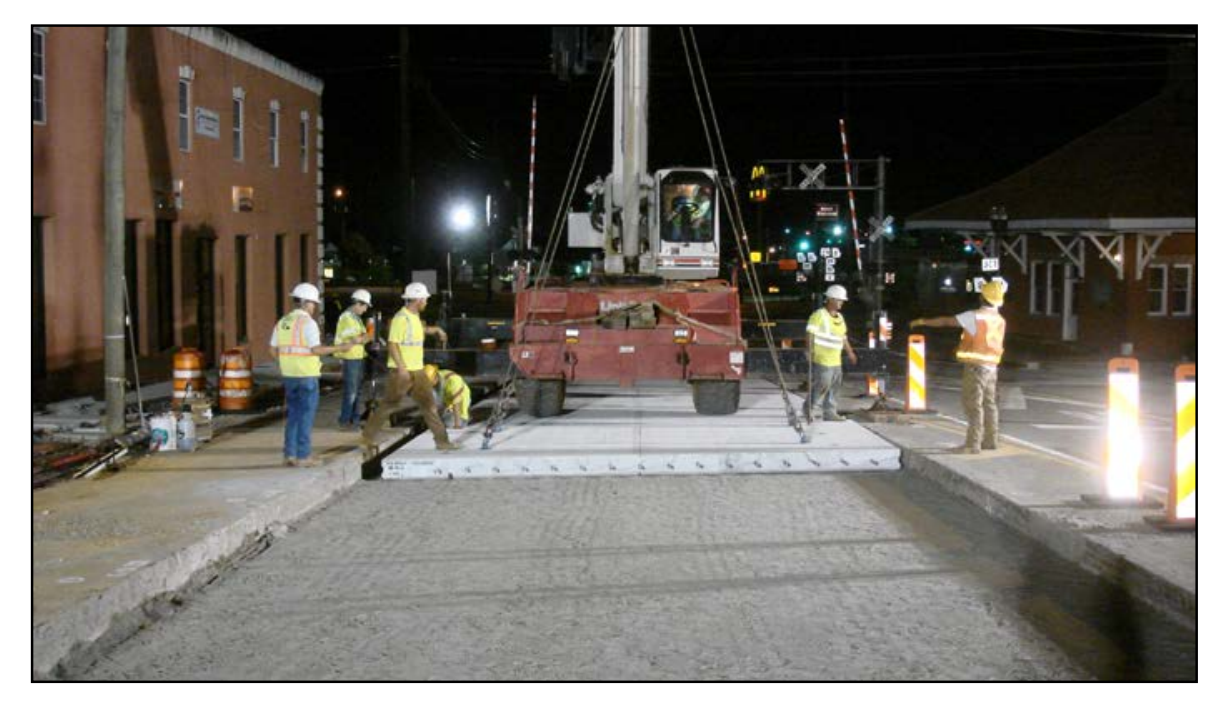

Crane Occupies Previously Placed Slabs

(18' wide $\times 11^{\prime}-3$ " long $\times$ 8-1/2" thick)

The Fort Miller Co., Inc. 


\section{GDOT Winder - Unique Challenges}
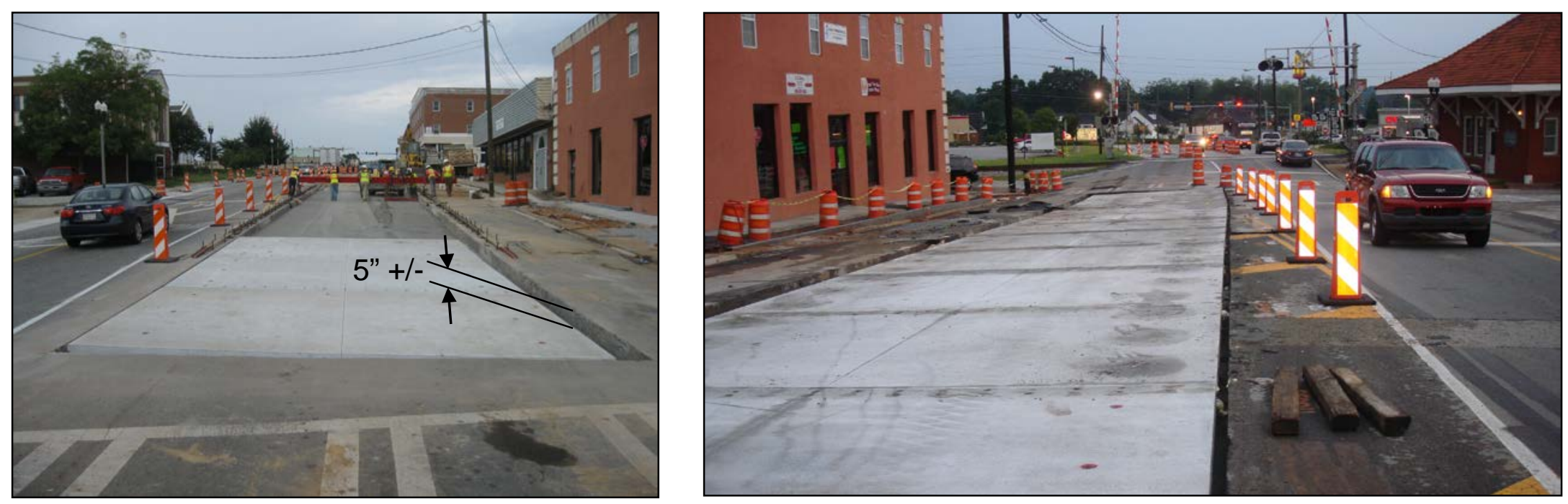

Change In Grade - 5" lower on Right

Cross Slope Change \& Horizontal Curve

The Fort Miller Co., Inc. 


\section{GDOT Winder, GA \\ Georgia Engineer - Feb-Mar 2014}

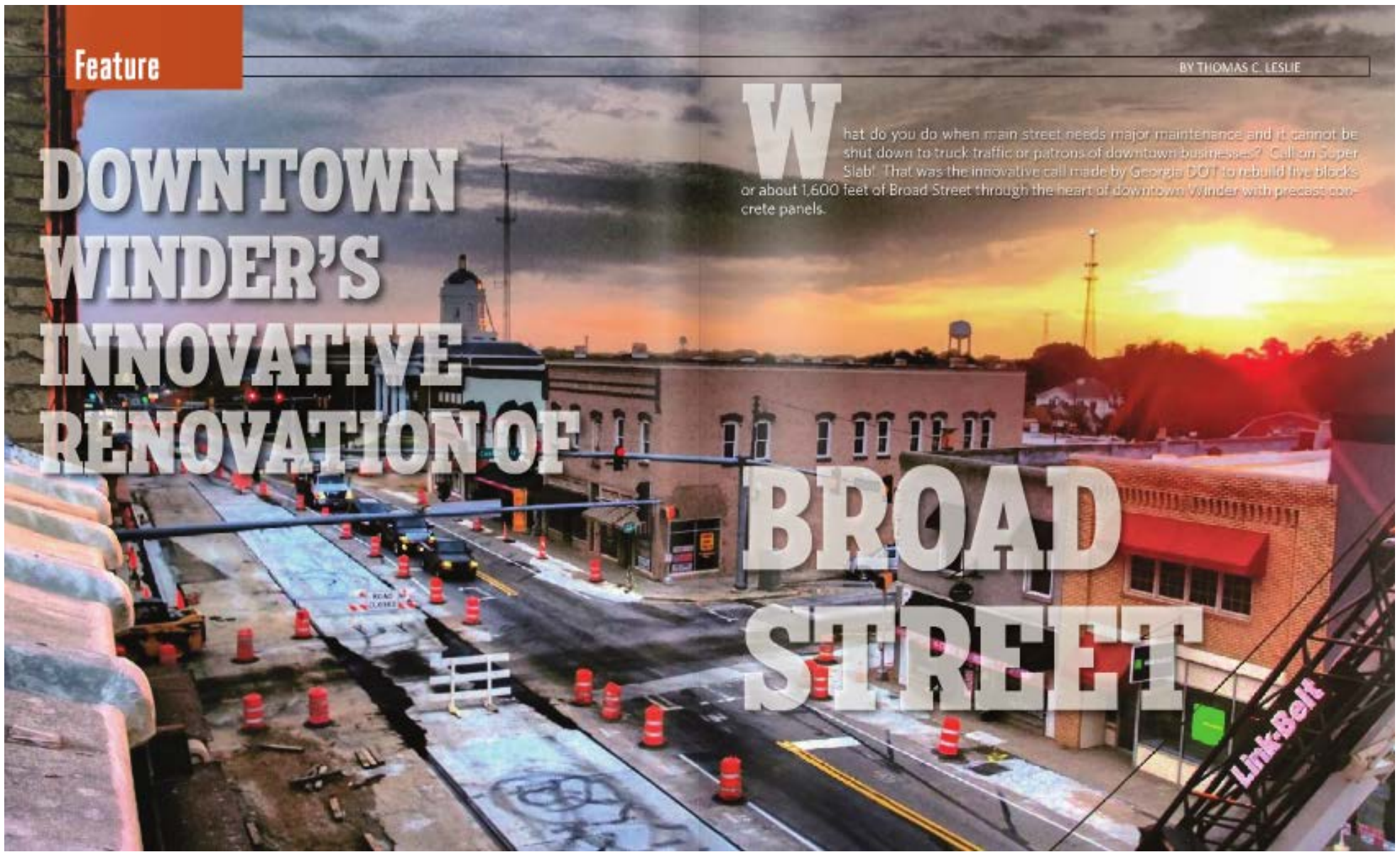

The Fort Miller Co., Inc. 


\section{Reconstruction Metropolitan Ave. (US-73) Leavenworth, Kansas}

- 294 slabs

- $4,555 \mathrm{SY}$

- 8-hour night work windows

- Part of larger cast in place project

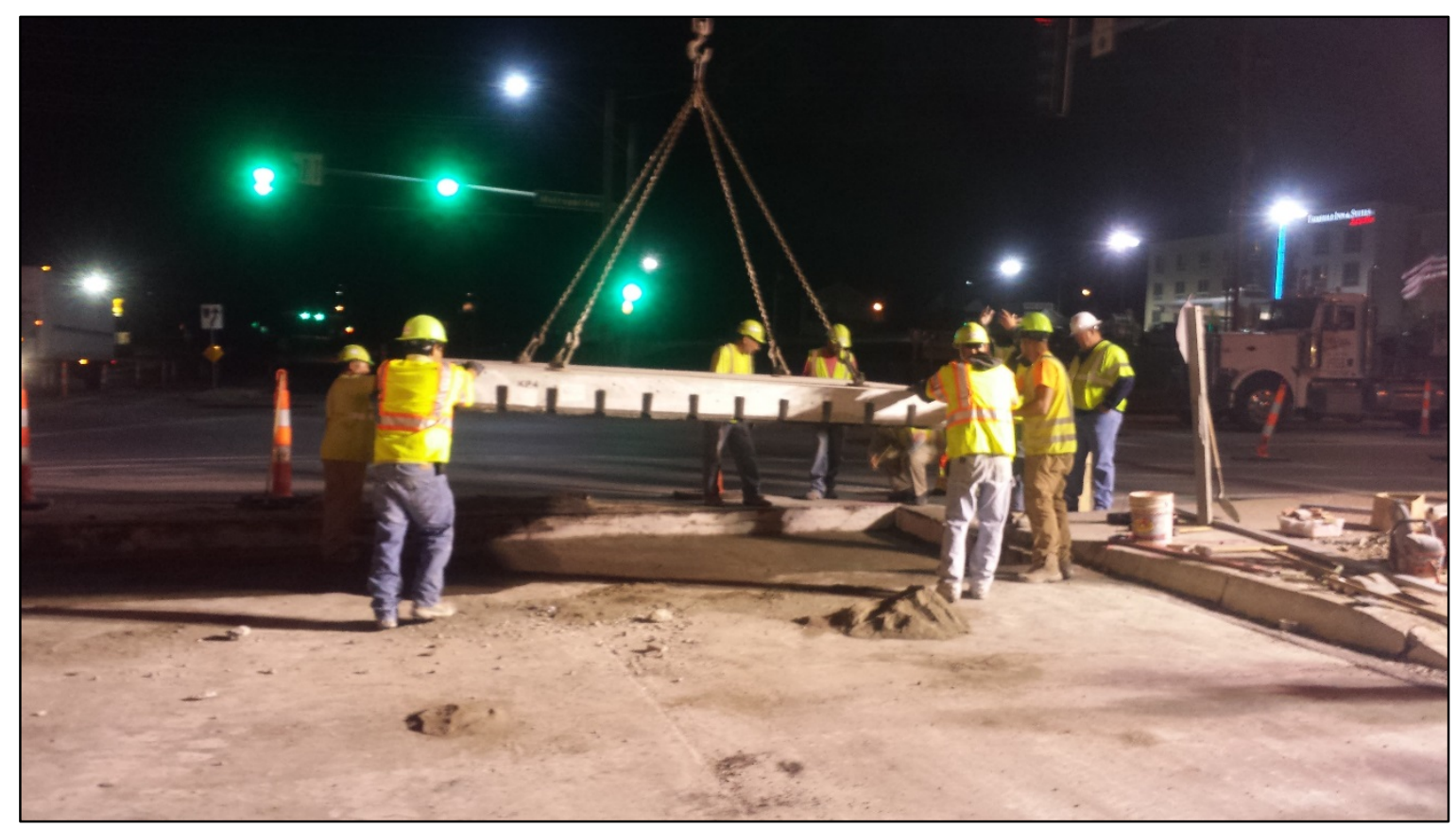

Two Intersections and One Bridge Approach

The Fort Miller Co., Inc. 


\section{Re-Construction Metropolitan Ave. (US-73) Leavenworth, Kansas}

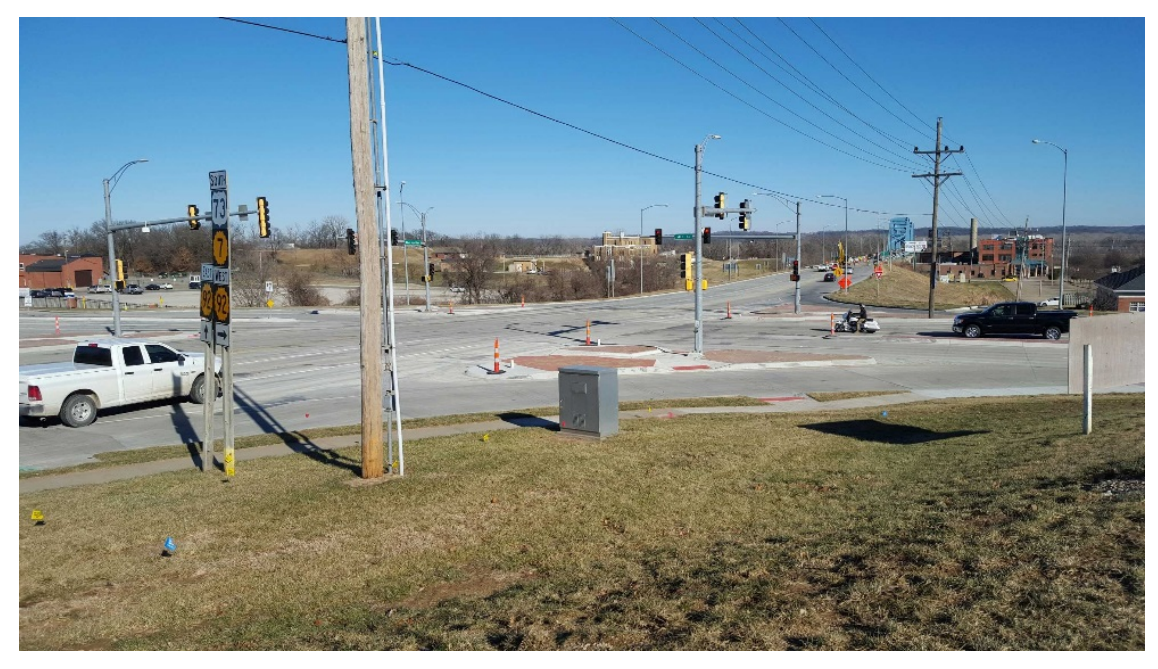

$4^{\text {th }}$ Street Intersection

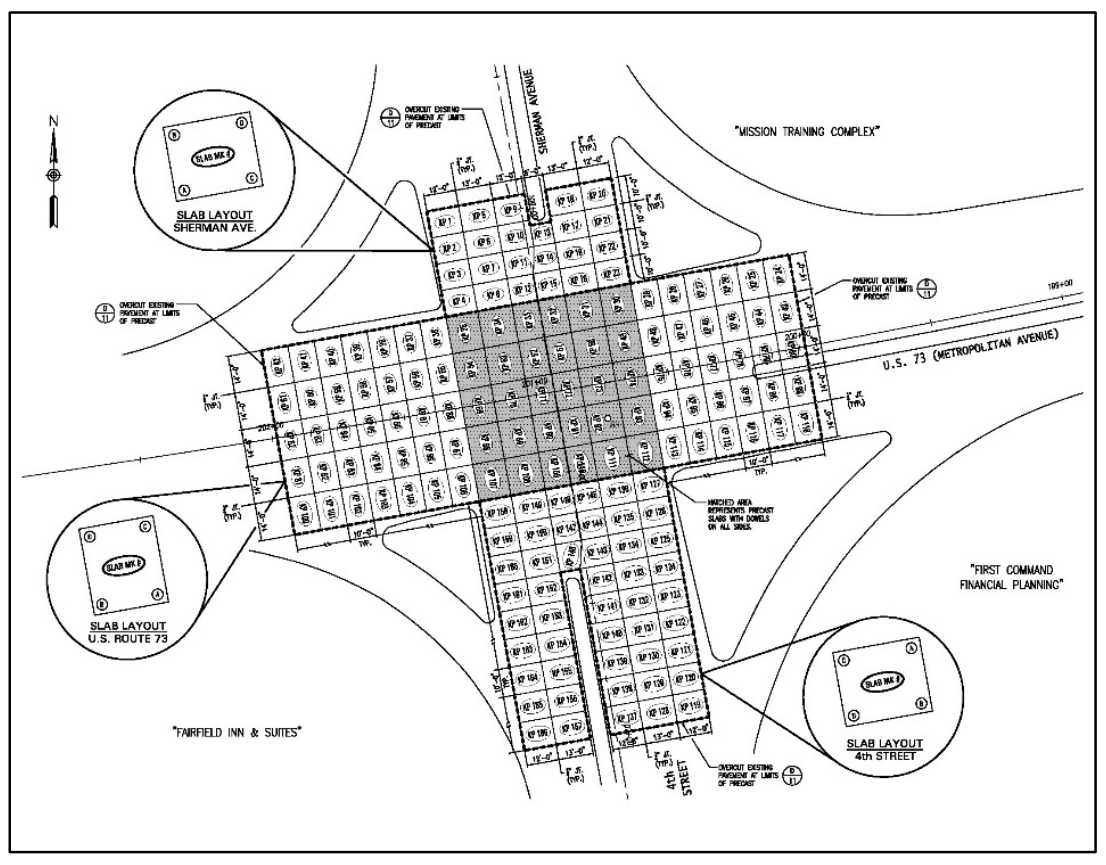

Slab Layout Drawing

The Fort Miller Co., Inc. 


\section{Reconstruction Metropolitan Ave. (US-73) Leavenworth, Kansas}

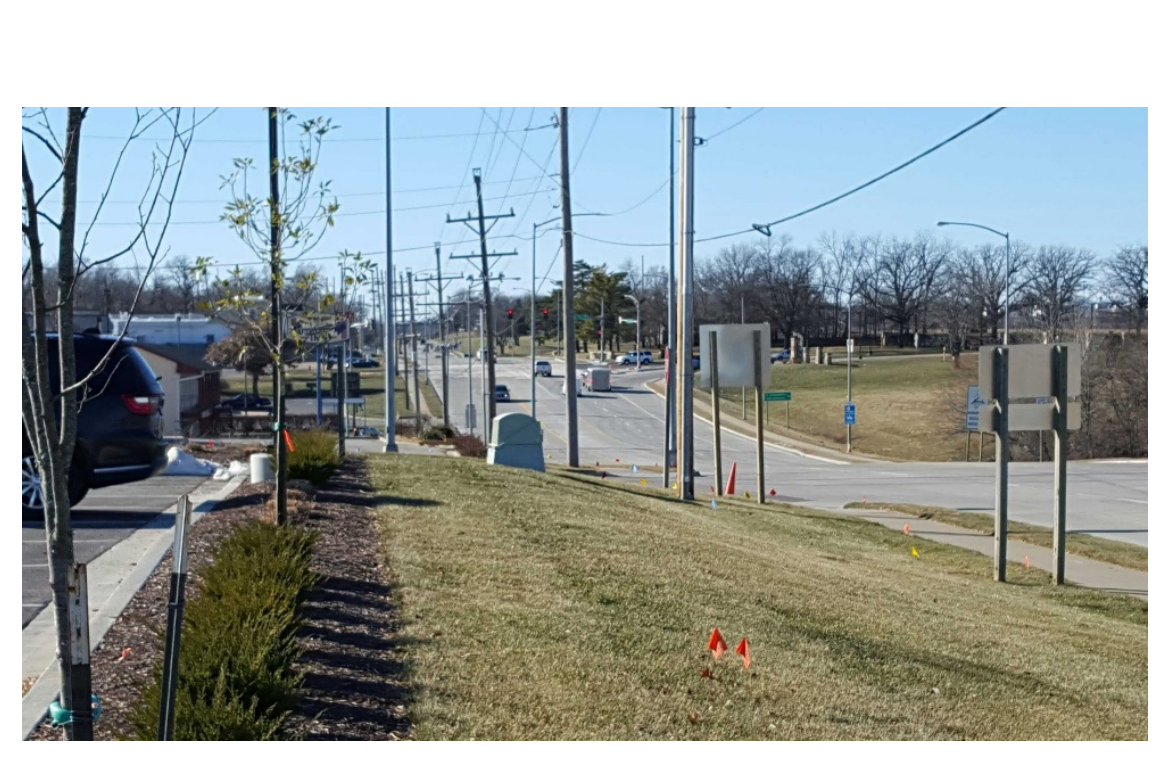

$7^{\text {th }}$ Street Intersection

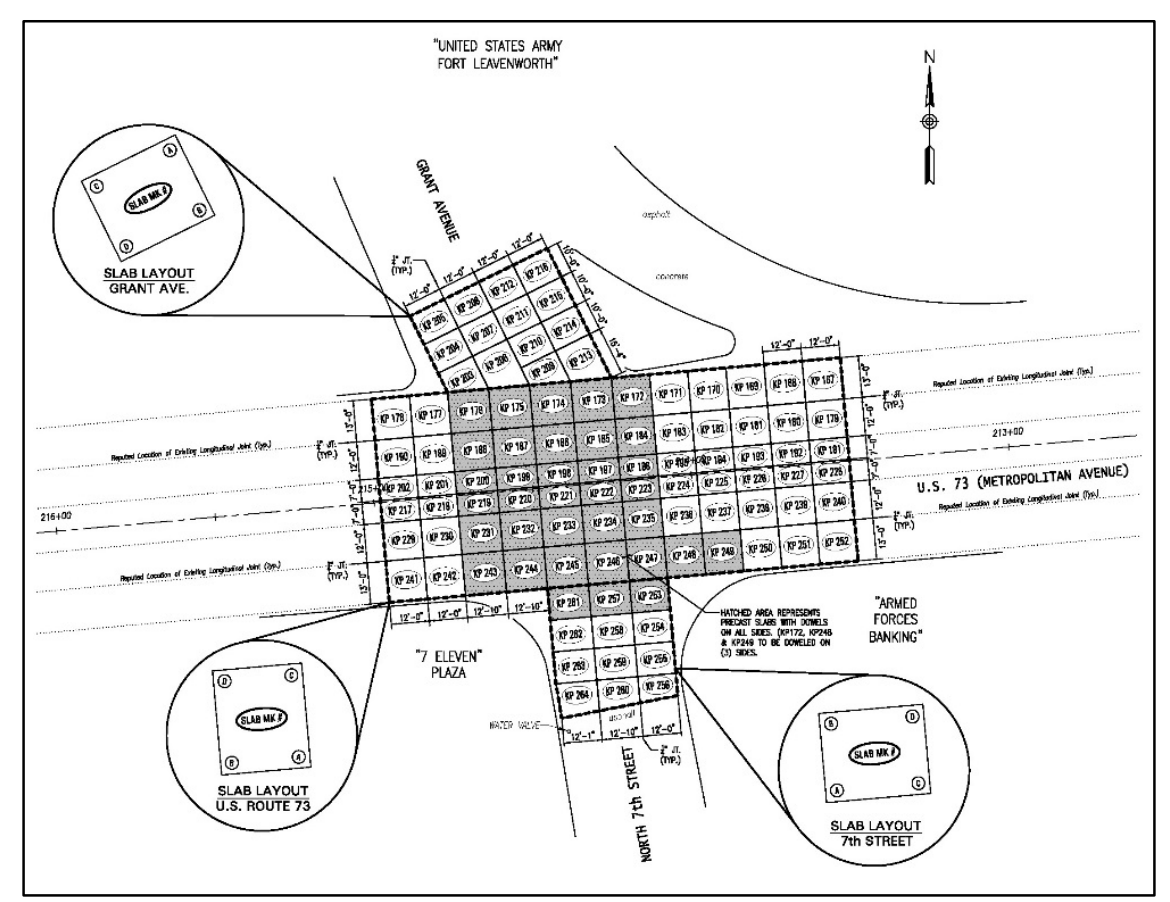

Slab Layout Drawing 


\section{Reconstruction Metropolitan Ave. (US-73) Leavenworth, Kansas}
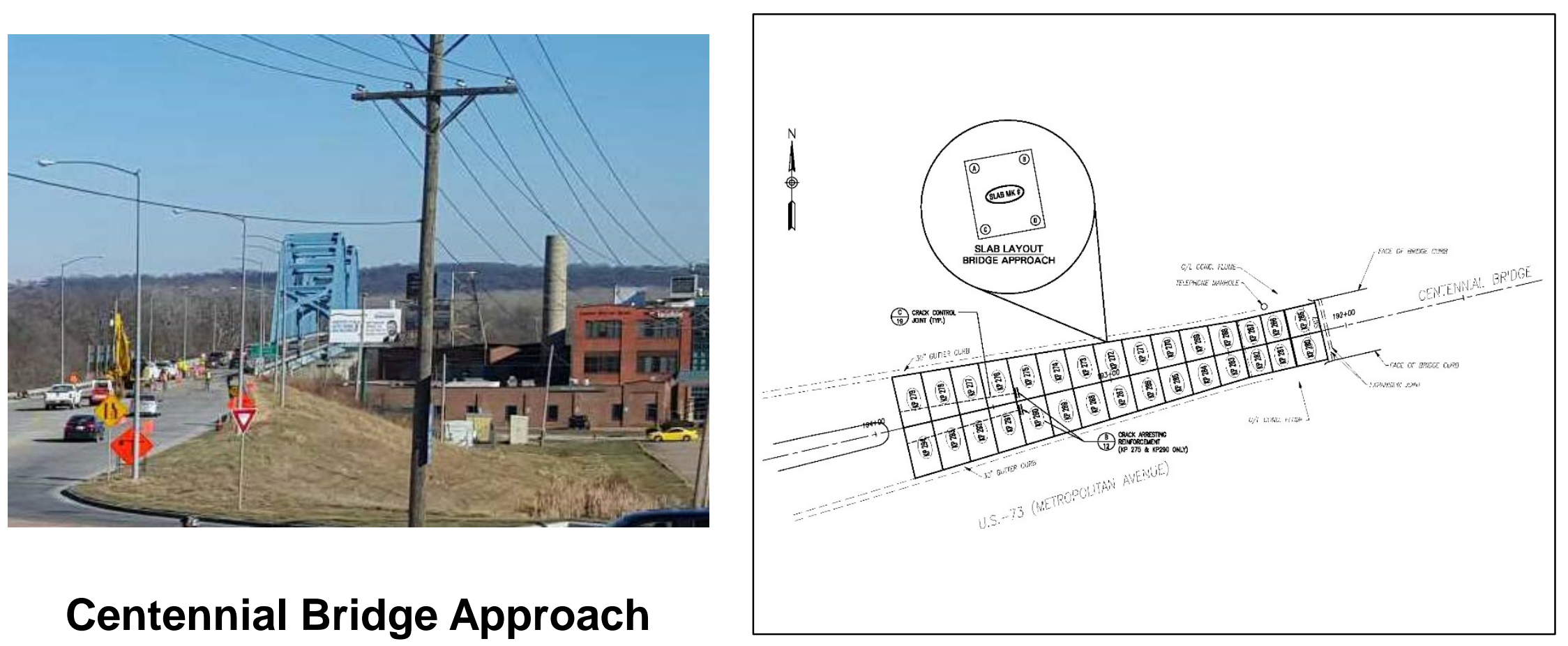

Centennial Bridge Approach

\section{Slab Layout Drawing}

\section{The Fort Miller Co., Inc.}




\section{Installing Slabs - At Night}

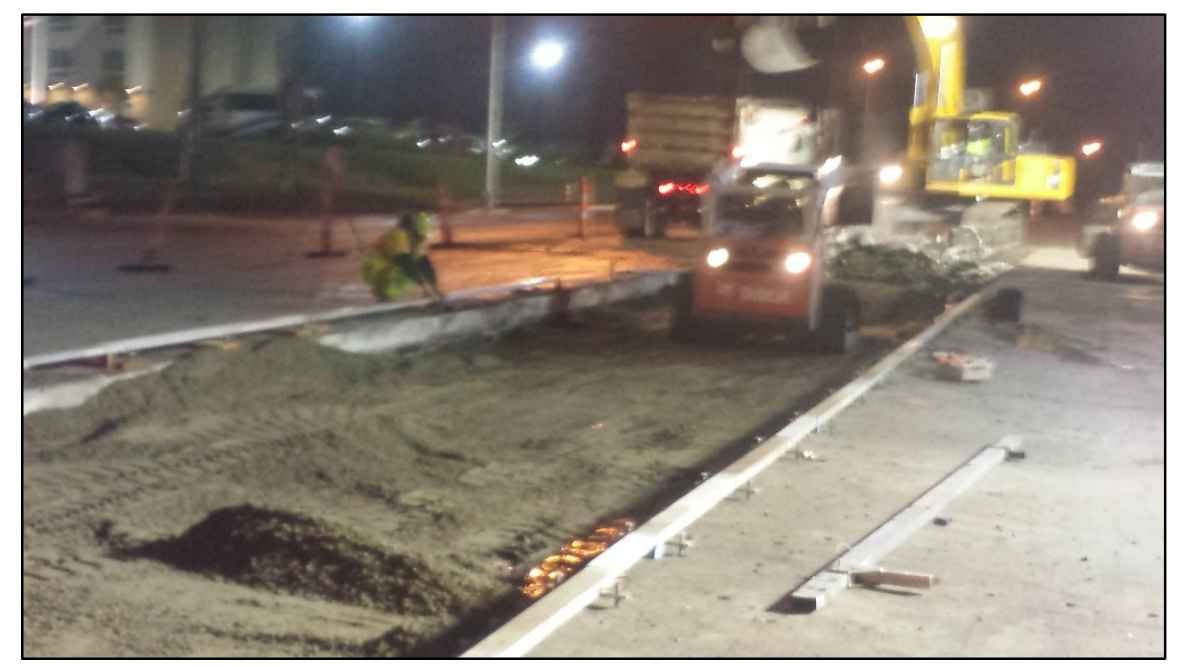

Removing Old Base, Placing New Cement-Treated Bedding Material

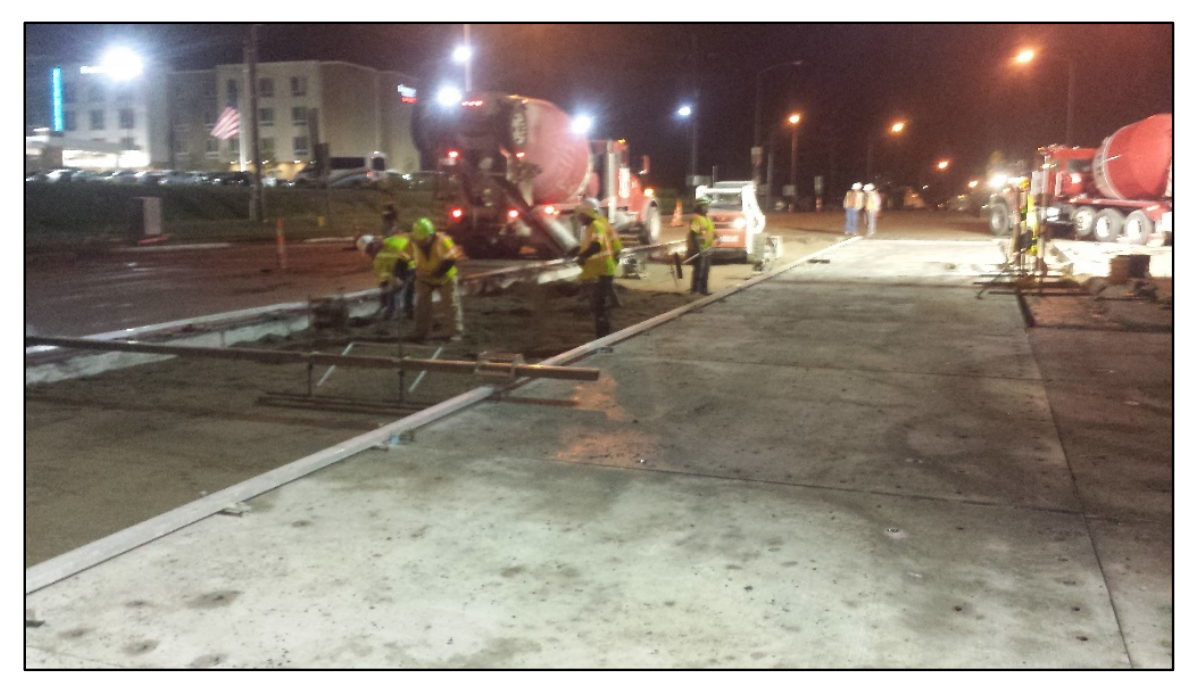

Grading Cement-Treated Bedding Material

294 Slabs - 24 Nights

The Fort Miller Co., Inc. 


\section{The Super Paver System - a Removable and Reusable Urban Pavement (RUP) System}

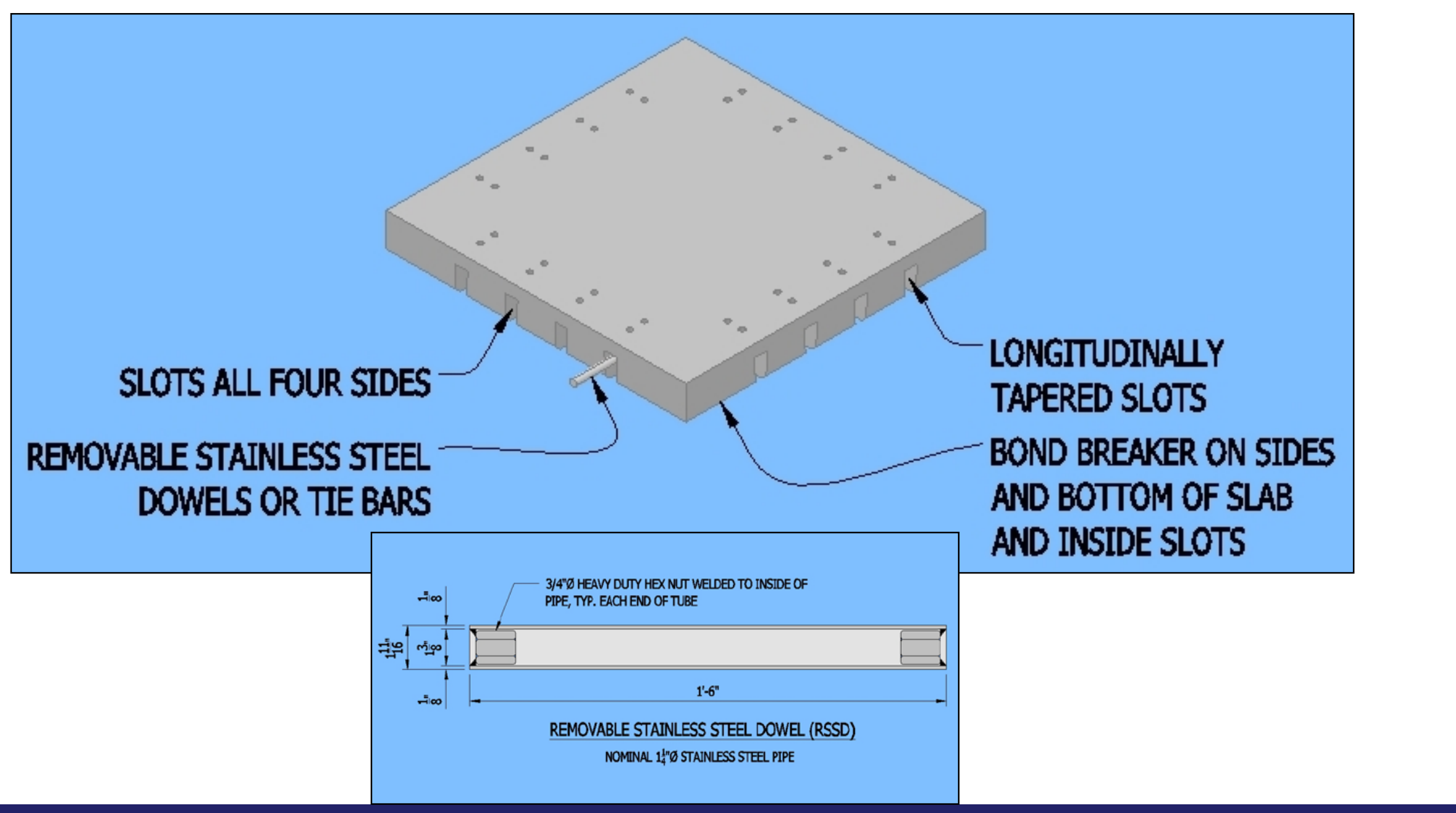

The Fort Miller Co., Inc. 


\section{Demonstrating the RUP Concept Technology Work Shop - Nov. 9, 2011}

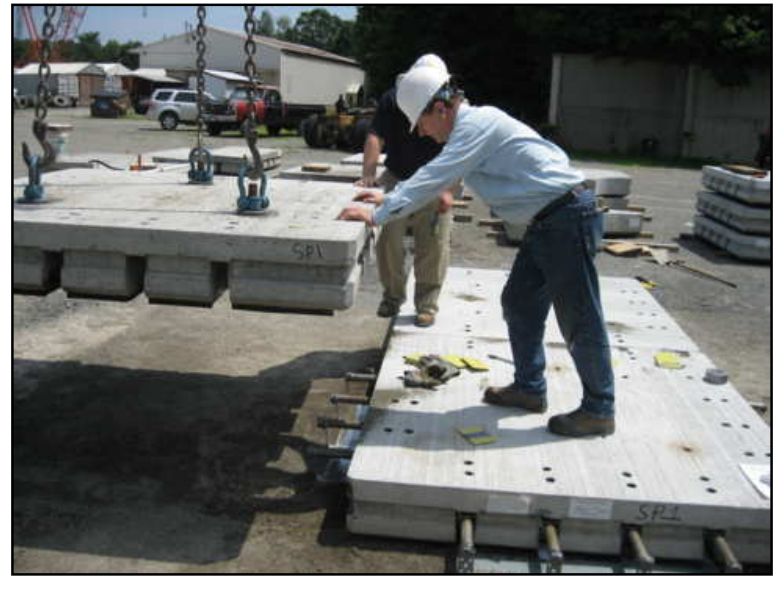

Each Paver Set to a Mark

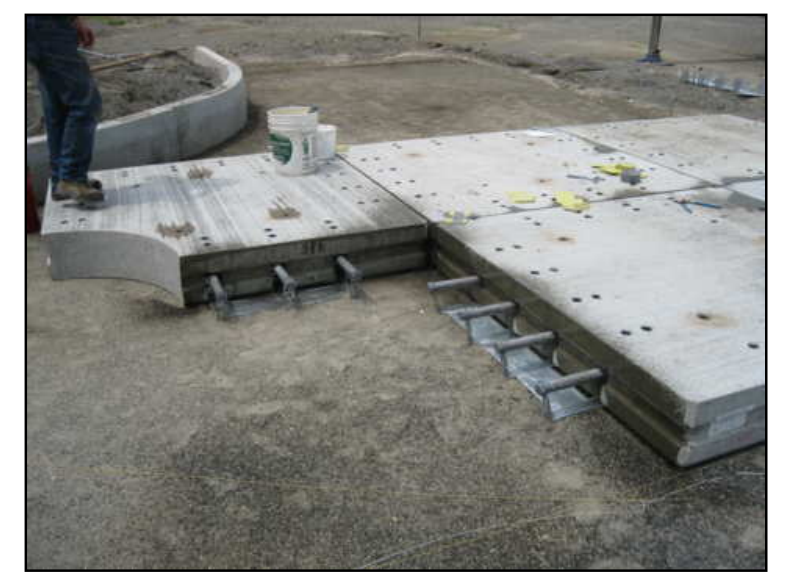

Independent Dowels Placed in Slots

Initial Placement

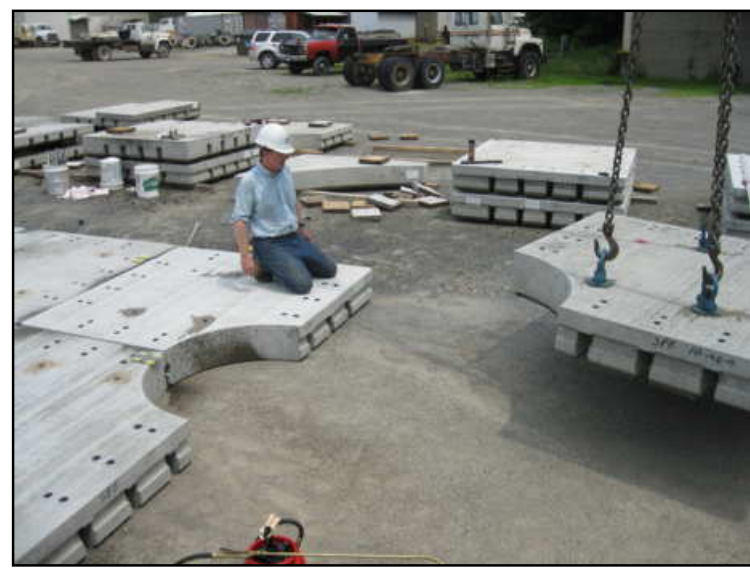

Utility Blockout

The Fort Miller Co., Inc. 


\section{Intersection Quarter}

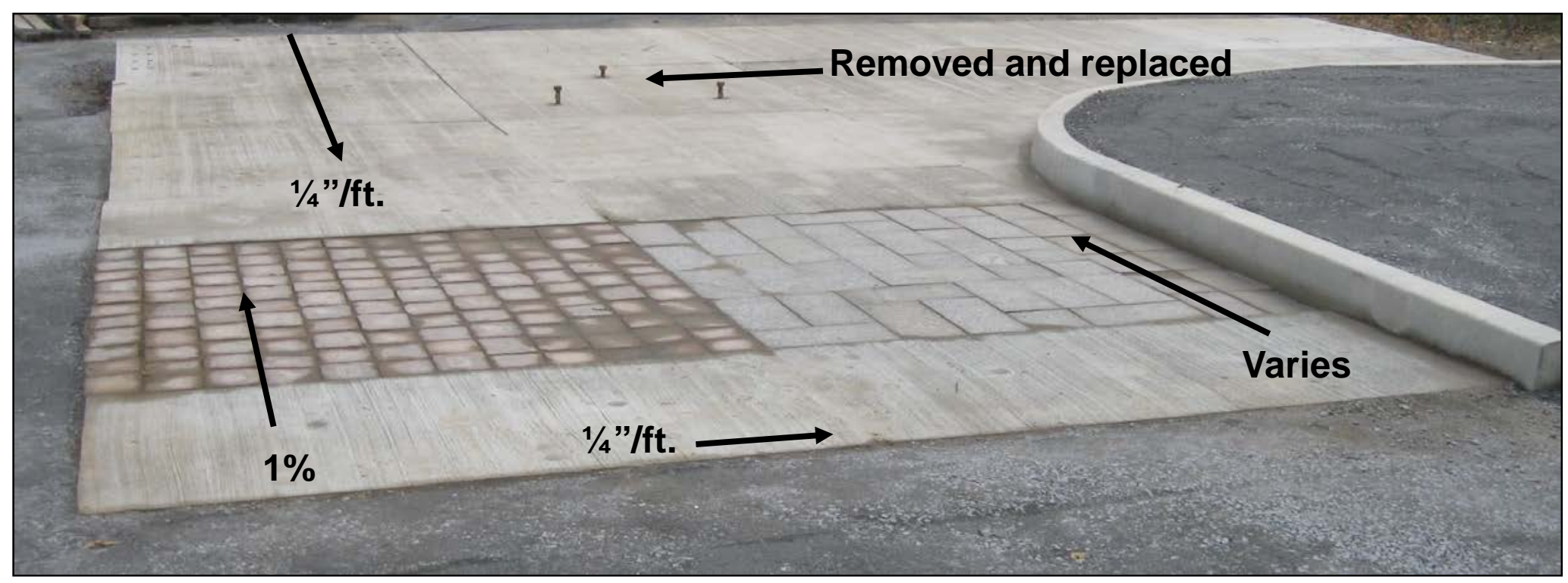

\section{Varying Cross Slopes}

(Crosswalks of Any Texture - Also Removable) 


\section{Slab Removal}

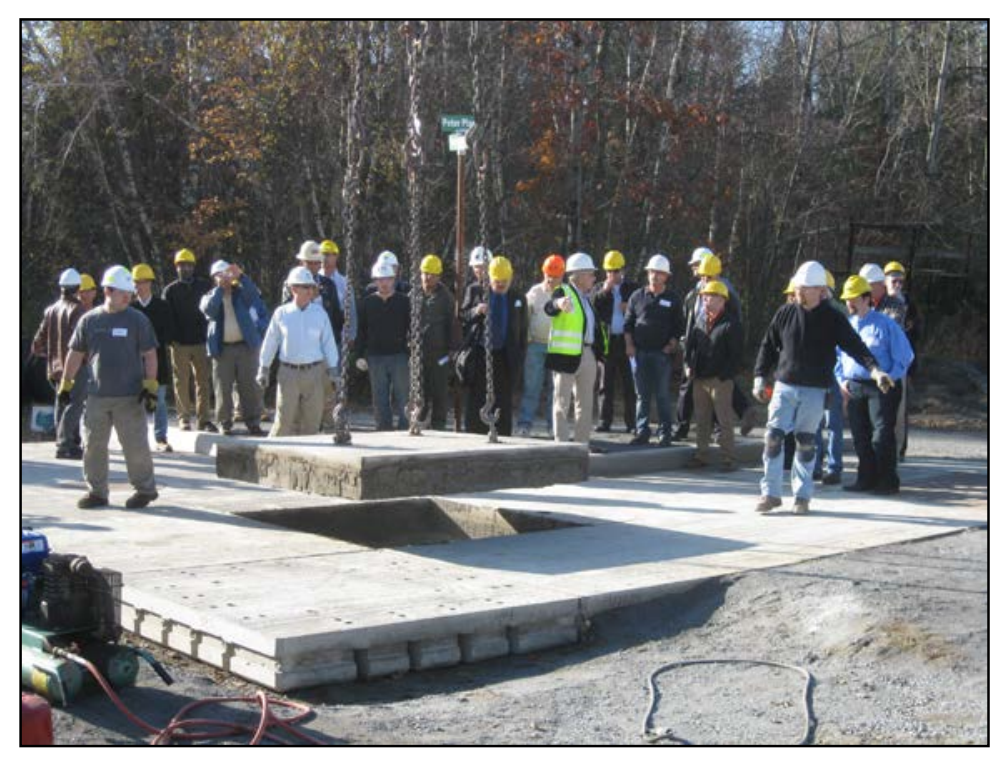

Remove Vertically

\section{Grout Plug Removal}

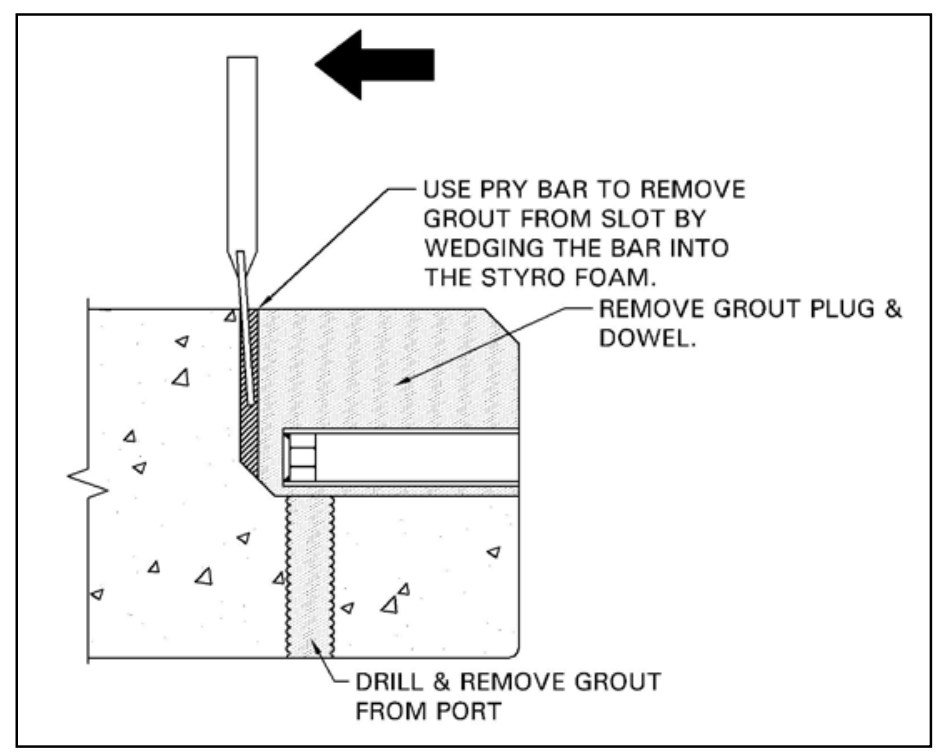

\section{Use Pry Bar To Remove Grout Plug in Inverted Slab}

The Fort Miller Co., Inc. 


\section{Cleanup of Removed Slabs}

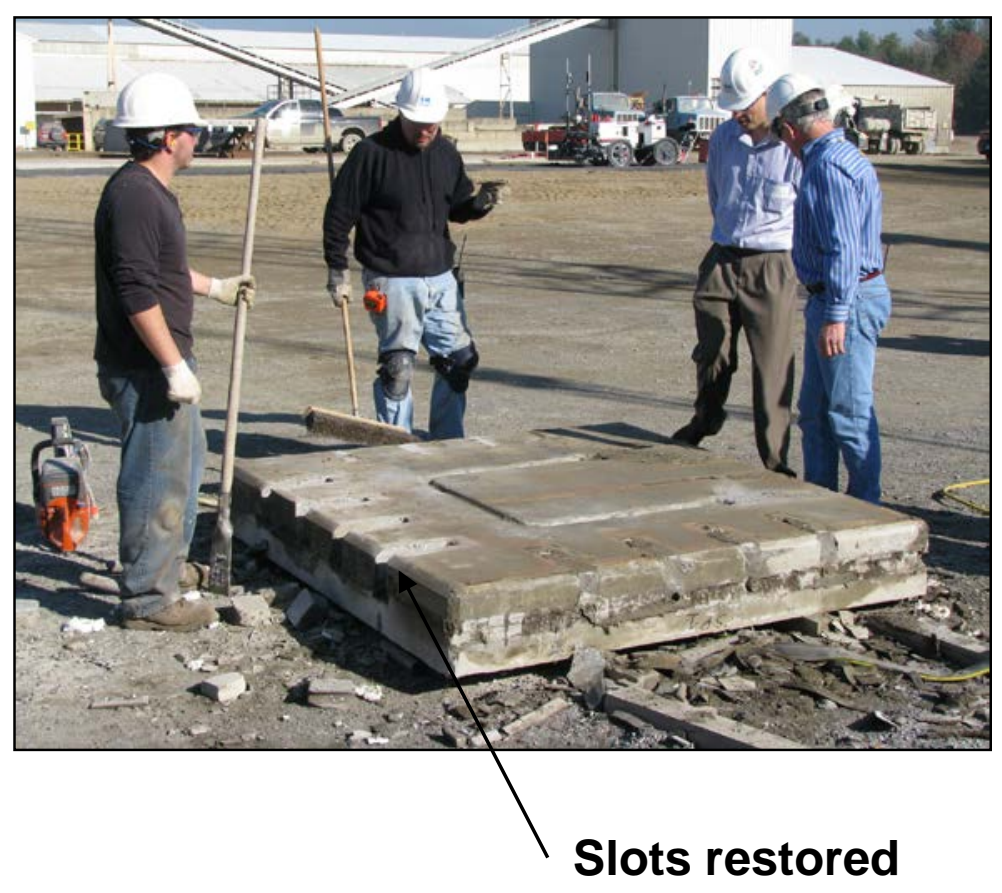

Removing Original Bedding Grout

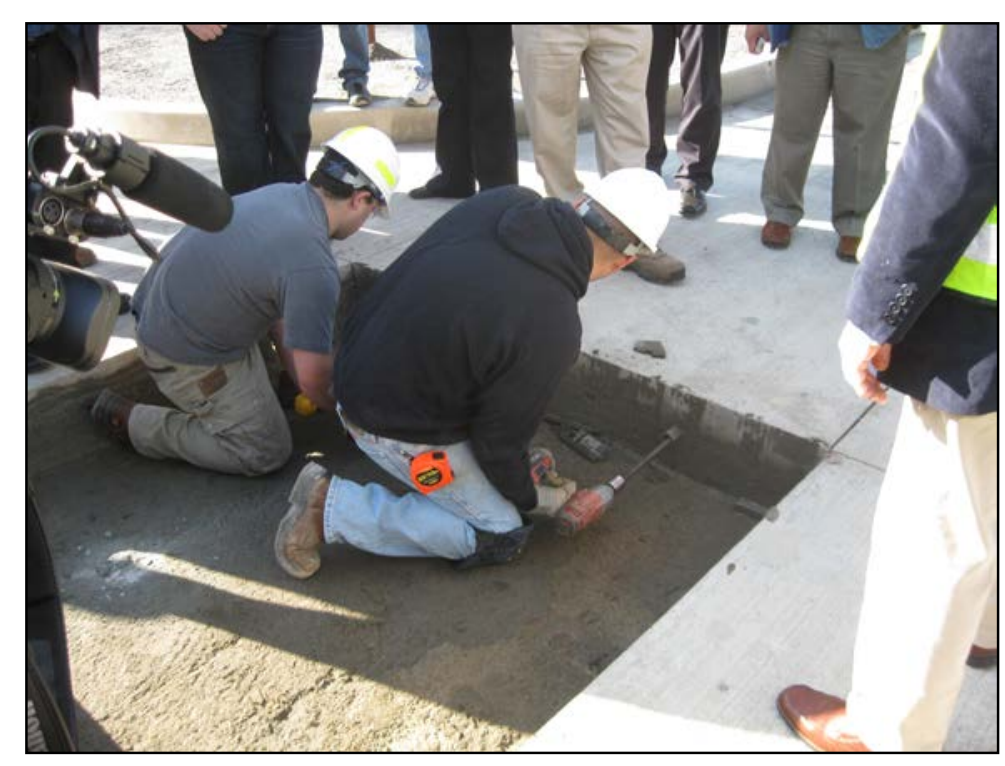

Extracting Half Dowel with Battery-Powered Drill

The Fort Miller Co., Inc. 


\section{(n)}

Extracting Half Dowels Left Behind

(1)

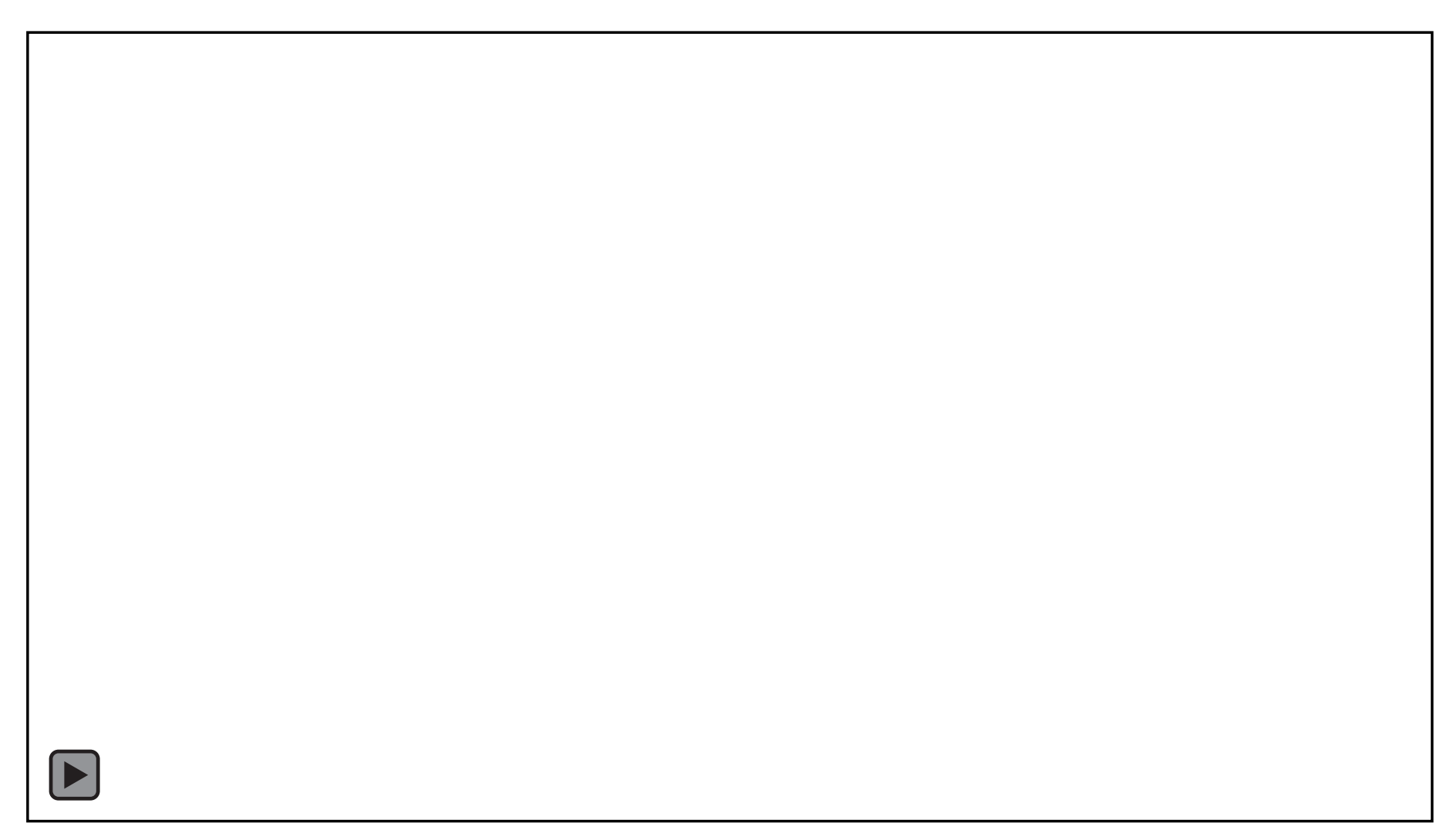

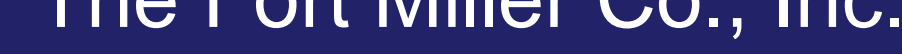

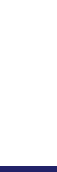

制
. 


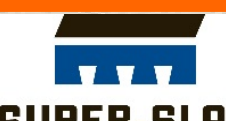

\section{Reusable Urban Pavement Workshop Sept. 22, 2015}

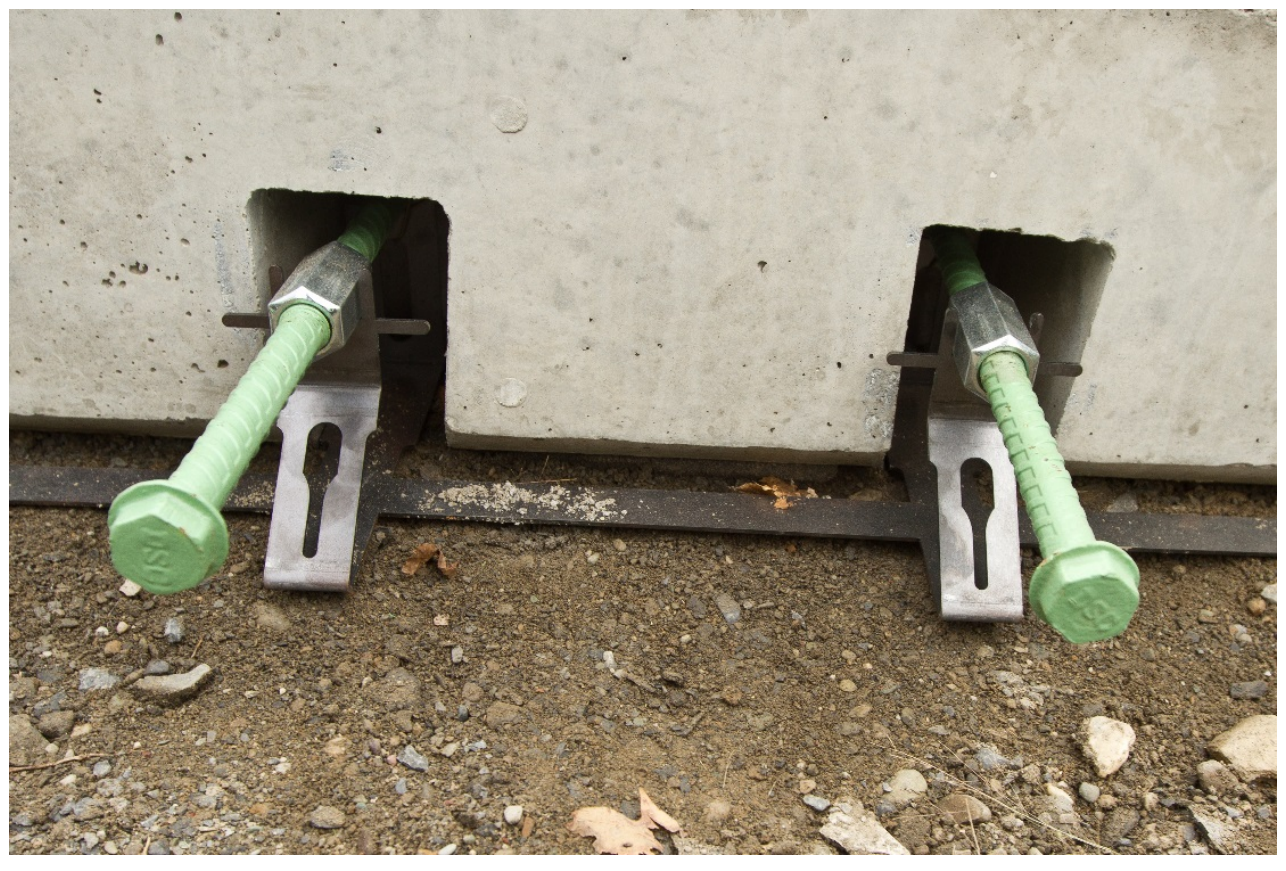

Removable/Replaceable Longitudinal Joint Tie 


\section{Removable/Replaceable Longitudinal Joint Tie}

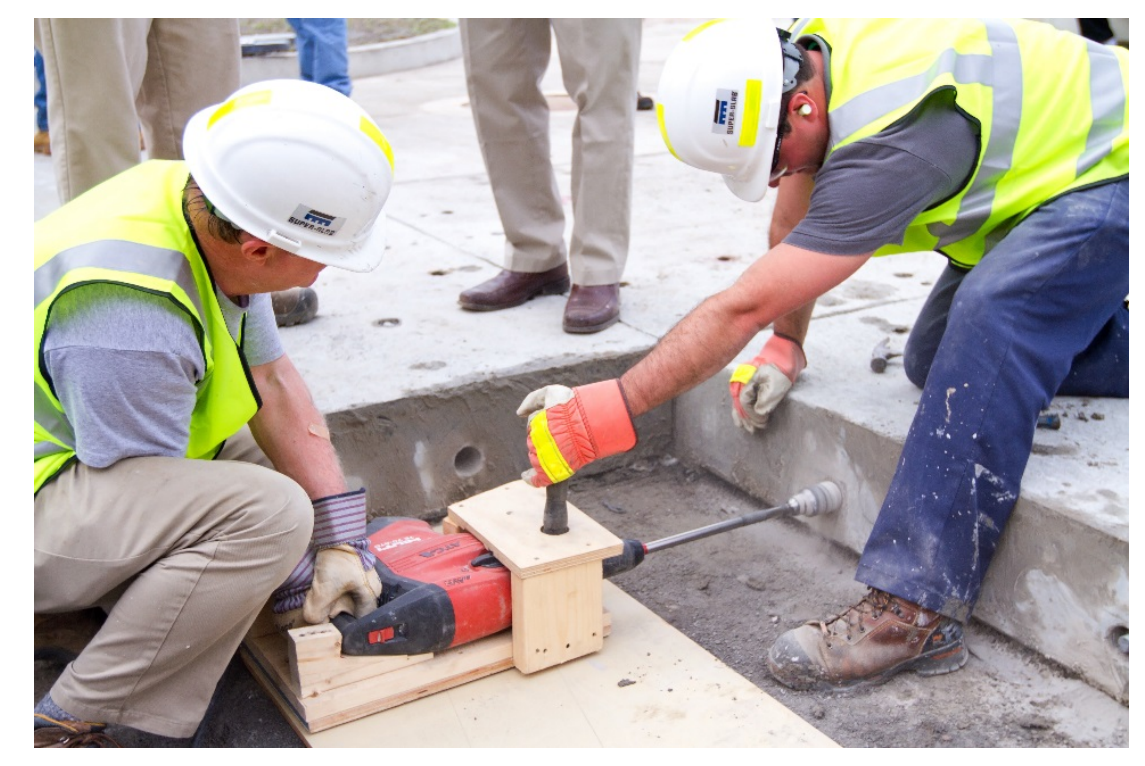

Core and Remove Coupler

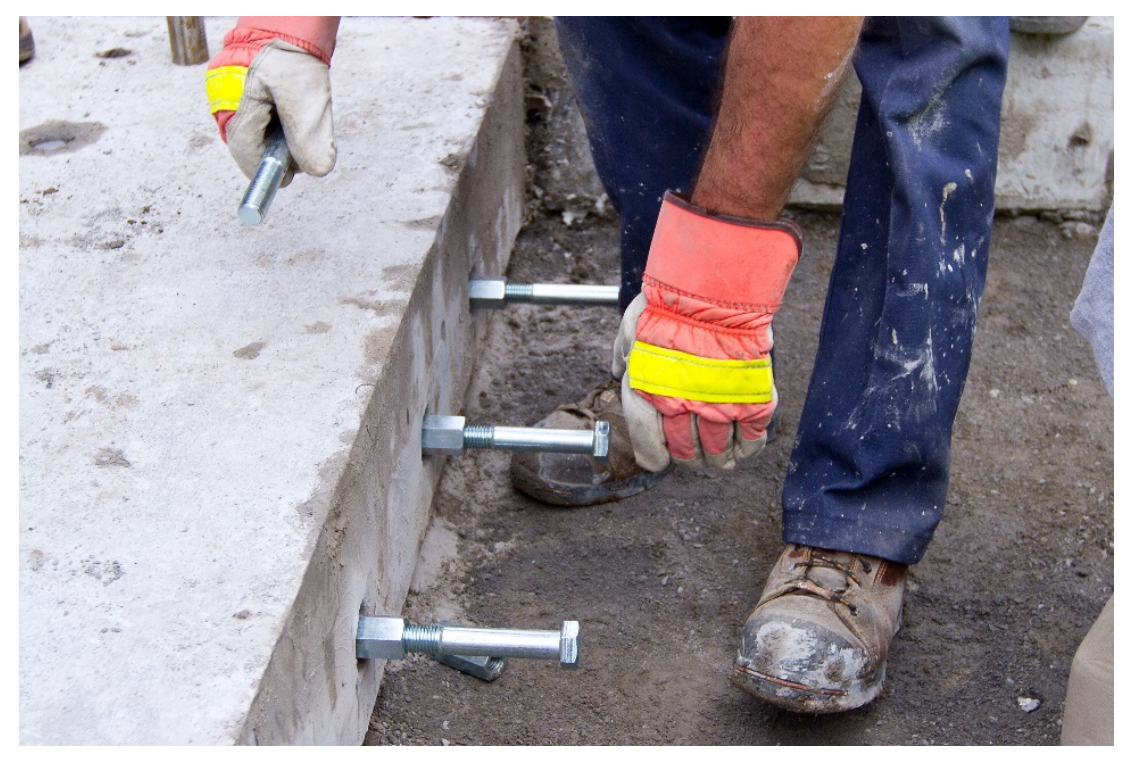

Replace Coupler and Headed Tie 


\section{Installing Restored Slab}

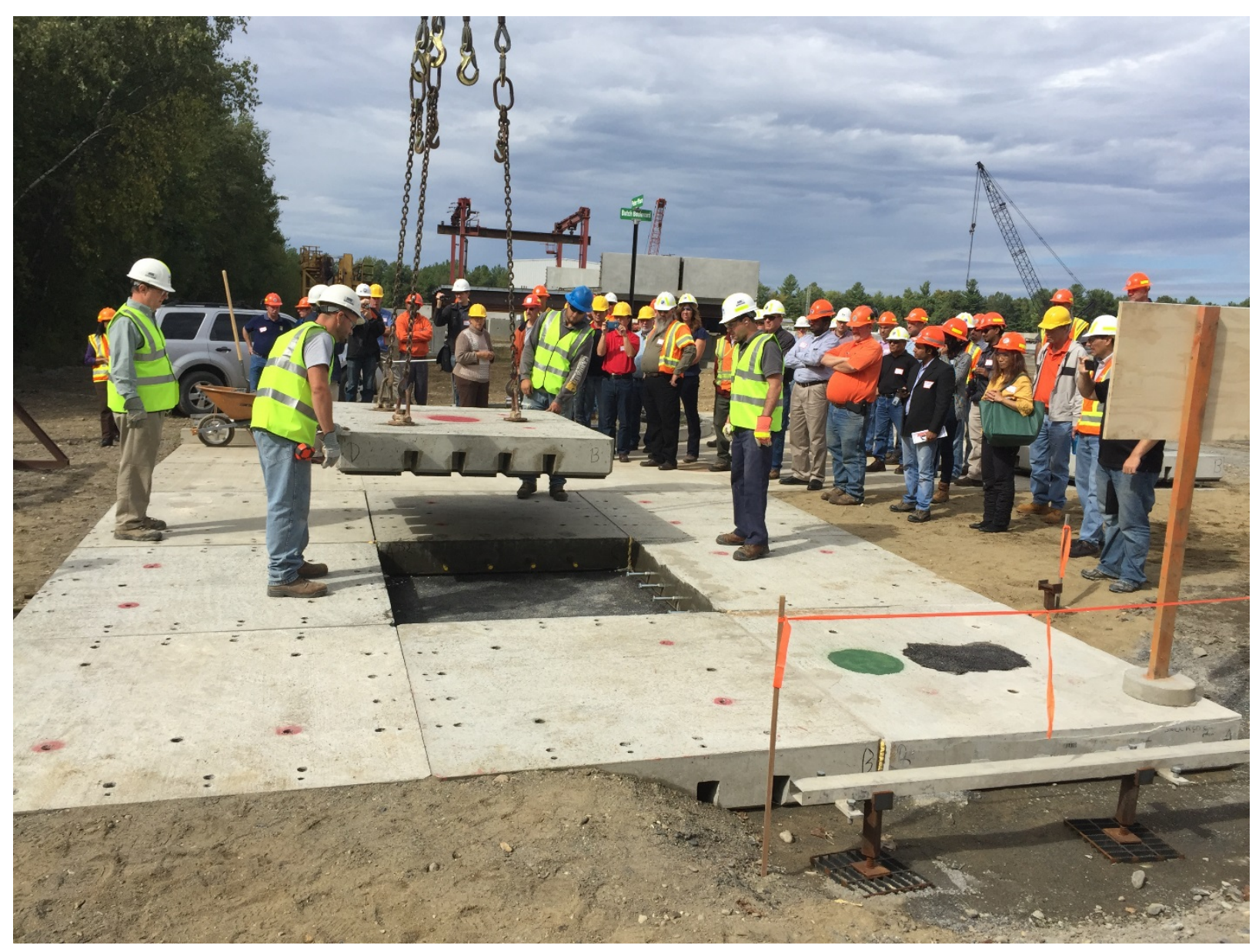

New Super-Dowels and Restored Longitudinal Joint Ties The Fort Miller Co., Inc. 


\section{Accommodating Utilities}

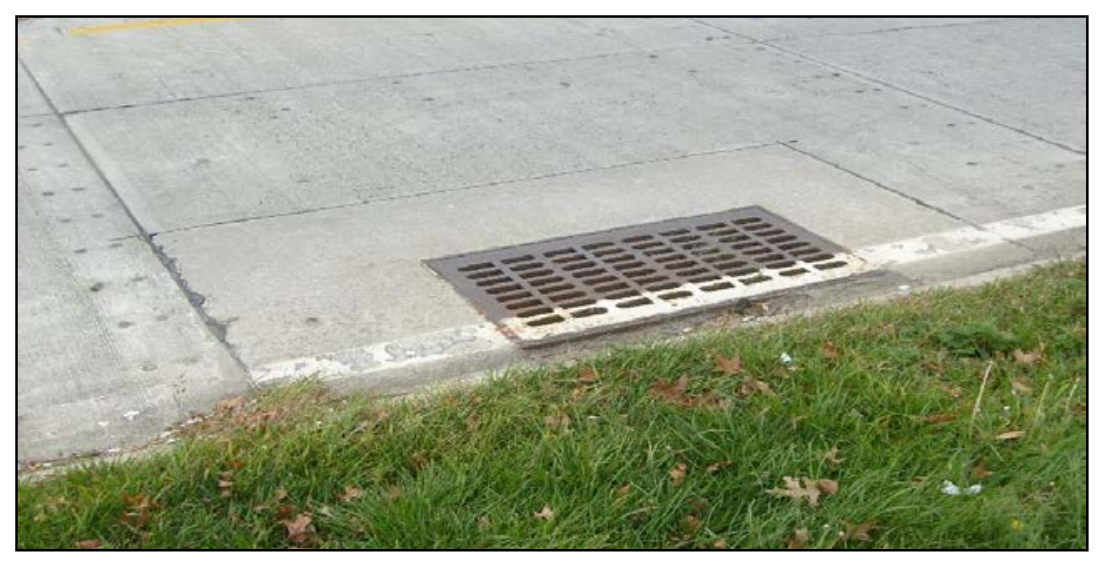

Curb Inlet

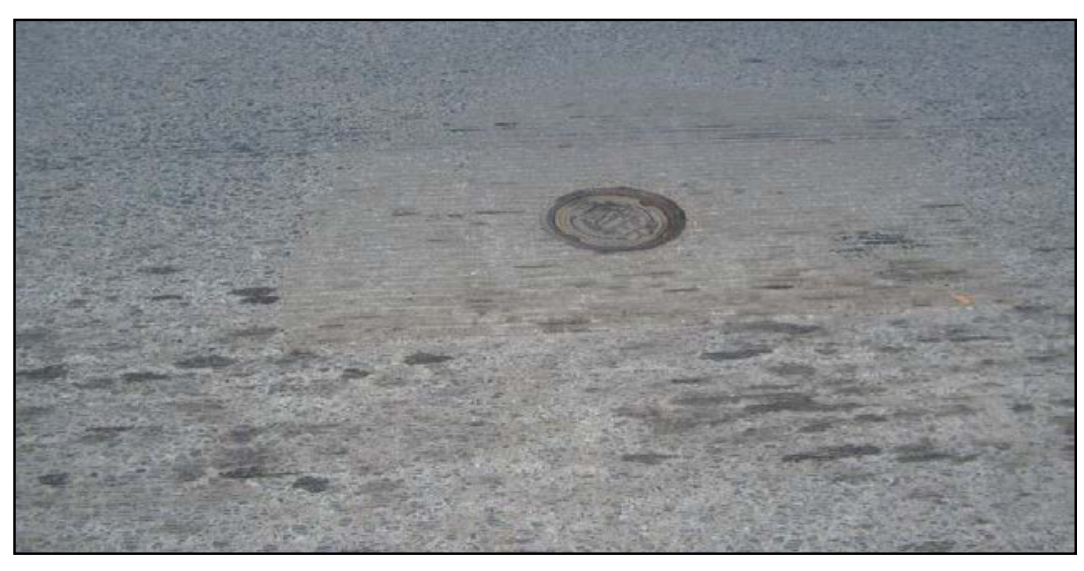

Water Valve - CIP Closure Pour

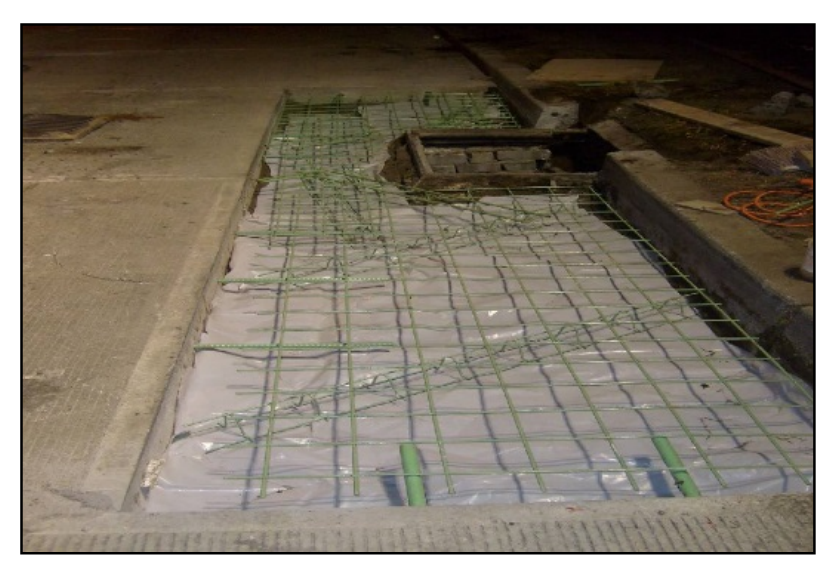

CIP Closure Pour

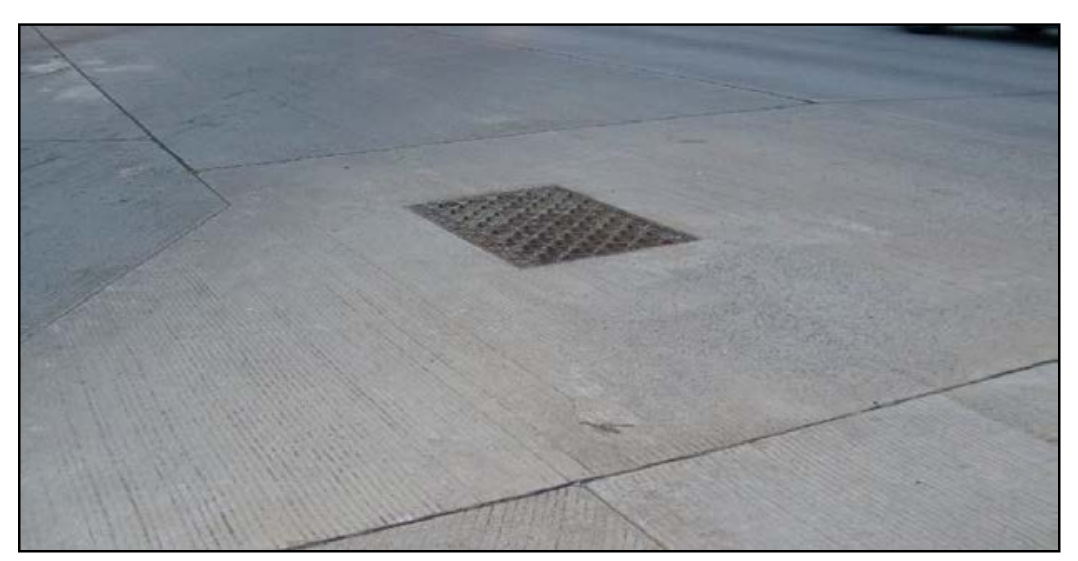

Drop Inlet CIP Closure Pour

The Fort Miller Co., Inc. 


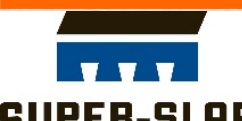

\section{Precast Crosswalk Slabs - Port Jefferson, NY}

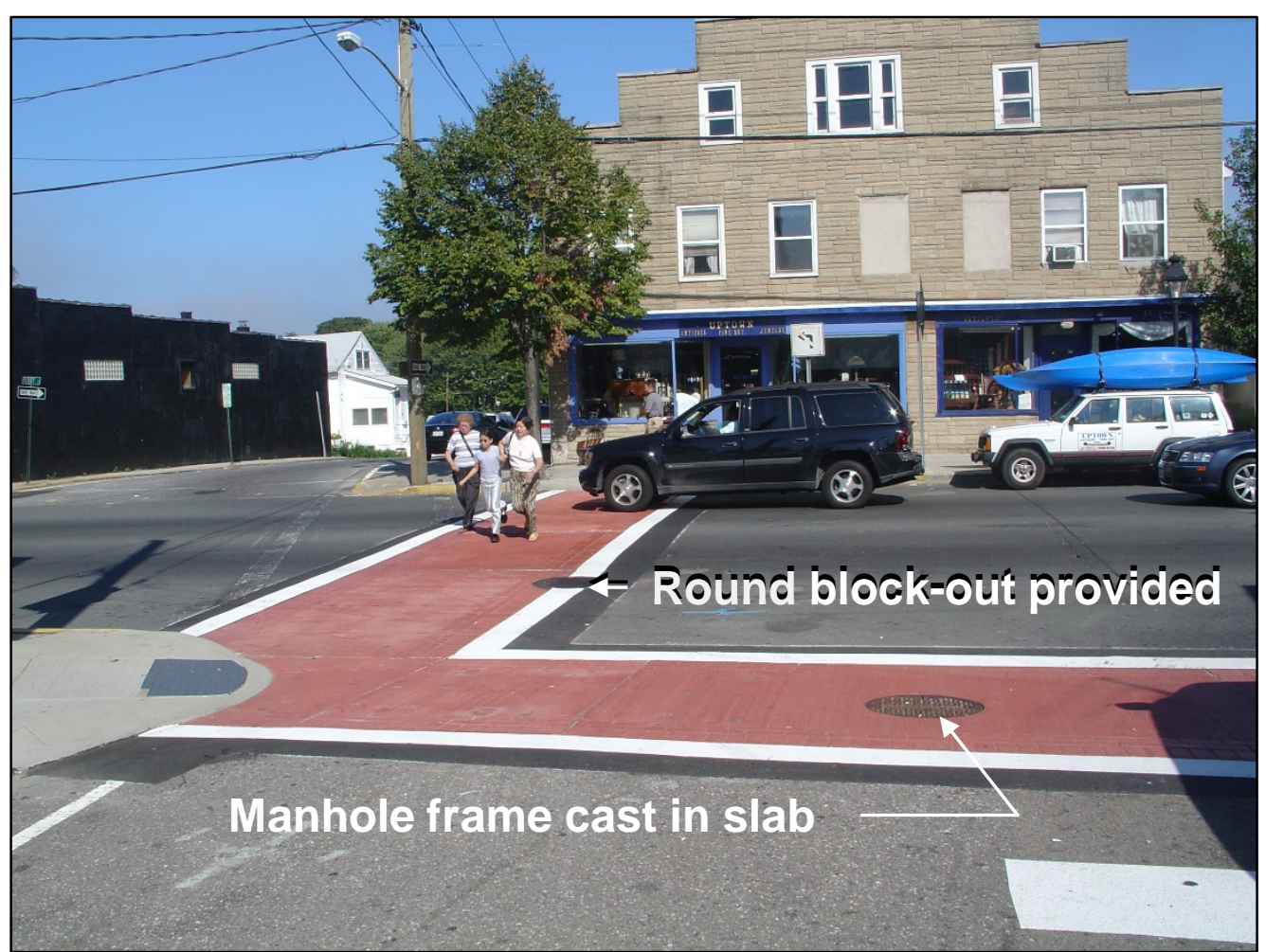

Two Methods - Block-outs for Manhole or Cast Manhole Frame in Slab

Casting in manhole frame logistically difficult

The Fort Miller Co., Inc. 


\section{Tra

\section{NYSTA New England Thruway l-95 Yonkers Construction WSP}
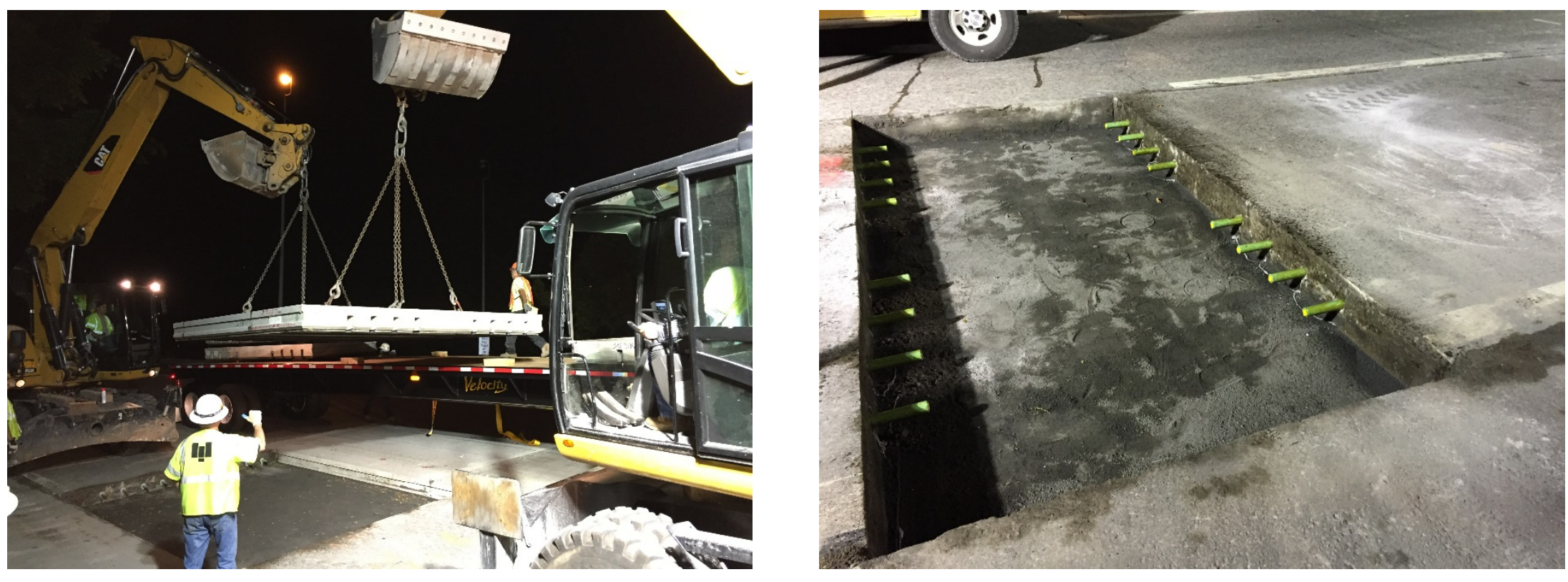

The Fort Miller Co., Inc. 


\title{
Precast Pavement Add-ons - Smart Patching with Super-Dowels
}

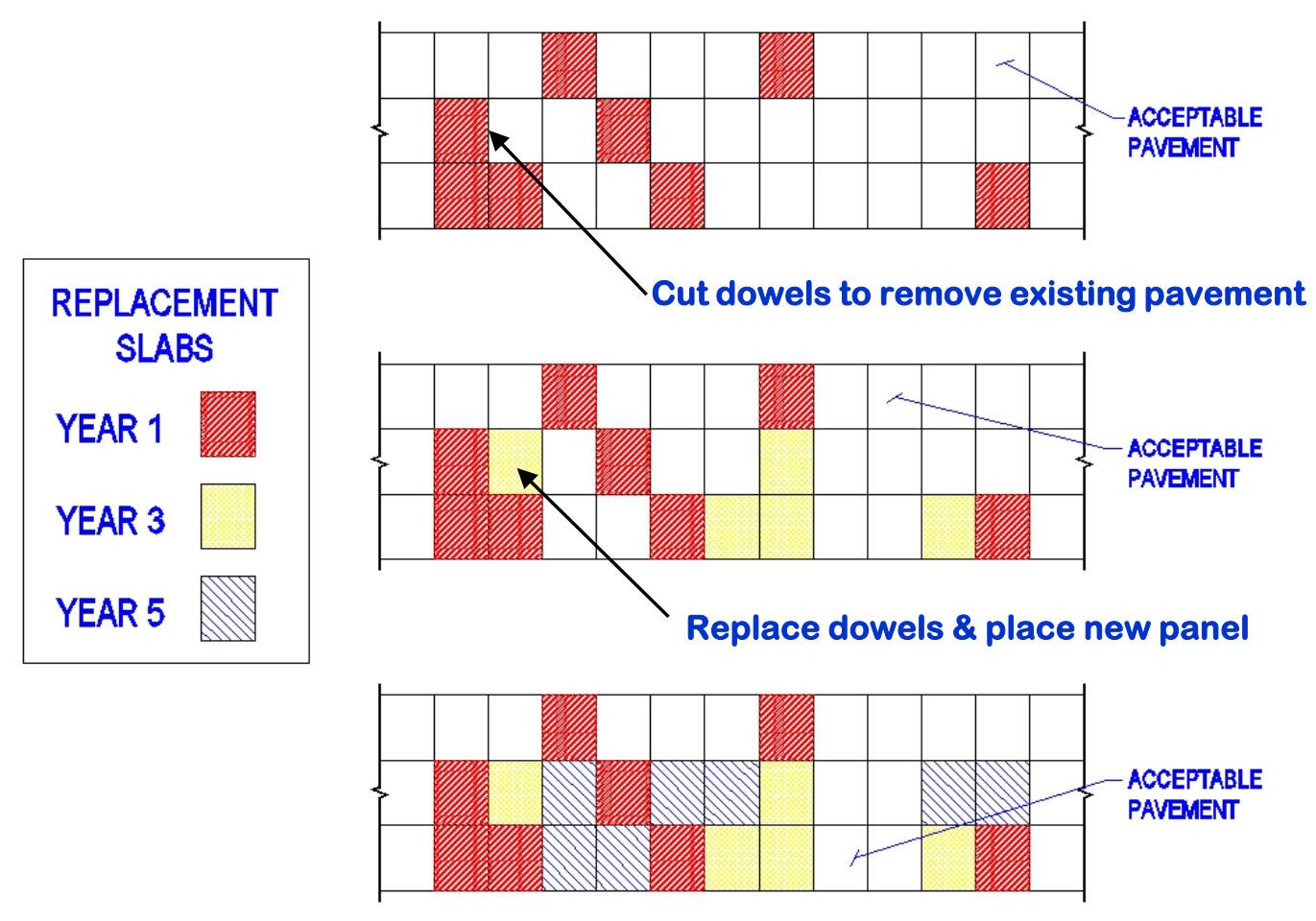

\section{Make The Most of Your Existing Concrete Pavement Assets}

\author{
The Fort Miller Co., Inc.
}




\section{Broadway Junction, Brooklyn, NY}

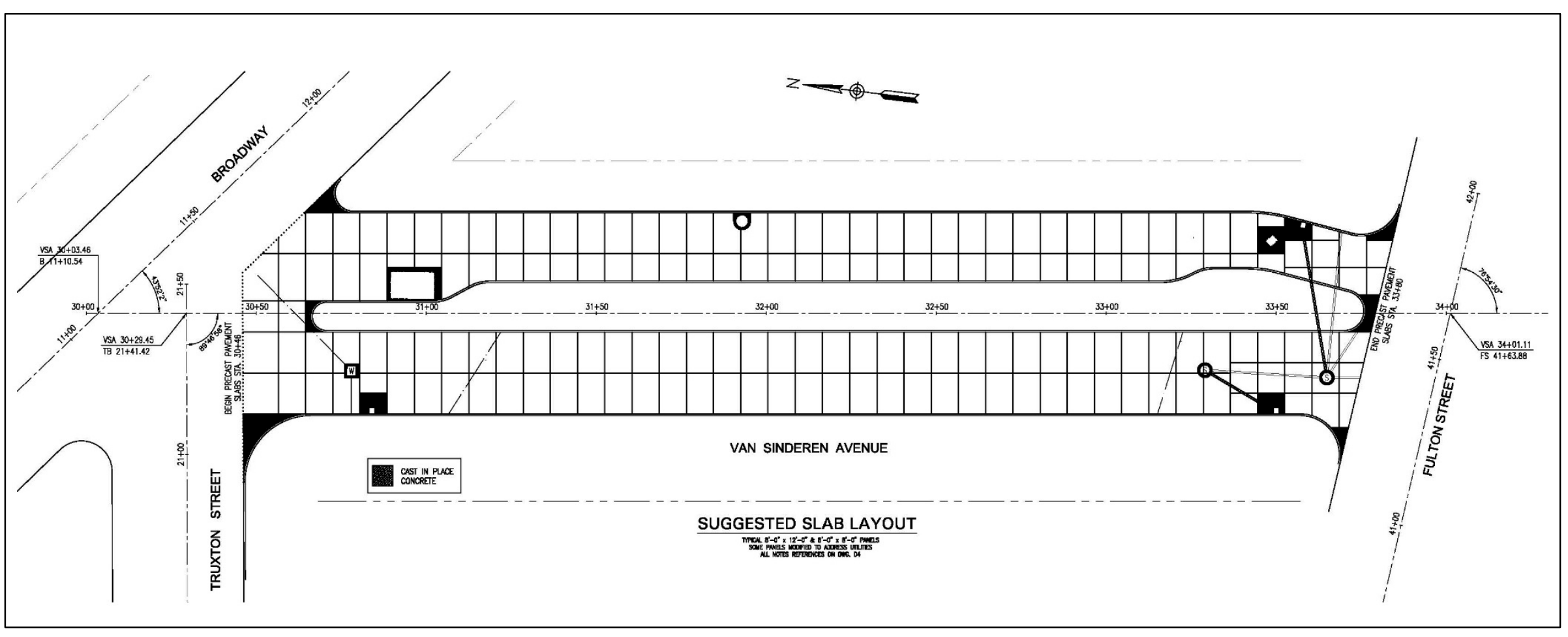

Van Sinderen Avenue Preliminary Slab Layout Drawing

167 Slabs - all removable and replaceable, 91 flat, 76 non-planar

The Fort Miller Co., Inc. 


\section{Broadway Junction, Brooklyn, NY}
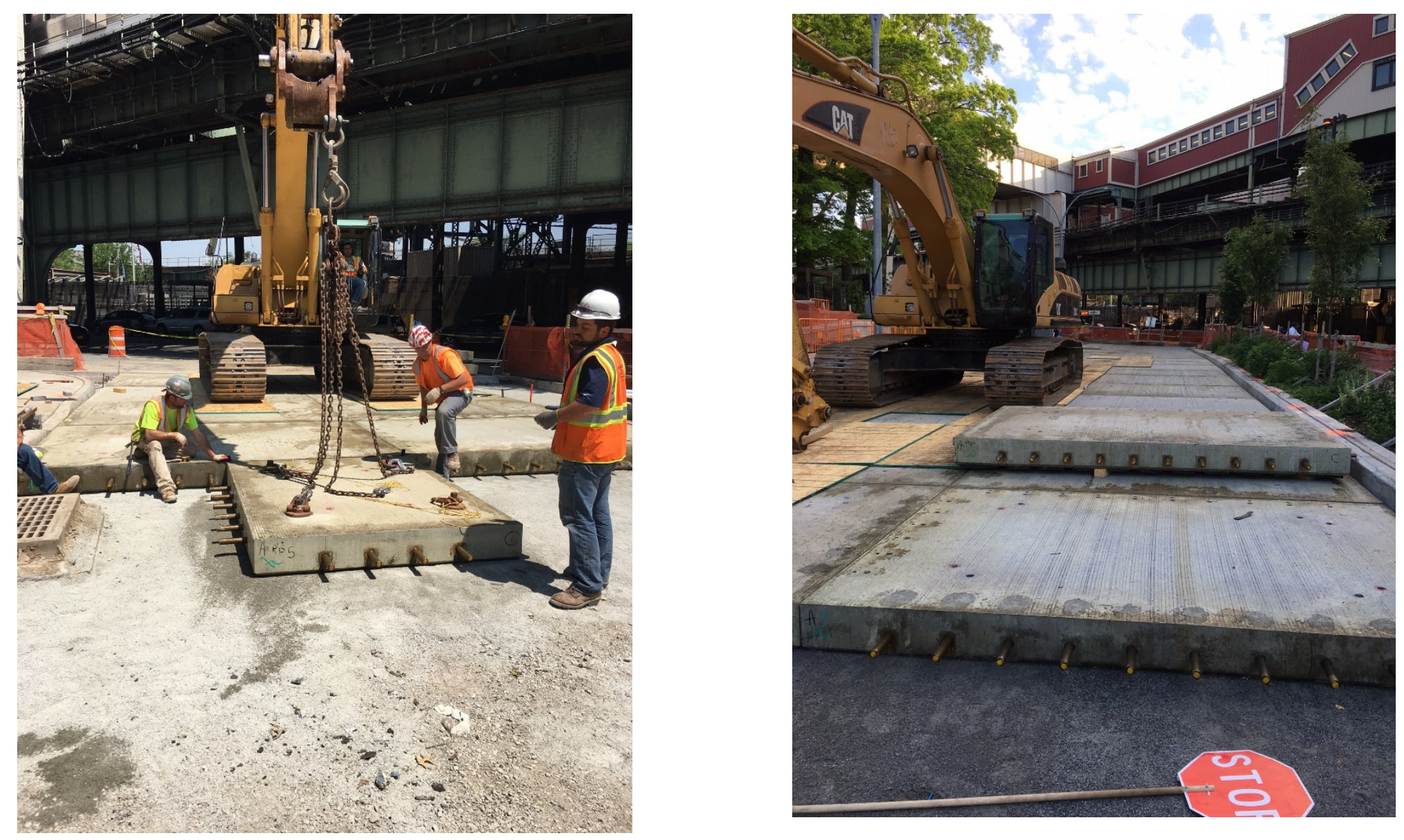

The Fort Miller Co., Inc. 


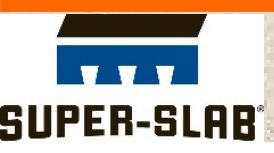

\section{Broadway Junction, Brooklyn, NY}

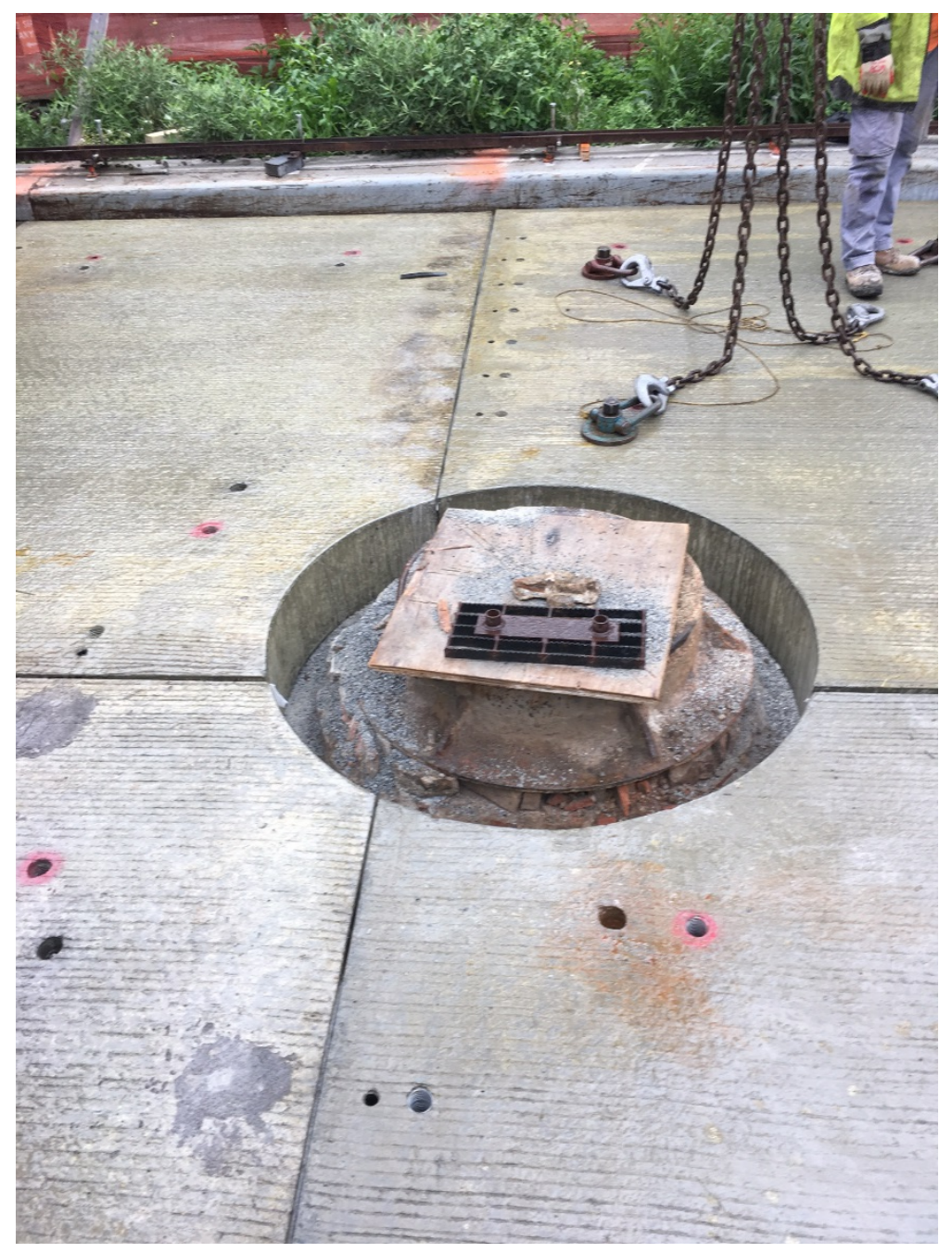

The Fort Miller Co., Inc. 


\section{Broadway Junction, Brooklyn, NY}
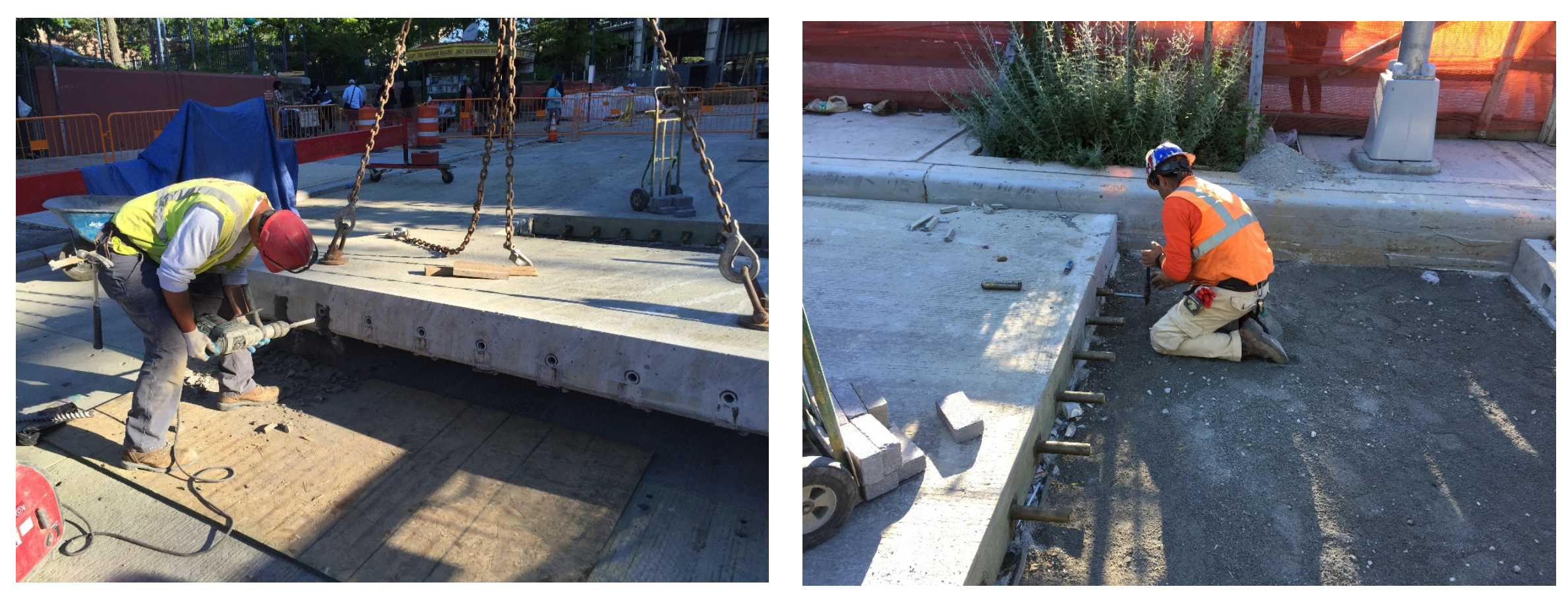

The Fort Miller Co., Inc. 


\section{Broadway Junction, Brooklyn, NY}

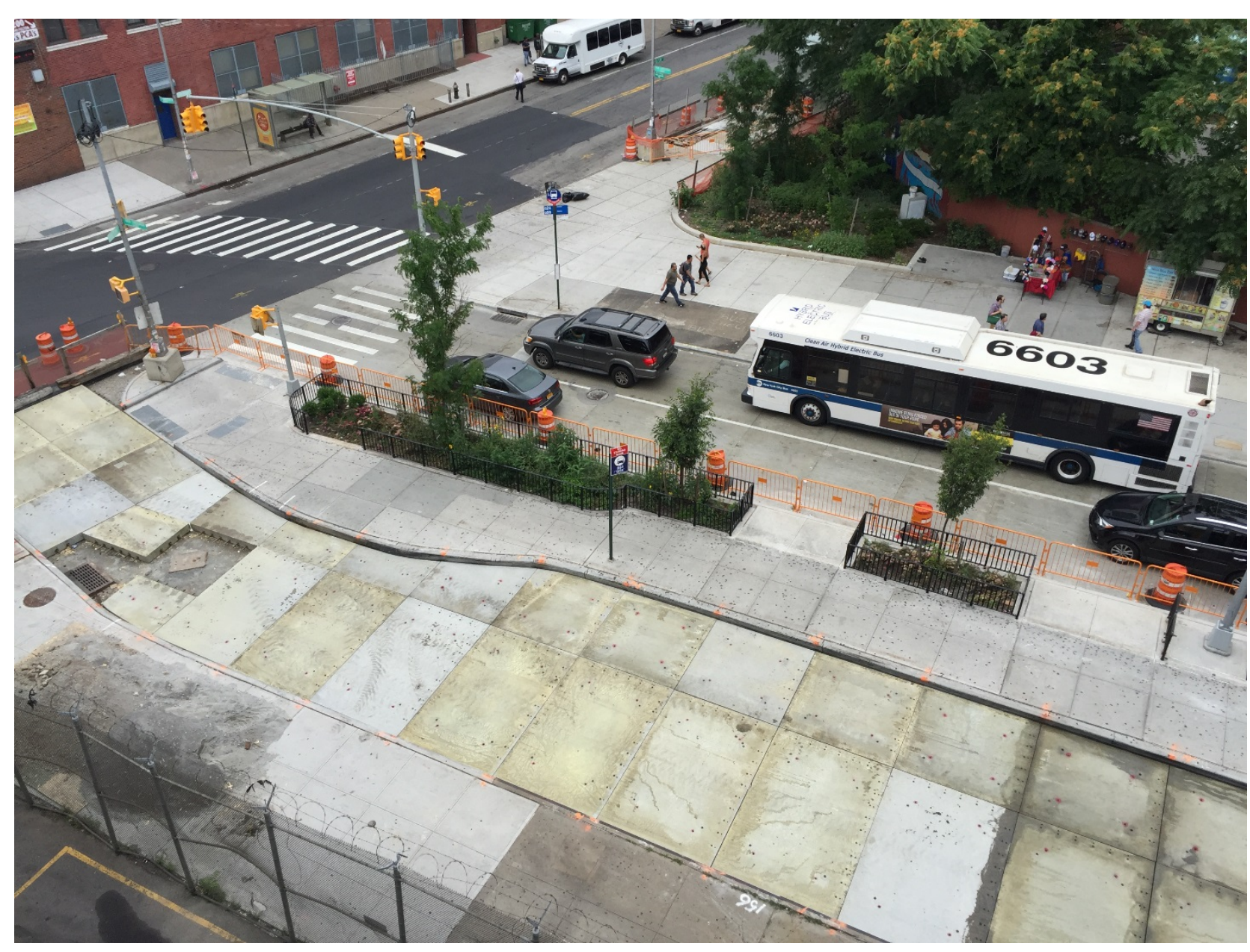

The Fort Miller Co., Inc. 


\section{US 40 Richmond}

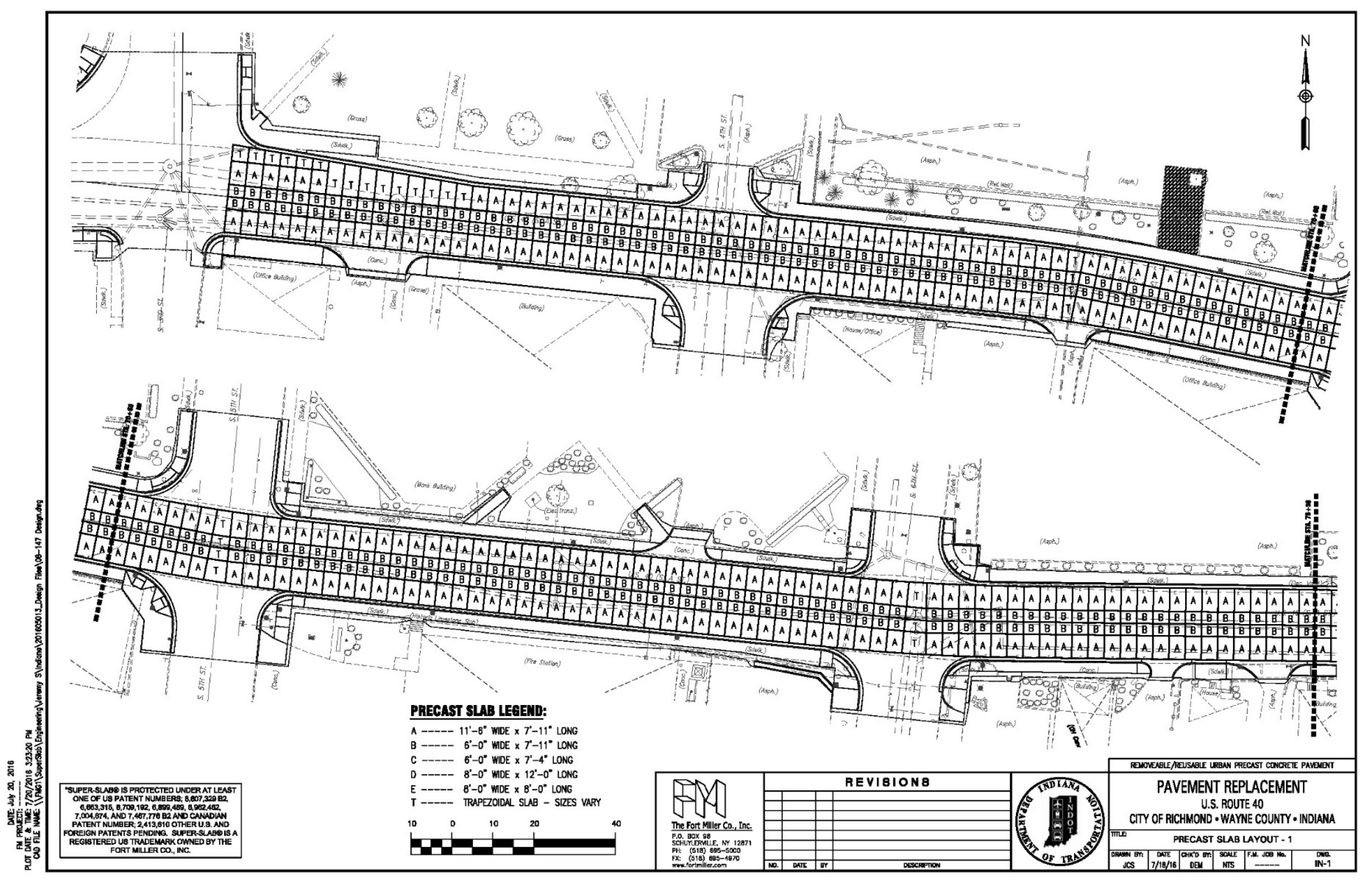

The Fort Miller Co., Inc. 


\section{INDOT US 40 Richmond}

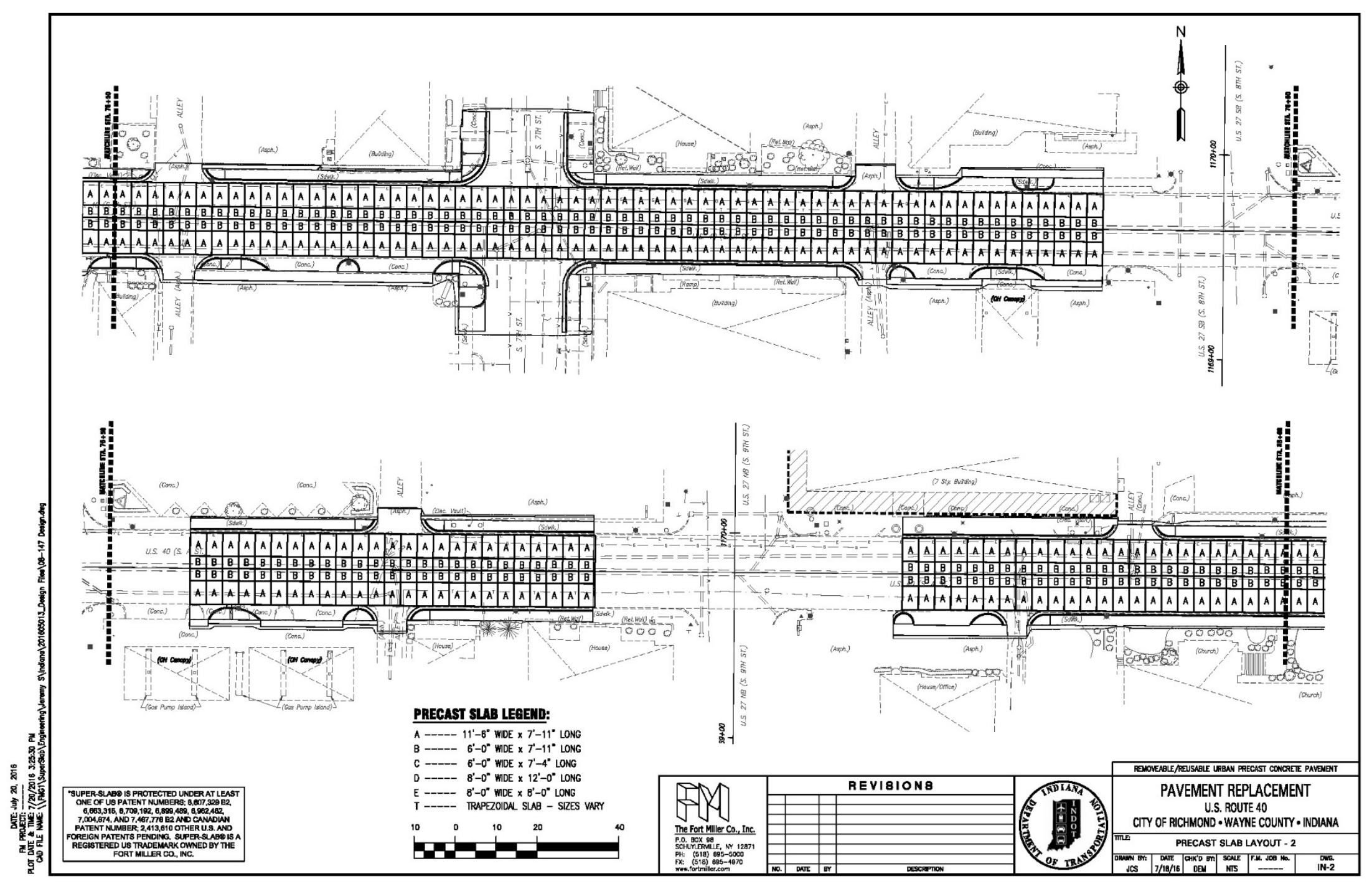




\section{INDOT US 40 Richmond}

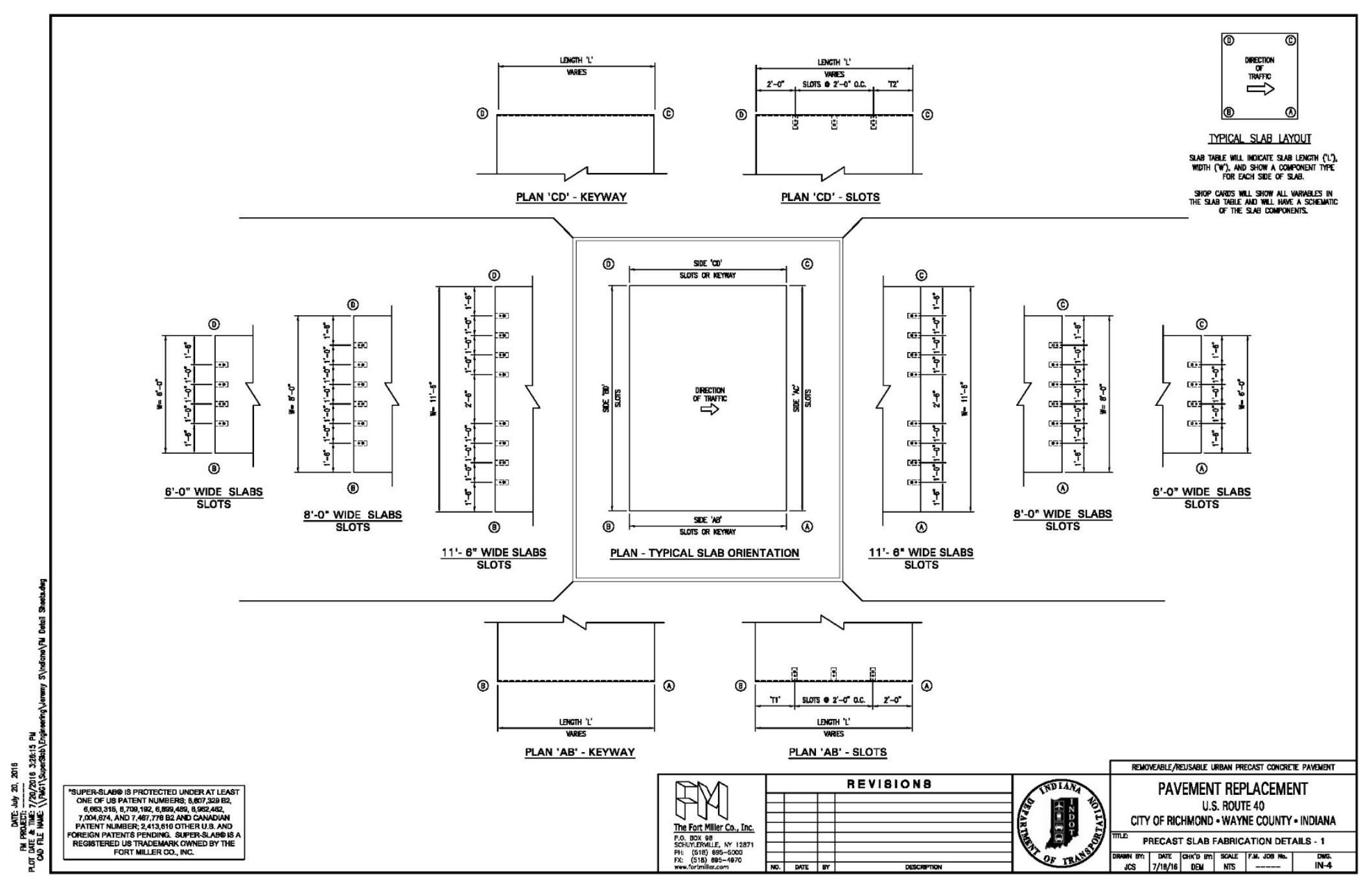

The Fort Miller Co., Inc. 


\section{INDOT US 40 Richmond}

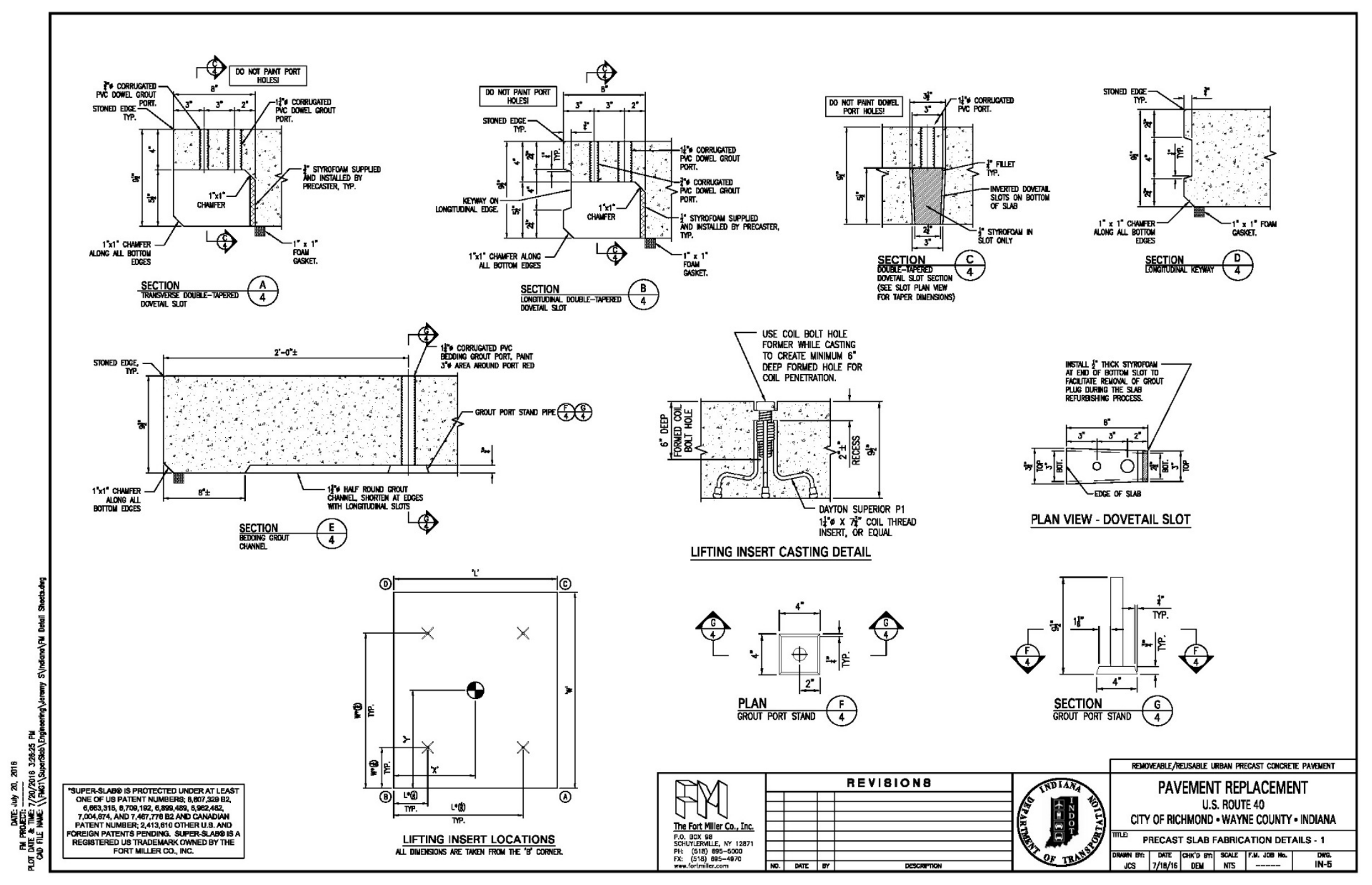

The Fort Miller Co., Inc. 


\section{INDOT US 40 Richmond}

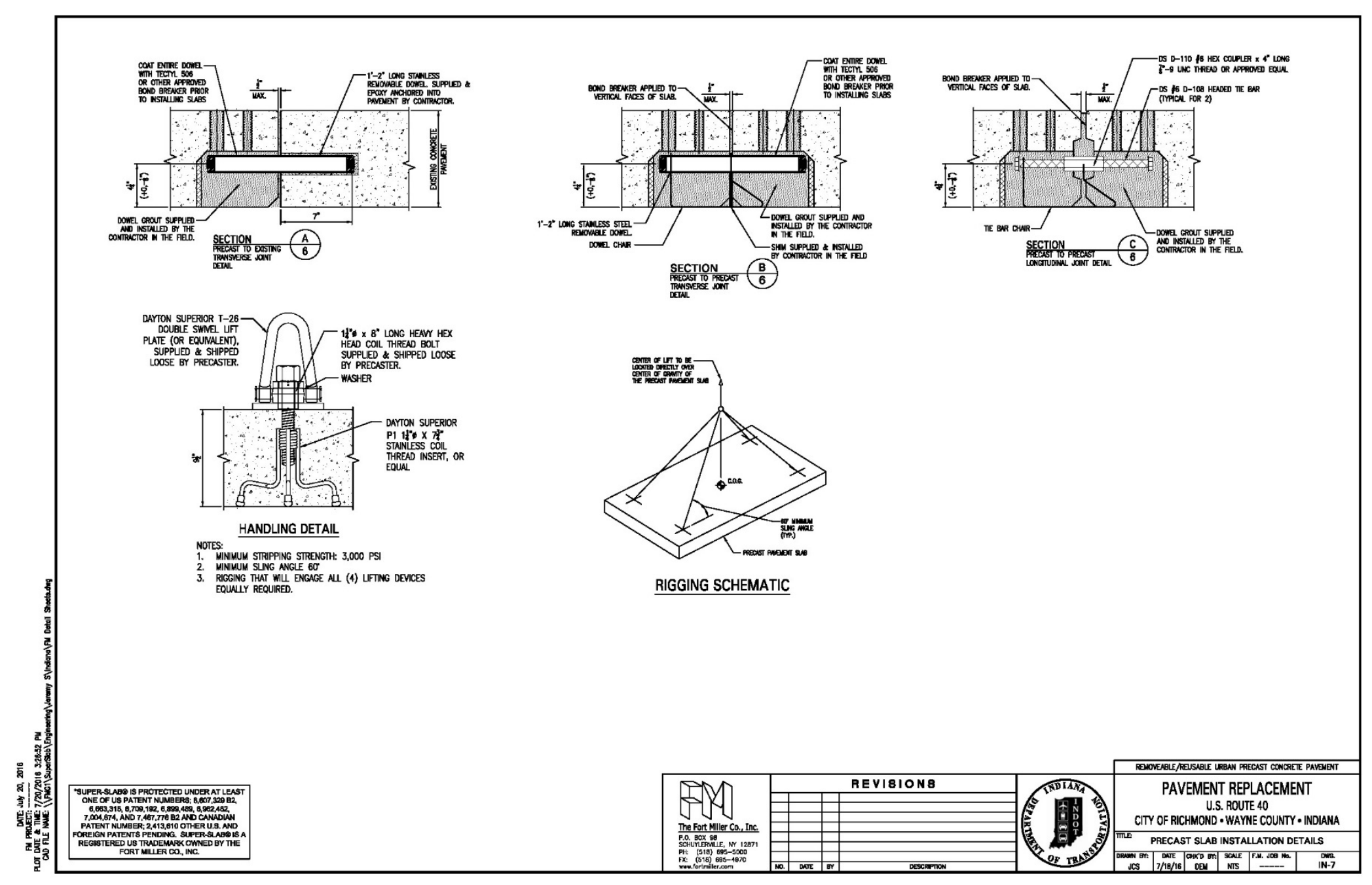

The Fort Miller Co., Inc. 


\section{Installed Costs (Bid Prices)}

- Installed Cost for Precast Repairs

- About \$ 244 to \$ 600 per SY

- Similar to rapid-set concrete costs (in some states)

- Varies greatly with

- Length of work window

- Size of project

- Local labor rates

- Typically includes excavation, grading, slabs, dowels and tie bars and grout - all installed 


\section{Bad Pavement Over Utility Cuts - Now Preventable}

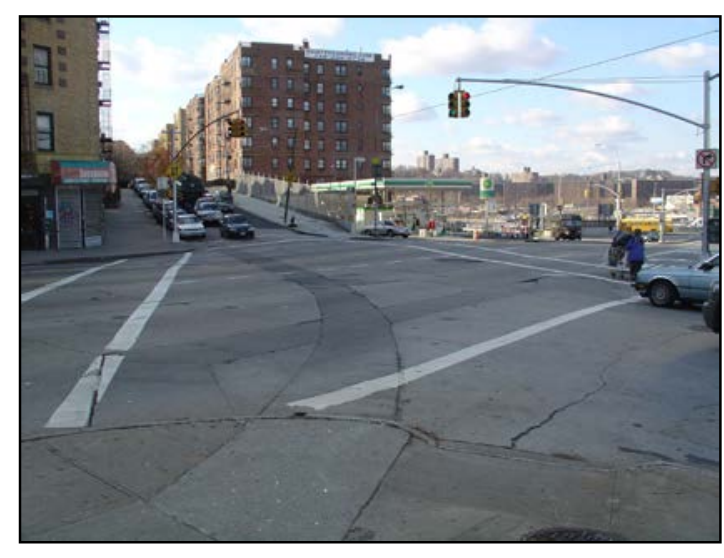

Fordham Rd., Bronx

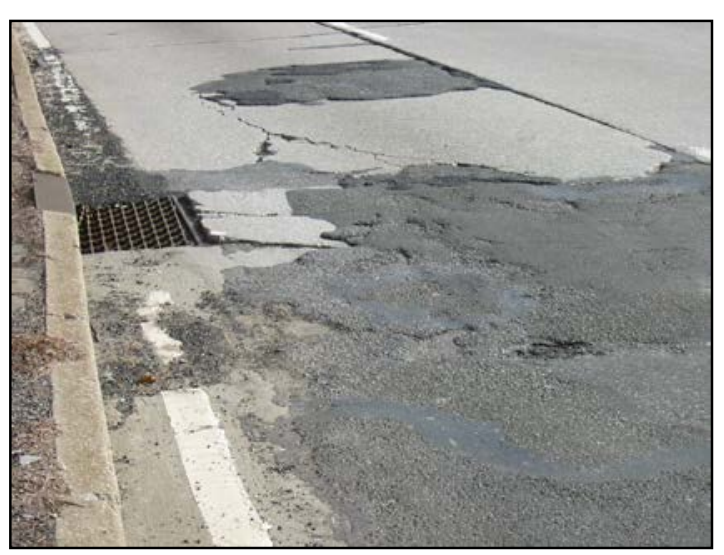

I-87 Major Deegan Off Ramp - Bronx

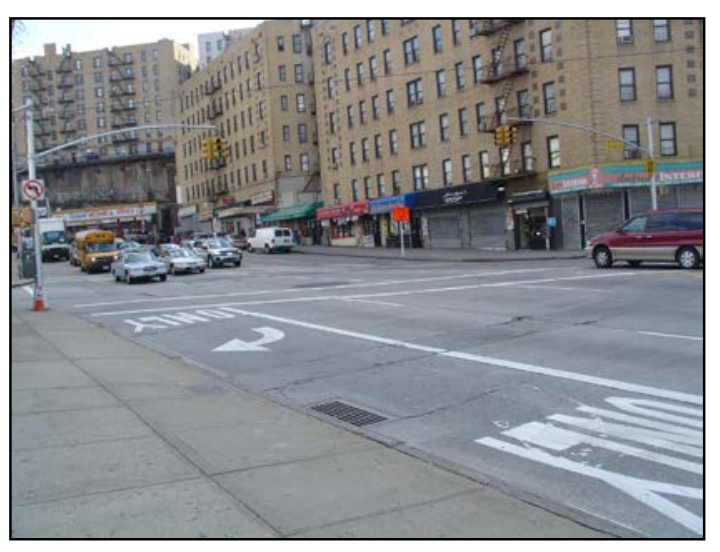

Fordham Rd., Bronx

The Fort Miller Co., Inc. 


\section{Benefits of Precast Pavement}

Reduce construction-related traffic congestion

Longer lasting pavement repairs - Asset Preservation

- 40+ years

- Reduced (long-term) repair costs

- "Get in, get out and stay out"

- "Total Incremental Replacement" - now possible

Reduces field inspection time and cost

- Precast slabs - plant inspected

Pre-engineered, pre-inspected slabs result in a superior finished pavement 


\section{Fort Miller Provides}

- Design and engineering support

- Super Paver Specifications

- Standard and special slabs as required

- Specialized grading equipment

- On-site technical assistance

- Installation guidance 


\section{Presentation Take-A-Ways}

- Long-life precast pavement can be installed overnight

- Drainage and subgrade can be up-graded in the process

- Precast pavement installation - minimum impact on traffic

- Precast pavement may be designed to be removable and replaceable to maintain utilities below

- Precast may be part of CIP project

- Use precast in most critical areas

- Precast RUP allows restoration of original pavement after a utility repair event

- Preserves appearance and functionality

- May save cost in the long run 


\section{Keys to Success (Still More to Learn)}

\section{Good engineering Open minds}

\section{Real partnering}

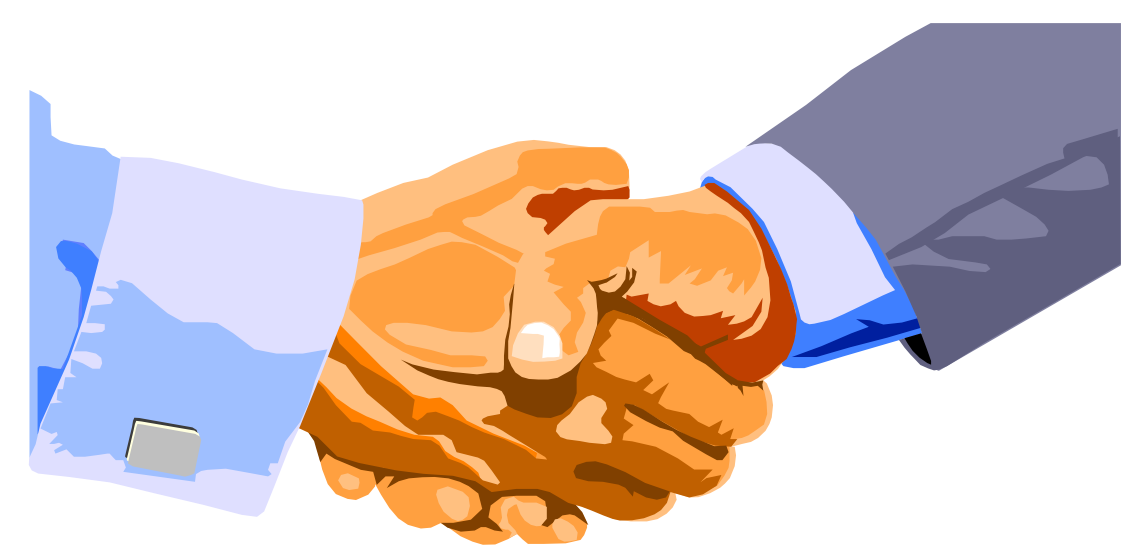

The Fort Miller Co., Inc. 


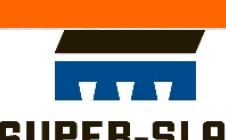

\section{www.super-slab.com}

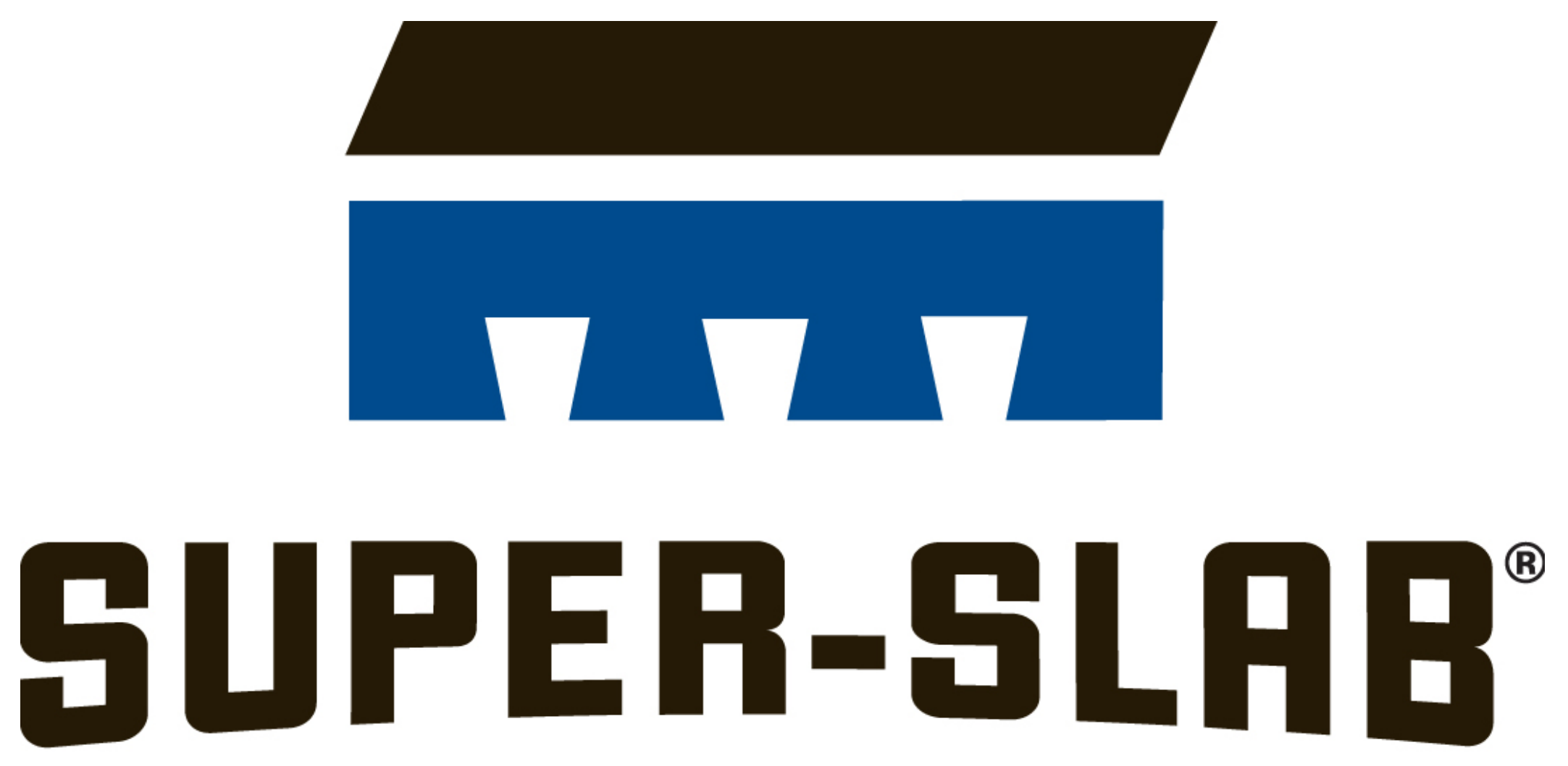

The Fort Miller Co., Inc. 


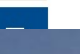

\section{Thank You}

Dan E. Moellman, PE

The Fort Miller Co., Inc.

- $\mathrm{O}$ - (518) 695-5000 C - (518) 461-4759

dmoellman@fimgroup.com

super-slap.com th 4 b the

The Fort Miller Co., Inc. 